Portland State University

PDXScholar

Fall 12-6-2013

\title{
Exploring the Effects of Multi-Level Protective and Risk Factors on Child and Parenting Outcomes in Families Participating in Healthy Start/Healthy Families Oregon (HS/HFO)
}

Peggy Nygren

Portland State University

Follow this and additional works at: https://pdxscholar.library.pdx.edu/open_access_etds

Part of the Family, Life Course, and Society Commons, Health Services Research Commons, Medicine and Health Commons, and the Social Work Commons Let us know how access to this document benefits you.

\section{Recommended Citation}

Nygren, Peggy, "Exploring the Effects of Multi-Level Protective and Risk Factors on Child and Parenting Outcomes in Families Participating in Healthy Start/Healthy Families Oregon (HS/HFO)" (2013).

Dissertations and Theses. Paper 1513.

https://doi.org/10.15760/etd.1507

This Dissertation is brought to you for free and open access. It has been accepted for inclusion in Dissertations and Theses by an authorized administrator of PDXScholar. Please contact us if we can make this document more accessible: pdxscholar@pdx.edu. 
Exploring the Effects of Multi-Level Protective and Risk Factors on

Child and Parenting Outcomes in Families Participating in

Healthy Start/Healthy Families Oregon (HS/HFO)

\author{
by \\ Peggy Nygren
}

A dissertation submitted in partial fulfillment of the requirements for the degree of

Doctor of Philosophy

in

Social Work and Social Research

Dissertation Committee:

Eileen Brennan, Chair

Beth L. Green

Daniel Coleman

Katharine Cahn

Leslie J. Munson

Portland State University

2013 
(C) 2013 Peggy Nygren 


\begin{abstract}
While many studies focus on the links between multiple risk factors and negative outcomes such as child maltreatment, less is known about the influence of protective factors in the face of risks. The theoretical base of this study was a social ecological model of interactive influences including individual parent, family, and neighborhood level factors to predict outcomes. Protective Factor Index (PFI) and Risk Factor Index (RFI) predictors were developed to explore potential multi-level protective factor buffering effects on key child development and parenting outcomes. Participants were first time mothers enrolled in a randomized controlled study of the Healthy Start/ Healthy Families Oregon (HS/HFO) home visitation program (treatment group) who completed a follow-up phone survey at the child's 12 month birthday $(n=405)$. Families were offered HS/HFO services prenatally after meeting risk screening eligibility criteria on the New Baby Questionnaire (NBQ). Program mothers having received at least one home visit $(n=248)$ were included in the final analyses. Families had an average of $3.1(S D=$ 1.2) NBQ risk factors at enrollment and $83 \%$ reported having trouble paying for basic needs. Families received an average of 16 home visits in the first 6 months of the program. Thirty-one percent of mothers were aged 19 or younger, $60 \%$ were White and Non-Hispanic, 31\% were Hispanic, and 9\% were another race/ethnicity. Hierarchical regression models with main effects (RFI, PFI, race) and an interaction term (RFI X PFI) were developed to predict eight outcomes. Interaction effects models were not significant. Five RFI main effects were significant: higher RFI scores were associated with greater likelihood of child welfare involvement, greater parenting stress, less favorable scores on child health and well-being, lower parent responsiveness and
\end{abstract}


acceptance, and less supportive learning environments. One PFI main effect was significant: higher PFI scores predicted lower parenting stress. A trend level result showed higher PFI scores were associated with less child welfare involvement. Race was significant in two models: White/Non-Hispanic families were more likely to have a home visitor report child welfare involvement and had more frequent parent-child activities compared to other race/ethnicity families. Unpacking the results with separate single risk factor (12 items) and protective factor (10 items) regression models followed. Results showed parent's prior family history of maltreatment and younger maternal age predicted child welfare involvement (home visitor report), while protection was seen for those with access to housing support. Social support and family functioning protectors were linked to lower parenting stress, while maternal depression showed the opposite finding. Better scores on a child health and well-being measure were seen with higher neighborhood cohesion and greater participation in $\mathrm{HS} / \mathrm{HFO}$; in contrast, neighborhood violence and frequent mobility were linked to worse scores. Developmentally supportive home environments were seen for families participating in additional parent support programs, in which the mother had greater knowledge of infant milestones and behavior, and if the family had access to housing supports. Unemployment proved to be associated with less enriched home environments. In summary, there was no support for the cumulative PFI in buffering risk for negative outcomes in this model. The RFI was also a more robust predictor of outcomes compared to the PFI in the main effects models. Overall, study findings provide some evidence for the utility of specific protective factors, as well as cumulative and specific single risk factors, for screening families for effectively targeting services and guiding the conceptual development of program and evaluation formats. 


\section{Dedication}

This dissertation is dedicated to the family and friends who made the continued and completed work possible. I never understood what 'my sincere gratitude' meant until it was time to put this project to rest during the summer of 2013. Those in my life who believed in my abilities, intelligence, and motivation to complete this work are all given credit for some part of the effort. Andrew, you are my rock and heart and soul.

Your enthusiasm and energy when mine was gone, your positive attitudes when mine was cranky, and your strong belief in me when I was wavering were essential to completion. Love and hugs to Andrew, Henry, Amy, Margi, Dewey, and Chester.

And to my mother Joan, who has passed, a saint in her own right. I remember well all the late nights you spent on that 'old school' typewriter when I was in High School, 'retyping' pages that I had to get just right! What patience you had. Your love and support are carried with me always. 


\section{Acknowledgements}

\section{Dissertation Committee}

Eileen Brennan, PhD (Chair)

Beth L. Green, PhD

Daniel Coleman, MSW, PhD

Katharine Cahn, MSW, PhD

Leslie J. Munson, PhD

My gratitude goes out to my dissertation committee for your dedication, patience, and continued support of me and my work over the last few years. Without your guidance and mentorship, this project would not have been possible.

Dr. Eileen Brennan graciously took over for Dr. Coleman as Chair of my Committee (even though retirement was imminent). Her work ethic and dedication to children and families is unwavering. How lucky I feel to have such a stellar role model. In the final stages of preparing my dissertation draft, both Eileen's content and practical advice were paramount. Basically, Eileen's guidance and counsel on how to balance expectations and thinking forward past the dissertation paper were essential in preparing me for this stage of the work and beyond. Without her faith in moving forward at various times, this work would not have been possible!

Specific gratitude goes to Dr. Beth Green for getting deeply involved in my ideas and efforts in sharing your HS/HFO data, staff time and pivotal thinking on both the proposal and final paper stages of my dissertation. I have no doubt that your stellar reputation and letter of support for my Quality Improvement Center on Early Childhood 
(QIC-EC) fellowship application were a crucial factor to tip the balance to my favor and help me receive the award. Beth's example and mentorship as a mother, hard worker, and scholar in early childhood and evaluation research has been inspiring. Your introductions to those in the early childhood community in Portland and beyond will undoubtedly foster my future career trajectories, and are much appreciated.

Also, Dr. Daniel Coleman, who started as my Committee Chair, deserves many accolades for his scientific and methodology knowledge. He has a calm and instinctual teaching approach, where he can guide students to new levels of understanding as they are ready. Dan also had a kind and balanced approach to my unique needs and those of all the students in the PhD program during his time at PSU. There were many times I felt that if it weren't for Dan's flexibility around my coursework and work/family balance and confidence in my ability to finish, that I would not have completed this program.

Dr. Katharine Cahn is a force on many levels. Enthusiastically accepting of me and my ideas from the get- go, emailing the director of the QIC-EC upon meeting me for the first time to introduce me as a 'highly qualified doctoral student' hoping to apply for their fellowship! Her insightful comments on the many versions of my dissertation have made important contributions on how to frame questions and approach future investigations with more awareness. Katharine has moved me and many others to think on a deeper level about engrained assumptions, and in turn foster ways to best help children and families. I appreciate her perspective and energy.

I thank Dr. Leslie Munson, the Office of Graduate Studies (OGS) outside appointed committee member for bringing another important perspective to the dissertation work 
with her expertise in early childhood special education and infant development. Your insight and gentle approach is appreciated on all levels. I have also appreciated working with Leslie on early childhood projects outside the dissertation as well. Your keen reminder to put 'people first' is a good one, in my dissertation paper and beyond! Family and Friends

My husband, Andrew Hamilton, gets the bronze, silver, and gold medals for this marathon adventure. A discussion on our first date in 2006 focused on what 'social problem area' my dissertation might focus on, and then in 2007 all discussion shifted to the needs of our new infant son Henry. He has been my rock and supporter and his humor and love have shined through both struggles and triumphs.

My sweet son Henry Hamilton gets an enthusiastic and loving "thank you"! His continued healthy growth and development has improved my ability to both mother and perform relevant early childhood research. His bright, funny, and practical take on the world is unique and cherished. Hugs to Henry!

My family and friend social support network is amazing! Active listening, spontaneous childcare, meals, and any other requests during the $\mathrm{PhD}$ years have been without question a part of the success of this journey. Dewey and Margi Hamilton have always been there for whatever was needed - unconditionally. Amy Silverman-Neuman --my sister in all senses of the word -- primo nanny, graphics consultant, and just an allaround rock star of a person! Finally, the Helen Gordon Child Development Center at PSU- an amazing place for children and parents to grow. Wouldn't our society be better off if every family was given the opportunity to have their children nurtured in a stellar 
early childhood environment? That is one of my hopes. Knowing that Henry was in a warm and nurturing environment with family, friends, and amazing teachers when I could not be with him, was a gift from you all.

Others who have supported me in many ways: Jerod Tarte, Paige Harrison, Jeff Baker, Pauline Duffy, Dustin Neuman, Matt and Tonya Hamilton, Chester Nygren, Miranda Pappas, Sonya Redmond, Susan Wingenfeld, Kathryn Pyle, Christina Bougatsos, Charlotte Shih, and Laurie Huffman.

\section{Dissertation Research Fellowship}

Charlyn Harper Browne, PhD, Quality Improvement Center for Early Childhood (QICEC), Center for the Study of Social Policy

I thank the QIC-EC, especially Dr. Charlyn Harper Browne, for believing in the importance of my dissertation project and funding this work as a QIC-EC fellow from 2011-2013. I appreciate the significance and perspective of the child maltreatment prevention work of the QIC-EC, and also hope to continue to find ways to collaborate and share knowledge in this field with both QIC-EC leadership and the other four QICEC fellows. Completion of this work would not have been possible without this support. [The QIC-EC is funded by the U.S. Department of Health and Human Services, Administration for Children, Youth and Families, Office on Child Abuse and Neglect, under Cooperative Agreement 90CA1763.] 
Abstract

Page

Dedication

Acknowledgements

List of Tables

List of Figures

Chapter 1. Introduction

Study Goals

Study approach and relevance

Literature Review

Child Maltreatment: Burden of the problem

Definitions

Measurement

Maltreatment prevention programs

Focus on two models

Multi-level factor approach to child and parenting outcomes

Defining risk and protective factors

Risk factors and protective factors in research on parenting and child outcomes

Factors associated with maltreatment

Cumulative effects for risk factors for maltreatment

Other child and parenting outcomes of interest

Factors associated with developmental delay

Factors associated with child health and well-being

Factors associated with parenting approaches and parent-child activities

Chapter 2. Theoretical Consideration and Framework

Approaches Embedded in the Current Model

Social learning and attachment theory

Neighborhood and social organization theory 36

Key Outcome Domains

Research Questions

Exploratory Research Questions Across all Outcomes 39

Chapter 3. Methods

Eligibility, Screening, and Recruitment

Random assignment

Characteristics of the Sample

Data Collection 
Model Development 48

Measures 48

Outcome measures 49

Predictors $\quad 59$

Protective factor predictors $\quad 59$

Risk factor predictors $\quad 64$

Analytic Approach $\quad 69$

Attrition and missing data $\quad 70$

Development of indices $\quad 72$

Regression Analysis $\quad 75$

Exploratory Analysis: Unpacking the PFI and RFI 76

Chapter 4. Results $\quad 78$

Psychometrics on Study Variables 78

Outcome and predictor variables $\quad 78$

Statistical properties of the indices $\quad 82$

Main and Interaction Effects Models Using Regression 84

Child welfare involvement $\quad 85$

Developmental delay or off track development screener 87

Child health and well-being $\quad 88$

Parenting approaches and bonding $\quad 89$

Corporal punishment $\quad 89$

$\begin{array}{ll}\text { Responsiveness and acceptance } & 90\end{array}$

Parenting stress 91

Supportive development $\quad 92$

Supportive learning environment $\quad 92$

Parent-child activities $\quad 93$

Unpacking the PFI and RRI Predictors 94

Summary of Results 99

Chapter 5. Discussion 104

Summary of Findings: Implications by Outcome 108

Implications for Practitioners Working with Children and Families $\quad 120$

Implications for Policy 123

Implications for Future Research 123

Overall Limitations of the Study 127

Conclusion 130

References $\quad 132$

$\begin{array}{ll}\text { Appendices } & 148\end{array}$ 
Appendix A: Comparison of Baseline Characteristics of Families Randomized to 148 Program Group $(\mathrm{n}=405)$ by Program Exposure - Home Visits $(n=248)$ and No Home Visits $(n=157)$

Appendix B: Comparison of Baseline Characteristics for Families with Outcome Data and Families With Missing Outcome Data $(n=248)$

Appendix C: Comparisons on Selected Participant Characteristics, Predictors, and Outcome Variables by Race/ Ethnicity

Appendix D: Normality Tests for PFI and RFI; Figures D1, D2, D3, D4 151

Appendix E: Bivariate Analyses for RFI and PFI Factor Indices and Individual 153 Factors: Tables E1 and E2

Appendix F: Correlation Matrices for All Individual Risk Factor Variables, 155 Race, and Outcomes; Tables F1 and F2 


\section{List of Tables}

Table 1 Sample Characteristics for HS/HFO Program Study Families 45

Table 2 Healthy Start/Health Families Oregon (HS/HFO) Data Collection 47

Table 3 Summary of Child and Family Outcomes and Measures in Study 50

Table 4 Developmental Delay or Off Track Development Screening Measures 52

Table 5 Individual Items in Child Health and Well Being Outcome Measure 54

Table 6 Supportive Development Outcome for This Study - 4 subscales 58

Table 7 Protective Factor Predictors and Measures $\quad 59$

Table $8 \quad$ Risk Factor Predictors and Measures $\quad 65$

Table 9 Baseline Data for Specific Factors: Protective Factor Index (PFI) 74

Table 10 Baseline Data for Specific Factors: Risk Factor Index (PFI) 75

Table 11 Psychometric Properties: Continuous Predictors and Outcomes 79

Table 12 Psychometric Properties: Dichotomous Predictors and Outcomes $\quad 80$

Table 13 Composition of Family Child Welfare Involvement Outcome 81

Table 14 Composition of Developmental Delay Screener Outcome 81

Table 15 Summary of Bivariate Analyses for Predictors (PFI, RFI, Race) and 83 Study Outcomes

Table 16 Independent Samples T-Test Comparing PFI and RFI Mean Scores by 84 Child Welfare Involvement, Developmental Delay Screen, and Race Groups

Table 17 Logistic Regression Main Effects and Interaction Effects Analyses $\quad 86$ Predicting Child Welfare Involvement

Table 18 Number and Percentage of Race/Ethnicity Groups and Child Welfare 87 Involvement

Table 19 Logistic Regression Main Effects and Interaction Effects Analyses 88 Predicting Screening Positive for a Possible Developmental Delay

Table 20 Linear Regression Main Effects and Interaction Effects Analyses $\quad 89$ Predicting Child Health and Well Being

Table 21 Linear Regression Main Effects and Interaction Effects Analyses $\quad 90$ Predicting Corporal Punishment 
Table 22 Linear Regression Main Effects and Interaction Effects Analyses

Predicting HOME Responsivity and Acceptance Subscales

Table 23 Linear Regression Main Effects and Interaction Effects Analyses

92

Predicting Parenting Stress

Table 24 Linear Regression Main Effects and Interaction Effects Analyses

93

Predicting HOME Supportive Learning Materials- 4 Subscales

Table 25 Linear Regression Main Effects and Interaction Effects Analyses Predicting Parent Child Activities

Table 26 Logistic Regression Models with Factors Predicting Child Welfare Involvement

Table 27 Logistic Regression Models with Factors Predicting Developmental Delay or Off Track Development Screener

Table 28 Linear Regression Models with Factors Predicting Child Health and Well Being Scores

Table 29 Linear Regression Models with Factors Predicting AAPI- Corporal Punishment Scores

Table 30 Linear Regression Models with Factors Predicting HOME Responsivity and Acceptance Subscale Scores

Table 31 Linear Regression Models with Factors Predicting Parenting Stress Index- Short Form Scores

Table 32 Linear Regression Models with Factors Predicting HOMEOrganization, Learning Materials, Involvement, and Variety Subscale Scores

Table 33 Linear Regression Models with Factors Predicting Parent-Child Activities Scale

Table 34 Summary of Regression Model Significant Predictors and Direction for All Outcomes, (a) Main Effects (PFI, RFI, Race) and Interaction Effects (PFI, RFI, Race, and PFI X RFI), and (b) Backwards Removal with Individual Risk Factors and Individual Protective Factors

Table 35 Details on Practice Implications Related to Services and Practice Approaches for Families with Multiple Stressors Based on Study Findings 


\section{List of Figures}

Figure 1 This graph shows the relationship between number of risk factors and percentage of children maltreated by maltreatment type.

Adapted from "A longitudinal analysis of risk factors for child maltreatment: Findings of a 17-year prospective study of officially recorded and self-reported child abuse and neglect," by J. Brown, P. Cohen, J. G. Johnson, and S. Salzinger, 1998, Child Abuse \& Neglect, 22, p. 1073. Reprinted with permission.

Figure 2 Conceptual overview of the basic theoretical model and five included outcome domains for this study.

Figure 3 The theorized study risk and protective factors embedded in a social ecological framework covering microsystem, mesosystem, and exosystem influences.

Figure $4 \quad$ HS/HFO primary study and current analysis participant selection including total number of eligible, enrolled, and engaged participants.

Figure 5 Risk factors and odds of victimization in HS/HFO evaluation study. 110 Adapted from "Oregon's Healthy Start Maltreatment Prevention Report 2007-2008. A report to the Oregon Commission on Children and Families," by B. L. Green, C. H. Lambarth, J. M. Tarte, \& A. M. Snoddy, A. M., 2009, Northwest Professional Consortium (NPC) Research, Portland, OR. Reprinted with permission. 


\section{CHAPTER 1: INTRODUCTION}

Many developmental changes occur in children from birth to three years of age. Infants need safe, stable, and nurturing environments and relationships to grow and thrive both physically and emotionally. Numerous studies point to familial and community risk factors linked to less than optimal parenting approaches, stress, and non-engaging home environments (Burchinal, Vernon-Feagans, \& Cox, 2008; Lee \& Guterman, 2010). Also, most agree that as such risk factors (e.g., low income, maternal depression) increase in intensity and number, so do rates of child maltreatment (Brown, Cohen, \& Johnson, 1998; Green, Lambarth, Tarte, \& Snoddy, 2009). Maltreatment affects close to one million U.S. children each year and has negative emotional and physical consequences for children at every stage of development (Diaz, Simantov, \& Rickert, 2002; Dube et al., 2001; Dubowitz, 2006; Maxfield \& Widom, 1996; Smith \& Fong, 2004; Thornberry, 2001; U.S. Department of Health and Human Services [USDHHS], 2012). Children who were maltreated, later as adolescents and adults, can have multiple problems including emotional, physical, social, and behavioral difficulties (Felitti et al., 1998; Hussey, Chang, \& Kotch, 2006). Long term issues include diminished quality of life, high demand for public and social services, and continuing maltreatment patterns throughout the life span (Larkin, Shields, \& Anda, 2012). Rigorous studies with a focus on protective factors are an important addition to the knowledge base for families at risk for negative early child development, parenting, and maltreatment outcomes (Centers for Disease Control and Prevention [CDC], 2011). 


\section{Study Goals}

Using data from families receiving Health Start/Healthy Families Oregon (HS/HFO) home visitation services (Green et al., 2009), the primary goal of the current study was to develop an innovative 10-item Protective Factor Index (PFI). Another goal was to test the ability for the PFI to buffer risk for child maltreatment and other negative child and parenting outcomes in families experiencing many stressors. In summary, this study aimed to better understand the contribution of different levels and combinations of protective factors relative to risk for negative child, parent-child relationship, and early learning environment outcomes in a sample of first time mothers in difficult circumstances.

\section{Study approach and relevance}

Empirical findings show support for the moderating influence of protective factors on the impact of risk factors in protection-risk models that take into account multiple levels of influence (Jessor, Turbin, \& Costa, 2010; Sameroff, Seifer, Baldwin, \& Baldwin, 1993). Five domains directly related to the healthy social and emotional development of infants and young children and the quality of the parent-child relationship were chosen for the current model; eight outcomes map to these domains. With a socialecological theoretical lens and guidance from published literature, risk and protective factors linked to these parenting and child outcomes were selected for study (Belsky, 1993; Bronfenbrenner, 1986). Ultimately, 10 protective factors and 12 risk factors were used to develop cumulative predictor indices and used in main effects and interaction effects regression models to predict study outcomes. Specific measures that made up the 
factor indices provided further insight into how specific family characteristics might guide social programming to better serve families at risk for negative parent and child outcomes.

The proposed investigation is relevant to the population most in need of effective maltreatment prevention supports, specifically parents and infants in families at high risk for maltreatment and other negative outcomes. An ecological approach taking into account individual parent, family, and neighborhood level protective factors relative to risk for problematic child and family outcomes, as well as the contribution of specific factors, is a priority for prevention research efforts (Belsky, 1993; Cicchetti \& Valentino, 2006). Knowledge of key factors linked to better outcomes may be especially helpful in driving prevention programming efforts so services can be offered with greater precision (Larkin et al., 2012).

This dissertation report contains five main sections. Chapter 1 puts forth the problem statement with study goals and relevance. The literature review in this chapter focuses on child maltreatment statistics, definitional and measurement issues, as well as two specific home visitation programs geared toward improving parenting and child outcomes and reduction of child maltreatment. The second half of the literature review speaks to the definition of risk and protective factors and research linking these factors to important parenting and child outcomes in early childhood, including maltreatment. The utility of cumulative risk and protection models for prediction of outcomes and for guiding services for families and children is also discussed. Chapter 2 addresses theories that inform the current work, a conceptual model, and hypothesis testing research 
questions. The methods are described in Chapter 3 including the data collection, development of risk and protective factor indices, and sample characteristics, as well the planned approach to analysis. Results in Chapter 4 lay out the properties of the risk and protective factor indices predictors, and all regression main effects and interaction models as well as specific factor regression models. Chapter 5 provides a summary and interpretation of the results of the analyses with a discussion on implications for practice, policy, and future research and program planning specific for targeting services to best serve children and families. Study limitations are also addressed in the final chapter.

\section{Literature Review}

Child maltreatment: Burden of the problem. In 2011, more than 3.5 million children in the U.S. received Child Protective Service (CPS) investigations, with under $20 \%$ of investigations resulting in founded allegations (USDHHS, 2012). Substantiated abuse was found in 676,569 of these cases, where at least one form of child abuse or neglect was seen (USDHHS, 2012). Most of the children categorized as maltreated suffered from neglect (78\%), with other forms less common. Children in the age group birth to one year have the highest rate of maltreatment at 20 per 1,000 children (USDHHS, 2012). When compared to older children, those under 4 years old are more likely to die as result of their maltreatment (USDHHS, 2012). Of those children who died of maltreatment in $2011,81 \%$ were under the age of 4 . The USDHHS (2012) report also stated that of the children who suffered from medical neglect, $35 \%$ were younger than 3 years of age. The true incidence of maltreatment is most likely greater than that shown by public child welfare reports or substantiated cases (Felitti et al., 1998; Swahn et al., 2006). 
In Oregon, the statistics are similar to national statistics overall and for the very young. In 2011, there were 26,261 unsubstantiated cases, and 12,214 substantiated cases of child maltreatment in Oregon (Oregon Department of Human Services [ODHS], 2012). Fifty-four percent of maltreatment cases involved children ages birth to 6 (35\% birth to age three), with $59 \%$ of fatalities occurring in children under age 5 (ODHS, 2012). The Oregon report notes that there were usually multiple stress factors in families where children are maltreated. The three biggest reported problems facing families of abused and neglected children were drug and/or alcohol abuse, domestic violence, and parental involvement with law enforcement (ODHS, 2012). In fact, $47 \%$ of families with child maltreatment substantiated cases had a parent or cargiever with an alcohol or drug use problem, 35\% domestic violence or parental relationship problems , and 26\% involved with law enforcement. Also associated with child welfare involvement were families with financial stress (24\%) and having a parent or caregiver with a history of child maltreatment as a child (13\%, ODHS, 2012).

Definitions. Every State has its own definitions of child maltreatment including forms of maltreatment and these definitions vary widely. The federal Child Abuse Prevention and Treatment Act (CAPTA) from 1974 defines child abuse as, ....any recent act or failure to act on the part of a parent or caretaker which results in death, serious physical or emotional harm, sexual abuse or exploitation; or an act or failure to act, which presents an imminent risk of serious harm (USDHHS, 2013b, p. 1). 
Statute additions and exceptions for States also exist, and are important to keep in mind when considering child welfare reporting by mandatory reporters, including home visitors who have ongoing contact with families in difficult circumstances in their homes. Oregon statutes include language about specific additional circumstances that would require mandatory reporting of child maltreatment (ODHS, 2012). These include exposure to manufacturing of methamphetamine or other illegal substances or exposure to a controlled substance that may cause risks to a child's health or safety (ODHS, 2012). Oregon also has an exception in its abuse statutes that states that abuse does not include reasonable (causes no bodily harm) exercise of parental discipline (USDHHS, 2013b). Zuravin (1991) advocated that for researchers, definitions of maltreatment that focused on the specific acts that harmed children would make comparison of identifiable behaviors possible across studies. Typically, the four main types of maltreatment categorized and reported in the literature are physical abuse, sexual abuse, neglect, and psychological/emotional abuse. Researchers have also developed, and urged the use of, key definitional details of maltreatment in case reporting including subtype, severity, frequency and chronicity, perpetrator, and developmental period(s) of the child (Manly, Cicchetti, \& Barnett, 1994). It seems logical that the negative effects of child neglect would manifest differently as children move through emotional, physical, and social stages of development. For instance, behavior problems due to omissions in care will manifest themselves in toddlers, school-aged children, and adolescents in complex and unique ways. For young children, toddlers may have language delays and an inability to concentrate, while school aged children will show extreme dependence on teachers and 
inappropriate peer interactions (Smith \& Fong, 2004). School failure, physical and emotional disorders, substance abuse, and physical and emotional problems may follow victims of maltreatment into adulthood (Diaz et al., 2002; Felitti et al., 1998; Maxfield \& Widom, 1996).

Measurement. Discussion of accurate measurement of child maltreatment in the literature has revealed controversy and division. Official child protective service reports (unsubstantiated and substantiated) are used most frequently in research to measure child abuse and neglect. Exclusive use of official child protection reports may underestimate rates of abuse, however, and are also subject to identification bias (Windham et al., 2004). Families experiencing difficulties who also have frequent contact with health and social service professionals may be more likely to be discovered and reported than families with minimal or no contact. For instance, because home visitors are mandatory reporters of maltreatment, families participating in services and programs often have higher rates of reported maltreatment due to what is often called a surveillance effect. Reporter bias is a consideration in using unsubstantiated child maltreatment measures as well. As noted, in evaluation studies where control group families are not subject to the same level of monitoring as program families, control families may have fewer child welfare reports. The number of self-reported incidents is typically substantially higher than administrative child welfare substantiated reports (Felitti et al., 1998; Swahn et al., 2006). Use of multiple sources of maltreatment data including self-reports, substantiated reports, and other measures of harsh parenting allows for a broader view of the 
potentially detrimental engagement styles of parents, disruption of a healthy parent-child relationships, and maltreatment.

Maltreatment prevention programs. Primary prevention maltreatment programs are geared toward families at risk for abuse and neglect prior to children becoming victims of maltreatment. Parenting and family programs delivering services to caregivers have focused on building parenting skills, parent attachment, social networks, coping strategies, and family cohesiveness, while also teaching child development, stress reduction, and anger management (Avellar, Paulsell, Sama-Miller, \& Del Grosso, 2012). Programs discussed here include evidence-based home visiting as the main service delivery system and include families at risk for child maltreatment and other negative parenting outcomes. However, reviews also exist that include program effectiveness for families with prior child welfare system involvement (Lundahl, Nimer, \& Parsons, 2006). Programs use screening eligibility guidelines for offering services to target those most at risk for maltreatment, however, most programs do not have the resources to serve all those who screen eligible for services (Green, et al., 2009). Depending on the program model, home visitors use techniques such as coaching, counseling, education, and modeling to allow caregivers to learn about developmentally-appropriate and nurturing child rearing behavior (Avellar, et al., 2012; Mitchell-Herzfeld, Izzo, Greene, Lee, \& Lowenfels, 2005; Olds, Henderson, Chamberlin, \& Tatlebaum, 1986). Improvements have been documented for families participating in home visiting programs, relative to comparison groups, for a variety of short and long-term parenting and social support outcomes and child and maternal health (Barth, 1991; Black, Nair, Knight, Wachtel, Roby, 
\& Schuler, 1994; DuMont et al., 2011; DuMont et al., 2008; Olds et al., 1986; Olds et al., 1997, 2007).

Programs like these, delivering services to caregivers with the aim of reducing risk factors and building family protective factors in order to decrease child maltreatment, exist in most U.S. states. Yearly, home visiting programs serve nearly 500,000 families in America, reaching about $2 \%$ of all children under six; nearly all states have a statewide home visitation program of some kind (Astuto \& Allen, 2009). U.S. policy promoting quality early childhood programs has increased funding for these programs over the last decade. Attention to the need for such programs moved to the national level in 2009 with President Obama's repeated endorsement of evidence-based home visitation models as part of his approach to comprehensive education (Astuto \& Allen, 2009). Focus on these programs is in large part due to The Patient Protection and Affordable Care Act recently establishing a Maternal, Infant, and Early Childhood Home Visiting Program (MIECHV) that provides close to two billion dollars over 5 years to States to establish home visiting program models for at-risk pregnant women and children birth to age 5 (Patient Protection and Affordable Care Act of 2009; USDHHS, 2013a). At least 75\% of the funds have gone to visitation programs with clear evidence of effectiveness based on rigorous methodology.

The Office of Research, Planning, and Investigation (OPRE) funded by the Administration of Children and Families provides a comprehensive review called the Home Visiting Evidence of Effectiveness Review (HomVEE) to determine which home visiting program models meet the DHHS criteria for an evidence-based early childhood 
home visiting service delivery model. Currently, 13 models have been endorsed for effectiveness including the Healthy Families America (HFA) model and Nurse Family Partnership (NFP) model (Avellar et al., 2012). Eight outcome domains were identified in the HomVEE review as key for program effectiveness, and positive program effects were seen across all outcomes for both children and families. Outcome impacts were found in many areas including child development, school readiness, child health and maternal health, positive parenting practices, reductions in family violence, and reductions in child maltreatment (Avellar et al., 2012). Program effects were not consistent across all studies.

Focus on two models. This review focuses on two child maltreatment prevention models using home visitation, Healthy Families America (HFA) Model (Healthy Families America [HFA], 2013) and Nurse Family Partnership (Nurse Family Partnership [NFP], 2013), chosen for their evidence base establishing improved child abuse and neglect outcomes and for their wide spread implementation in the U.S. Also, the current study focuses on families participating in the HS/HFA model in Oregon. For the HFA model, there are currently 400 affiliated HFA program sites in 40 States, the District of Columbia, all 5 U.S. territories, and Canada (HFA, 2013). The HomVEE review identified 166 published studies from 1979 to 2011, with 50 studies eligible for the review, but only one study provided evidence of reductions in child abuse and neglect (Avellar et al., 2012). The NFP model employed over 1,500 nurse home visitors serving over 25,944 currently enrolled families in 43 States and the Virgin Islands (NFP, 2013). Since 1996, over 170,000 families participated in the NFP program. Of the 101 NFP studies identified, 27 
met criteria to be included in the review, with seven showing reductions in maltreatment for families in the program (Avellar, et al., 2012).

The Healthy Families (HF) community-based home visitation prevention program model uses trained staff to work with families until the child's fifth birthday or the child is enrolled in Head Start or kindergarten. Program components include support, education, and referrals to community services aimed at addressing positive parenting skills and parent-child interaction; prevention of child maltreatment, abuse, and neglect; optimal prenatal care and child health and development; and, parents' self-sufficiency (HFA, 2013). Early evaluation results for HF-New York were favorable for treatment mothers when compared to controls on measures of childbirth outcomes (low birth weight), and self-reported neglect, severe physical abuse, and psychological aggression against their children (Mitchell-Herzfeld et al., 2005). The accredited Healthy Start/Healthy Families Oregon (HS/HFO) uses this model as a primary prevention program for Oregon children with the aim of preventing maltreatment, and fostering optimal child development and family functioning (HFA, 2013). First time parents are offered home visitation at the child's birth; services can continue until children are 3 years of age. Services include developmental screenings, parent education and support, and linking families to community resources such as concrete supports, public services, and counseling. In some of the most recent evaluation findings from the HFA home visitation model in both New York and Oregon, program mothers had better parentchild outcomes, less severe forms of negative parenting, and lower maltreatment rates 
compared to control families (DuMont et al., 2011; DuMont et al., 2008; Easterbrooks et al., 2013; Green et al., 2009; Mitchell-Herzfeld et al., 2005).

The original randomized controlled trial $(N=400)$ of the NFP program in Elmira, New York, included comprehensive nurse home visitation and education services provided to first time mothers at risk for maltreatment, from the prenatal period to the child's second birthday (Olds et al., 1986). Evaluation results showed significant treatment effects for lower rates of maltreatment in later follow-up studies, improvements in maternal health behavior, lower parenting stress, fewer child behavior problems, and less family need for public assistance (Olds et al., 1986; Olds et al., 1997; Zielinski, Eckenrode, \& Olds, 2009). Another encouraging finding is a non-significant trend level reduction in mortality in the treatment group where the odds of death were 4 times lower in the program group mortality data than in the control group (OR $0.22,95 \%$ CI 0.03 $1.74, p=0.08$; Olds et al., 2007).

Both the NFP and the HFA models have mixed results for child maltreatment prevention effects, due in part to the challenges of measurement and home visitor surveillance effects as described previously. Despite these barriers, the overall trend continues to point to program effects for reductions in child maltreatment and for other positive parenting and child outcomes. Although reliable program effects for maltreatment are elusive, outcomes that are said to be related to maltreatment (e.g., parenting stress, parent functioning, harsh discipline practices) show strong and sustained favorable program effects across study sites and populations (Howard \& Brooks-Gunn, 2009). 
Multiple attempts to summarize home visitation intervention study outcomes and levels of program exposure were made with formal and informal review methods in the last decade (Avellar et al., 2012; Howard \& Brooks-Gunn, 2009; Nygren, Nelson, \& Klein, 2004; Peacock, Konrad, Watson, Nickel, \& Muhajarinez, 2013; Reynolds, Mathieson, \& Topitzes, 2009; Selph, Nelson, Bougatsos, \& Blazina, 2013; Sweet \& Appelbaum, 2004). The most recent review for the U.S. Preventive Services Task Force found that 15 of the 22 outcomes studied showed beneficial effects for program children, compared to children receiving no program, spanning multiple domains including maltreatment, child health, measures of child development, physical punishment, and mortality (Selph et al., 2013). Differences in individual study samples, outcome measurement (e.g., lack of abuse type specified), and program implementation sometimes produce heterogeneity in findings, making combining results challenging. Debate continues about under what conditions children and their families can best be served by these programs (Astuto \& Allen, 2009; Ross \& Vandivere, 2009).

Multi-level factor approach to child and parenting outcomes. The capacity of parents to provide safe, nurturing, and stable environments in which infants and young children grow and develop in positive ways, is influenced by many factors. By the time a child welfare maltreatment report is substantiated, an infant or young child may have experienced a host of exposures to conditions that are potentially detrimental to health and well-being. Social ecological theory proposes a dynamic multi-dimensional sphere of influence on individuals and families that determines behavior and outcomes, and posits four systems each contained within the next, all influencing each other 
(Bronfenbrenner, 1979, 1986). This way of thinking includes a multi-level view of the supports and stressors at play in a child's and family's world including social support, political climate, socioeconomic status, neighborhood, employment, and cultural mechanisms (Coohey, 1996). Attention to the multiple domains influencing a child's environment (individual parent, family, neighborhood) can provide insight into optimal child growth and development and potentially protect against maltreatment (Goldman, Salus, Wolcott, \& Kennedy, 2003). Many experts have argued for the necessity of using an ecological approach in the development of prevention programs to combat child maltreatment (Belsky, 1993; Cicchetti, Lynch, \& Manly, 1997; Cicchetti \& Valentino, 2006).

If families are not providing healthy and stable environments for their children and maltreatment ensues, this is often seen to be the direct result of social, cultural, and situational factors (Belsky, 1993; Bronfenbrenner, 1986). The nature of child maltreatment is not one dimensional, but rather multi-determined, and includes individual, family, and neighborhood or community level influences. "When stressors (of a variety of kinds: parent, child, social conditions) outweigh supports (also a variety of kinds), or when potentiating factors are not balanced by compensatory ones, the probability of child maltreatment increases" (Belsky, 1993, p. 413). Risks may tend to aggregate in the lives of children and families under particular stressful life circumstances. For the most part, the more risk factors that are present, the more considerable the threat to a child's well-being (Appleyard, Egeland, van Dulmen, \& Sroufe, 2005; Brown et al., 1998; Easterbrooks et al., 2013; Sameroff, 2000; Sameroff, 
Seifer, \& Zax, 1982). In turn, protection comes in many forms in the face of risks, helping families to avert maltreatment.

Defining risk and protective factors. Originally seen in the epidemiology research literature, the term risk factor is more widely used and has a more universally accepted definition than protective factor. Risk factors are said to be conditions or variables that are associated with higher likelihood of negative or socially undesirable outcomes, specifically behaviors that counter health and well-being (Jessor, Van Den Bos, Costa, \& Turbin,1995; Sameroff, 2000). Risk factors are behaviors or conditions that compromise positive outcomes. Protective factors have the reverse effect, being conditions or variables that enhance the likelihood of favorable or positive outcomes and mitigate or eliminate risk. The movement to articulate the variables that may serve to moderate or buffer risk began in the developmental psychopathology field (Garmezy, Masten, \& Tellegen, 1984; Rutter, 1987, 1990). Although it has been argued that risk factors and protective factors are mere opposite ends of a similar spectrum, most agree that protective factors are independent variables that can both moderate risk for undesirable behavior, and influence behavior on their own (Jessor et al., 1995). The Department of Health and Human Services, Administration for Children and Families defines protective factors as follows:

Protective factors are conditions or attributes in individuals, families, communities, or the larger society that, when present, mitigate or eliminate risk in families and communities that, when present, increase the health and well-being of children and families. Protective factors 
help parents to find resources, supports, or coping strategies that allow them to parent effectively, even under stress. (U.S. Department of Health and Human Services [USDHHS], 2013c, p. 1).

Some risk and protective factors are not changeable (e.g., ethnicity) and are sometimes called fixed factors. Other are malleable to change (e.g., education level) or would be expected to change over time and are called variable factors (USDHHS, 2013c).

\section{Risk factors and protective factors in research on parenting and child}

outcomes. As noted earlier, to best understand the causes of child maltreatment or other negative parenting outcomes and child outcomes, multiple levels of interacting influence must be examined (Belsky, 1993; Belsky \& Jaffee, 2006). Studies shifted from single factors to multiple factors in the individual, family, and broader community domains in considering child maltreatment. While many studies exist regarding the numerous risks for child abuse and neglect, data on protective factors or factors that promote resilient parenting are lacking. An overview follows of studies including risk or protective factors linked to child maltreatment, and associated parenting and child outcomes also interrelated with maltreatment. Although individual parent, family, and neighborhood factors were emphasized, interactions among these ecologies are probable.

Factors associated with maltreatment. Three systematic reviews provide insight into factors associated with maltreatment specific to physical abuse and neglect using 155 studies (Stith et al., 2009), physical abuse in 46 studies (Black, Heyman, \& Smith Slep, 2001), and 10 studies of child neglect (Schumacher, Smith, \& Heyman, 2001). Each of the reviews calculated effects to gauge the strength of the relationship between each factor and 
the maltreatment outcome. Many factors were not able to be combined due to heterogeneity in the data. Factors included in these reviews and other studies are discussed throughout this section where appropriate. Although not exhaustive of the literature, other research providing evidence for links between risk and protective factors and maltreatment are highlighted.

Individual child-level factors were not included in the current study as predictors for outcomes, however a very brief overview of factors noted in the literature that put children at higher risk for maltreatment is included here. As noted earlier, young age of the child has been shown to be a risk factor for maltreatment, with the highest maltreatment incidence seen from birth to toddler age at 2 years (Sedlak et al., 2010; USDHHS, 2012). Many other infant risk factors for maltreatment have been studied and typically included conditions of the child that create greater stress for the caregiver, such as prematurity, medical conditions, disabilities, and difficult child disposition (Sidebotham, Heron, \& ALSPAC Study Team, 2006; Stith et al., 2009; Strathearn, Gray, O'Callaghan, \& Wood, 2001; Zhou, Hallisey, \& Freymann, 2006). Researchers have also looked at child race/ethnicity as a risk factor for greater child welfare system involvement (Sedlak \& Broadhurst, 1996; Sedlak et al., 2010). A more detailed discussion of race and maltreatment is provided later in this section.

Infant protective factors for maltreatment have included being born on time, having no birth weight issues, and having a mild temperament (Sedlak et al., 2010; Sidebotham et al., 2006; Strathearn et al., 2001). Protective or resiliency factor research for older children is more prevalent in the literature than for the youngest of children. 
Individual parent level risk factors for maltreatment in the current literature are numerous. However, no consistent set of factors has reliably shown prediction of different types of abuse. Maternal risk factors in the literature include young age of mother (Black et al., 2001) and maternal low education (Black et al., 2001; Brown, et al., 1998). Also, maternal depression or psychopathology (Belsky, 1993; Herrenkohl, Sousa, Tajima, Herrenkohl, \& Moylan, 2008; Schumacher et al., 2001; Timmer, Borrego, \& Urquiza, 2002; Windam et al., 2004) and self-esteem issues (Belsky, 1993; Shook-Slack et al., 2011) were linked to greater rates of child maltreatment. Parental history of maltreatment (Wolfe, 2006), interpersonal problems (Black et al., 2001), and substance use (Herrenkohl et al., 2008; Sedlak et al., 2010; Windam et al., 2004) were also reported as risks for child maltreatment. Individual parent risk factors related to the act of parenting and increased abuse include parenting stress (Stith, et al., 2009; Timmer et al., 2002; Windam et al., 2004), use of coercive discipline practices (Belsky, 1993; Black et al., 2001), negativity toward the child (Belsky, 1993; Black, 2001), and lack of understanding infant/child milestones and development (Black et al., 2001).

Individual caregiver protective factors with some empirical evidence include parent positive coping skills, breastfeeding (Strathearn, Mamun, Najman, \& O’Callaghan, 2009), social support (CDC, 2011; Bishop \& Leadbeater, 1999), and knowledge of child development (Olds et al., 1986). A meta-analysis of 155 studies by Stith and colleagues (2009) found parent age, the quality of the parent-child relationship, parent perception of the child as a problem, and parent anger/hyper-reactivity to be related to a greater likelihood of physical abuse and neglect. The strongest predictors of neglect were 
parent's perception of the child as a problem and poor parent-child relationship, while parent anger/hyper-reactivity was the best predictor of physical abuse (Stith et al., 2009).

Family-level risk factors for maltreatment have included troubled family relationships including interpersonal violence (Stith, et al., 2009), single marital status (Sedlak \& Broadhurst, 1996; Sedlak et al., 2010; Whitman, Borkowski, Keogh, \& Weed, 2001) families with many children (Sedlak et al., 2010), domestic violence (Windam et al., 2004), and poverty (Sedlak et al., 2010; Shook-Slack et al., 2011). Poverty has been shown to be linked to greater child maltreatment rates (Sedlak et al., 2010); this relationship is especially strong in cases of neglect (Slack, Holl, McDaniel, Yoo, \& Bolger, 2004). Other socio-economic status factors seen in the literature to have wellestablished links to child welfare system involvement include receiving financial support (Brown et al., 1998), unemployment (Sedlak et al., 2010), and residential mobility (Sedlak et al., 2010).

Social support has emerged as a significant family level protective factor (Bishop \& Leadbeater, 1999; CDC, 2011; Coohey, 1996), with greater connections to social networks and friends found to have a buffering effect on negative outcomes in families at high risk for maltreatment (Cicchetti \& Valentino, 2006). In addition, families with intact social support networks tended to show better parenting skills than families with less satisfying social support (Black et al., 2001; Easterbrooks et al., 2013; Slack et al., 2004). Further work in this area has shown that lack of quality social support can lead to a decrease in parental function and increased depression, leaving parents more likely to abuse their children (Cicchetti \& Valentino, 2006). Both positive family functioning 
(Chu, Pineda, DePrince, \& Freyd, 2011; Stith et al., 2009) and access to concrete supports (Coulton, Crampton, Irwin, Spilsbury, \& Korbin, 2007) have been linked to lower maltreatment rates. Receipt of and access to financial support has shown mixed evidence of links to maltreatment. Further study is needed to better understand the multiple socioeconomic stressors in families (e.g., unemployment, receipt of financial assistance).

Neighborhood-level risk factors linked to child maltreatment are not as widely studied as individual child and parent or family level risk factors. Studies have shown that neighborhood violence and residential instability are linked to higher rates of child maltreatment (Coulton, et al., 2007; Eckenrode, Rowe, Laird, \& Brathwaite, 1995; Garbarino \& Kostelny, 1992; Sampson, Raudenbush, \& Earls, 1997; Stith et al., 2009).

In areas where risk factors may be high, neighborhood cohesion may provide a protective effect for maltreatment (Coutlon, et al., 2007; Daro \& Dodge, 2009). Protective factors related to neighborhood or community levels systems are less studied than risk factors in this area.

Poverty, race, and maltreatment. The interaction of poverty, culture, and risk factors associated with child welfare involvement is complex (Macmillan \& Wathen, 2005; Maxfield \& Widom, 1996). There have been strong links found between poverty and child maltreatment (Sedlak \& Broadhurst, 1996; Sedlak et al., 2010) and between non-dominant culture or foreign-born status and maltreatment (Smith \& Fong, 2004). Children of the lowest income groups were at highest risk of child maltreatment (72.3 per 1,000 children), compared to higher income groups ( 1.6 per 1,000 children; 
Smith \& Fong, 2004). Socio-economic factors outweigh race/ethnicity in indicating highest levels of risk. These relationships are complex and not straightforward.

Those who interpret administrative child welfare data recognize the complexity in understanding the multiple contributing factors related to a greater proportion of children of color being involved with child welfare (Baumann, Dalgleish, Fluke, \& Kern, 2011). Persons of color experience a higher incidence of poverty. African American children have disproportionately more substantiated child welfare reports and a higher probability of being placed out of home compared to White/Non-Hispanic youth (Lemon, D'Andrade, \& Austin, 2005). This adds to the complexity of detangling the issues of the overrepresentation of children of color in the child welfare system (Sedlak \& Broadhurst, 1996; Sedlak et al., 2010). Caution must be exercised when equating child welfare system involvement with actual victimization though, given empirical support for the existence of institutional bias and disproportionality (Baumann, et al., 2011). This may be due to greater surveillance or visibility bias of this population in different communities based on discriminatory practices. As stated earlier, higher percentages of persons of color live in poverty and in turn, less than optimal neighborhood conditions. Use of statistical techniques to include poverty and race/ethnicity factors in child maltreatment models can lead to a more accurate picture of these complicated relationships. Also, there is comprehensive discourse regarding research and potential change mechanisms for disproportionality in the U.S. child welfare system (Hill, 2006). The stress of poverty, greater surveillance of low income populations, racial discrimination, and cultural differences in child rearing practices may all be contributors. 
Cumulative effects of risk factors for maltreatment. The many multi-level risk factors linked to maltreatment as previously described span from the individual to the family and into the neighborhood levels (Belsky, 1993; Bronfenbrenner, 1979). Beyond these influences, there are also the larger societal norms and cultural influences on behavior that are often not as well studied. Some research has shown that while certain individual, familial, and community level characteristics increase the likelihood of maltreatment as they begin to increase and cluster (Appleyard et al., 2005; Brown et al., 1998), so does the level of child maltreatment. In a retrospective longitudinal community sample in upstate New York, Brown and colleagues (1998) reported child maltreatment prevalence went from $3 \%$ when no risk factors were present to $24 \%$ when at least four risk factors were present (Figure 1). 


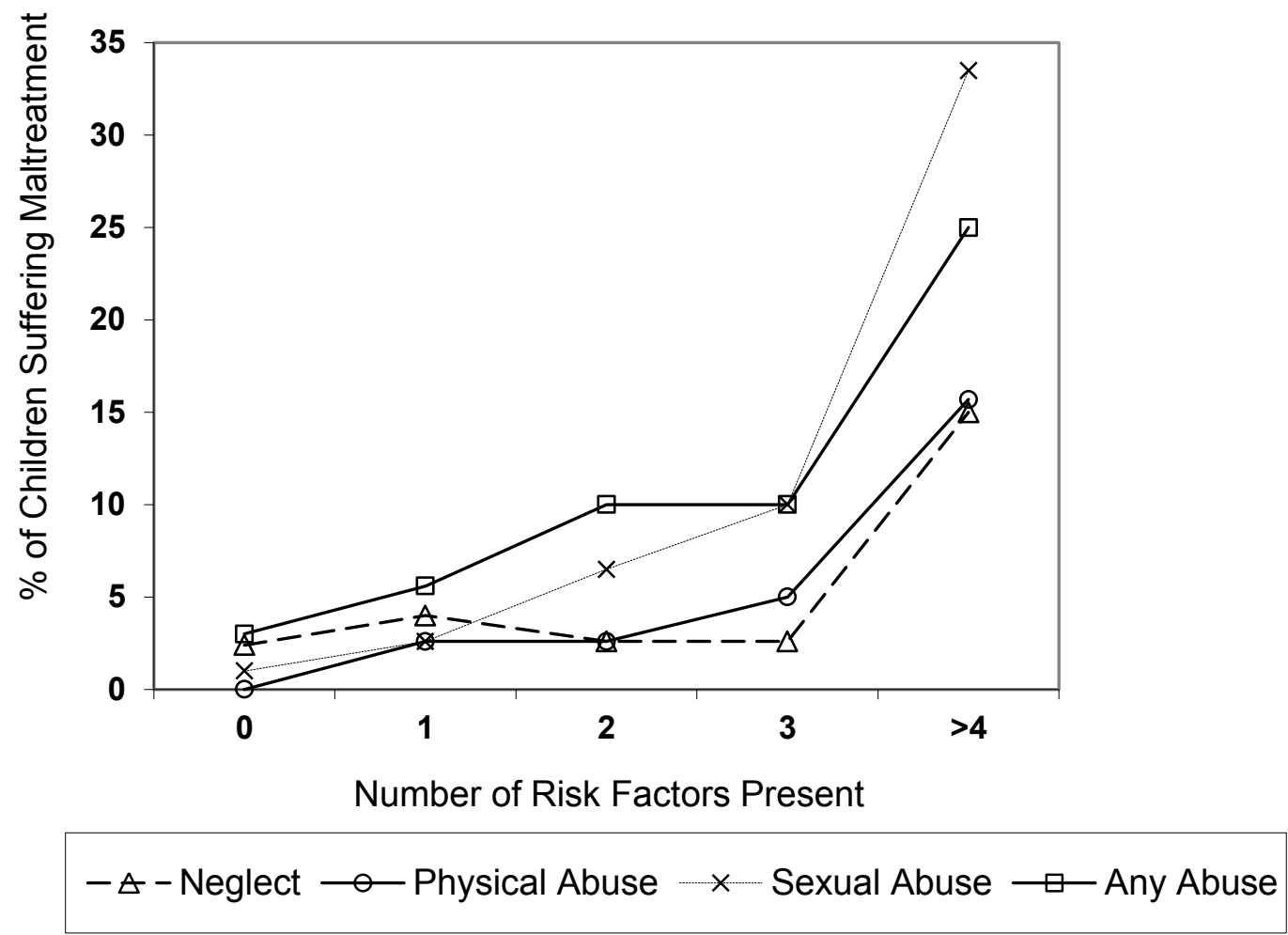

Figure 1. This graph shows relationship between number of risk factors and percentage of children maltreated by maltreatment type. Adapted from "A longitudinal analysis of risk factors for child maltreatment: Findings of a 17-year prospective study of officially recorded and self-reported child abuse and neglect," by J. Brown, P. Cohen, J. G. Johnson, and S. Salzinger, 1998, Child Abuse \& Neglect, 22, p. 1073. Reprinted with permission.

Although many conceptualizations of suggested protective factors for child maltreatment and various ways they may interact with risk have been postulated, most agree that more empirical research is needed to provide evidence of direct links with reduction in maltreatment $(\mathrm{CDC}, 2011)$. Risk and protection research has gone through shifts in focus over the last two decades moving from an emphasis placed specifically on individual child and parent characteristics to models with multiple ecologies which interact to influence each other and the child's development (Belsky, 1993; Cicchetti \& Lynch, 1993; Cicchetti \& Valentino, 2006). Debates in the literature have included the view of 
some that risk and protection are opposite sides of the same continuum, with others arguing that risk and protection are separate mechanisms looking to the balancing effects and interactions in predictors (Jessor et al., 1995; 1998). Cumulative risk and protection models provide insight on how multi-level factors play a role in child maltreatment and other child and parenting outcomes (Burchinal et al., 2008; Burchinal, Roberts, Hooper, \& Zeisel, 2000; Cabrera, Fagan, Wight, \& Schadler, 2011).

Other child and parenting outcomes of interest. As described earlier, although maltreatment outcomes can be difficult to measure, many parenting and child outcomes have been linked to increased likelihood for child abuse and neglect. There is evidence that sets of outcomes considered risk factors for maltreatment are highly correlated (e.g., parenting stress and corporal punishment). Several were discussed in the context of the maltreatment prevention programs in the prior sections such as maternal parenting practices and stress in the home environment. Considering the focus of this study was on families participating in the HS/HFO program, which has the goal of reducing child maltreatment, additional outcomes were deemed important on their own in contextualizing parent-child interactions in the home environment beyond the maltreatment outcome. Research on risk and protective factors related to other outcomes in this study are included next.

Factors associated with developmental delay. Having a child with medical, emotional, or developmental disabilities can be stressful for parents, potentially putting children at greater risk for maltreatment. To complicate these findings, risk factors (e.g., stressful life events) linked to maltreatment have also been associated with greater 
likelihood of possible or diagnosed delays in children (King, Logsdon, \& Schroeder, 1992). Using a variety of methods, studies in the U.S. have focused on risk factors linked to positive screens for developmental delay and diagnosed developmental delay (Burchinal et al., 2008; King et al., 1992; Delgado, Vagi, \& Scott, 2007; Simon, Pastor, Avila, \& Blumberg, 2013; Simpson, Colpe, \& Greenspan, 2003). King and colleagues’ (1992) early work summarized the thinking of the time which highlighted biologic processes of the individual child (e.g., prematurity) and environmental risks to the child (e.g., parent's lack of knowledge of infant stimulation) as influencing developmental delays. Use of varying definitions of developmental delay (e.g., screening verses verified delay) make comparison of results across studies difficult and have shown an inconsistent literature base (Delgado et al., 2007).

More recently, Simon and colleagues (2013) looked at the 2007 National Survey of Child Health data for children ages 18 months to 5 years to examine socio-demographic risk factors for developmental delay. This phone survey used the Parents' Evaluation of Developmental Status (PEDS) which asks parents about their concerns about their child's development, providing data on different levels of potential risk for developmental delay (not probable, possible, and probable). Data for the youngest group showed incidence of possible delay to be $13.9 \%$ and $8.2 \%$ for probable delay. Although data are not available for the youngest age group by risk factor, for the cohort as a whole some individual child and family characteristics were associated with probable vs. not probable delay. Factors associated with probable delay included being older, male, low birth weight, nonHispanic Black or Hispanic living in a Non-English speaking household vs. Non- 
Hispanic White, and lower household income (Simon et al., 2013). A large retrospective cohort study by Giannoni and Kass (2012), with children at high risk for development disabilities, looked at multi-level risk factors associated with developmental disabilities. Among other factors, those children with a history of poisoning or maltreatment were at greater risk for developmental disability. Another study looking at cumulative risks found that African-American children with higher social risk levels and less responsive parenting showed worse academic achievement and adjustment in early elementary schools compared to those with lower risks and engaged parenting (Burchinal, Roberts, Zeisel, Hennon, \& Hooper, 2006).

Factors associated with child health and well-being. Studies have used retrospective accounting to link harsh parenting practices linked with health behavior later in life, while less has been done to examine associations between parenting practices or parent-child interactions and health outcomes in early childhood (Belsky, Bell, Bradley, Stallard, \& Stewart-Brown, 2006). Belsky and colleagues (2006) report on a prospective cohort study in 10 U.S. cities where multiple types of data were gathered including well-validated parenting measures and observations of parent-child interactions in the home. Multivariate analysis showed that parental warmth toward the child, low negativity about the child, and positive control (low coercion), were predictive of increased general health ratings (reported by mother) of the child up to age 7. In short, this study reports support for the link between nurturing parenting and higher preschool child health ratings (Belsky et al., 2006). 
A recent position statement from the Academic Pediatric Association and the American Academy of Pediatrics Task Force on Childhood Poverty (2013) specifically discusses the level of poverty among our U.S. children, and how such conditions lead to negative outcomes for children and are threats to child well-being. This group has reported,

Neighborhood characteristics (such as poverty, crime, residential turnover, availability of quality child and family institutions, poor social control and interaction, negative normative expectations, and low employment and marriage rates) all have negative impacts on poor children's health and well-being (APA-AAP, 2013, p. 3).

One of the most recent reviews of home visitation programs reported that some studies found that program participants showed higher child health scores than those not participating in services (Selph et al., 2013). Studies of parenting practices, family socioeconomic status, and neighborhood factors as they related to child health and wellbeing are important emerging areas of research.

\section{Factors associated with parenting approaches and parent-child activities.}

Cumulative risk has been associated with negative parenting behaviors (Belsky et al., 2006; Burchinal et al., 2008). Children who grow up in environments where parents are affectionate, engaging, and available have the best chance to thrive (Belsky \& Jaffee, 2006). Selected studies that include parenting outcomes relevant to this study are described here. 
Understanding the risk and protective factors linked to use of corporal punishment behavior can better guide services and programs to teach families more positive approaches to discipline, and reduce child maltreatment. Use of and support for corporal punishment remain high in the U.S. according to reports from national samples, where $55 \%$ of mothers reported having spanked their toddlers at least once in the last month (Straus \& Stewart, 1999; Taylor, Guterman, Lee, \& Rathouz, 2009). Families that used spanking or hitting with objects were 3 to 9 times more likely to have self-reported child maltreatment than families that did not use harsh physical punishment (Zolotor, Theodore, Chang, Berkoff, \& Runyan, 2008). In addition, studies have shown the association of low socioeconomic status and stress to higher levels of corporal punishment (Giles-Sims, Straus, \& Sugarman,1995; Jackson et al., 1999).

The Fragile Families and Child Well Being Study is a large, longitudinal birth cohort study $(n=4,898)$ of newborns and their families recruited at 75 hospitals in 20 U.S. cities (Lee \& Guterman, 2010). At the child's third birthday, families were interviewed about their parenting behavior using the Conflict Tactics Scale, psychological and physical subscales. Controlling for many factors, multivariate analyses showed that younger mothers reported higher levels of harsh parenting behavior compared to older mothers, including both psychological and physical aggression. Paternal characteristics were also associated with mother's use of harsh discipline on their children. Father's use of spanking, being unemployed, and cohesive behavior toward the mother were associated with mother's increased use of aggressive discipline practices (Lee \& Guterman, 2010). The association between parenting stress and 
aversive parenting was also shown to be higher in economically disadvantaged families than in advantaged families (Dumas \& Wekerle, 1995).

In a diverse multi-site U.S. study (Family Life Project), infants and their families were followed from birth to 15 months of age (Burchinal et al., 2008). A Social Risk Index was developed that included maternal education, family income, single status, number of children in household, stressful life events, parent unemployment, and neighborhood safety. Higher mean scores on the Social Risk Index were linked to negative parenting outcomes including lower learning and literacy activities, less warm and engaged parenting, and harsher infant interactions. Given the same social risk levels, families that were more isolated vs. those living in public housing in cities and towns, showed more parental warmth (Burchinal et al., 2008). Also, risk severity was linked to worse outcomes on measures of cognitive development for children at 15 months. Protective factors were not identified (Burchinal et al., 2008). Studies have shown less parent-child engagement for families living in high stress or poverty environments (Burchinal et al., 2000, 2008).

Developmentally appropriate learning and stimulation in the home environment is paramount for healthy infant and child development (Belsky \& Jaffee, 2006). In a national study by Cabrera and colleagues (2011), parental risk factors and stressors were investigated using toddlers and parents participating in the Early Childhood Longitudinal Study (ECLS), Birth Cohort $(n=4,200)$. Findings pointed to the direct link between higher maternal and paternal risk factors to lower quality of interactions with their children, as well as less supportive behavior toward their children, and less frequent engagement (Cabrera et al., 2011). 
For the current study, research questions were developed based on the literature on cumulative risk and protection, important predictors and outcomes in child maltreatment and optimal child development, and the available data from the HS/HFO program. Specific hypotheses and exploratory research questions using 12 risk factor predictors and 10 protective factor predictors in an ecological framework, and 8 parenting and child outcomes are described next. 


\section{CHAPTER 2. THEORETICAL CONSIDERATIONS AND FRAMEWORK}

The theoretical base of this study is a developmental, social ecological model of nested, often interactive, risk and protection influences on child and parenting outcomes (Belsky, 1993; Bronfenbrenner, 1979, 1986). The ecological framework for this study was developed based on existing research and theory linking parent, family, and neighborhood factors to child maltreatment and other child and parenting outcomes as reviewed in the previous section (e.g., Belsky, 1993; Bronfenbrenner, 1979, 1986; Cicchetti \& Lynch, 1993; Cicchetti \& Valentino, 2006). Although maltreatment was the main outcome of interest in this study, other child and parenting outcomes were of interest on their own, and as potential intermediate variables linked to maltreatment.

Figure 2 provides a conceptual overview of the basic theoretical model and five included outcome domains for this study.

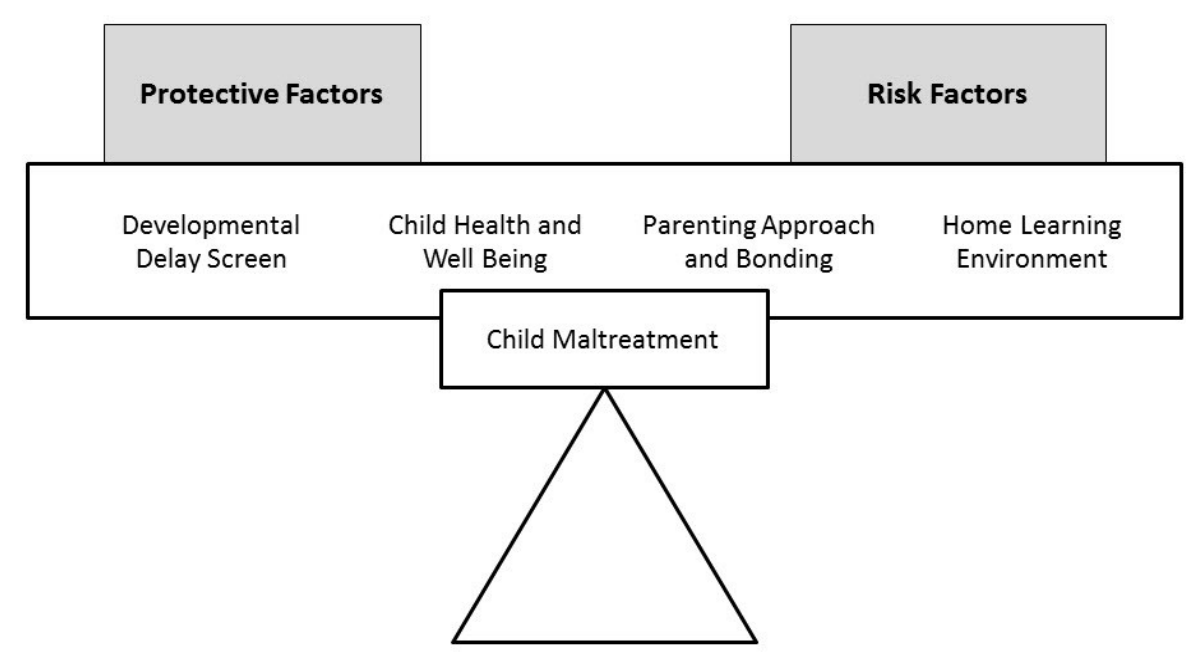

Figure 2. This figure depicts the currently articulated model with multiple risk and protective factors in a balance as they relate to the potential for negative child and parenting outcomes. 
Work to articulate the risk and protective mechanisms for children and families has received much attention. Bronfenbrenner's (1986) early thinking on the ecology of child development places the individual child in a central position, with multiple layers of influence surrounding the child's immediate environment and experiences called the microsystem. In this study too, the child is the central focus, however, the complex social relationship between the caregiver and child makes the caregiver (in most cases the mother) a dominant focus as well (Belsky, 1993).

Figure 3 depicts the 10 protective factor predictors and 12 risk factor predictors conceptualized in an ecological model for this study (microsystem, mesosystem, exosystem, and macrosystem). The microsystem is a "pattern of activities, social roles and interpersonal relations experienced by the developing person in a given face-to-face setting...with features that invite, permit, or inhibit engagement..." (Bronfenbrenner, 1994, p. 39). Thirteen of the 22 factors in this model reside in this zone; eight in the risk factor category (e.g., depression, young age) and five in the protective factors group (e.g., social support, family functioning). The mesosystem level encompasses the linkages and processes between two microsystem settings influencing the development of the child. There are seven factors in this system in the model, three risk factors (e.g., residential mobility) and four protective factors (e.g., access to housing support). Here, the family system interacts with housing systems, with financial support systems, and with service systems. Exosystem level processes happen between two or more settings and are usually outside the most direct influences on young children. This model includes the exosystem 
concepts of neighborhood cohesion as a protective factor and neighborhood violence as a risk factor.

Broader forces like societal beliefs, norms, and cultural practices exert a constant presence in the macrosystem level. Although factors were not explicitly measured in the macrosystem for this study, some findings will be discussed in the context of broader U.S. social structures like poverty and racial discrimination. A final dimension in

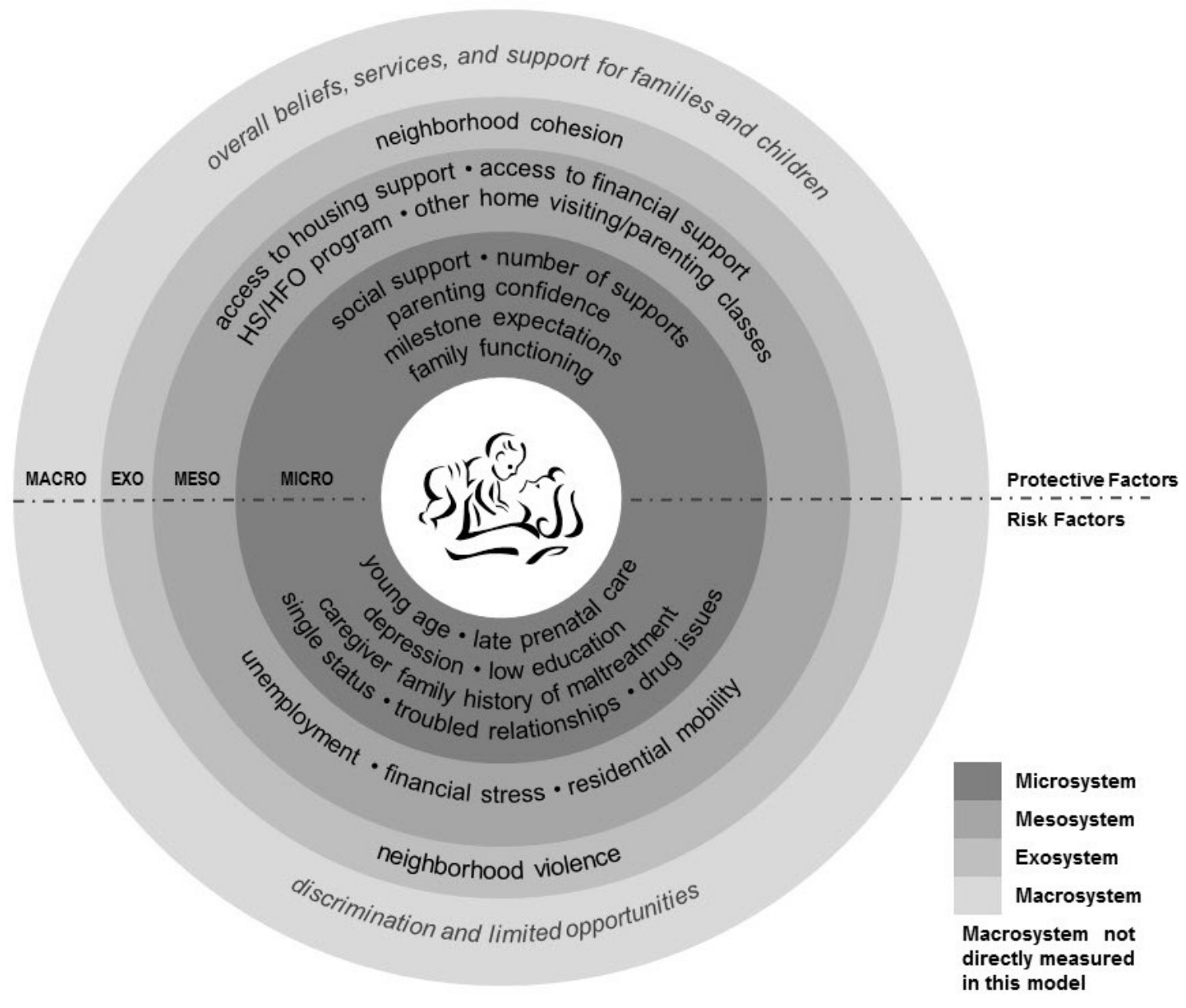

Figure 3. The theorized study risk and protective factors are embedded in a social ecological framework covering microsystem, mesosystem, and exosystem influences. The macrosystem depicts broader forces at work in the society and culture of the child and family. 
Bronfenbrenner's model not in the current study is the chronosystem. This level is characterized by the passage of time (analogous to chronological age).

\section{Approaches Embedded in the Current Model}

The risk and protective factor framework previously discussed in Chapter 1 was largely used to develop the study model and guide the analysis plan (Cicchetti \& Cohen, 2006; Jessor et al., 1995; Rutter, 1990; Toth \& Cicchetti, 1996). Theoretical approaches

embedded in the current model also include social cognitive theory and attachment theory (Bandura, 1979, 2004; Bowlby, 1977), as the sample was actively participating in a home visiting program geared toward healthy attachment and parenting behavior, and prevention of child maltreatment. In addition, neighborhood level constructs in the study were derived from neighborhood and social organization theory (Sampson et al., 1997; Belsky, 1993; Leventhal \& Brooks-Gunn, 2000). An overview of these selected theories is provided here.

Social learning and attachment theory. The social cognitive (or observational learning) theory, based on the work of Albert Bandura, is steeped in the behavioral psychology tradition, in which changes in behavior take place based on reinforcement and punishment (Bandura, 1979; 2004). In this theory, mind, behavior, and the environment all play an important role in the learning process. Basically, learning occurs through the simple processes of observing live models (e.g., parents and community members) and symbolic models (e.g., television, movies, and verbal descriptions, Bandura, 1979). Some feel that this theory has great explanatory power for how children who witness abuse and neglect in their family of origin tend to repeat such patterns, often 
referring to the "intergenerational transfer" of such behavior. In this way, this theory does place importance on norms established in a community as behavior that is learned. The inverse is also true, that parents who have deficient social connections (Coohey, 1996) do not interact with others or receive modeling of normative parenting behavior or feedback regarding their own parenting behaviors (Smith \& Fong, 2004). Many home visitation programs focus on re-parenting the parent, providing support and modeling of appropriate behaviors, aiming to give parents a chance to "re-learn" healthy parenting behaviors (Avellar et al., 2012; Olds et al., 1986).

Attachment theory hypothesizes that a good relationship between caregiver and child is pivotal in the healthy development of the child. Emotional intimacy and a strong caregiver/child bond create a secure and comforting environment, allowing children to move toward developmental milestones (Belsky \& Jaffee, 2006). This relationship is also been said to be reciprocal in nature (Bowlby, 1977; Bretherton, 1992; Bronfenbrenner, 1986). Attachment theory also argues that a caregiver's level of responsiveness to her child is directly linked to her own childrearing history and attachment experiences with caregivers. Home visitation programs aim to enhance parent-child bonding and attachment (Avellar et al., 2012; Olds et al., 1986). Home visitation programs work to help caregivers see themselves as deserving of love, support, and attention. In turn, mothers begin to see their children as deserving the same. If a caregiver is insensitive and unresponsive to a baby's cues and needs, physical and emotional harm can come to the child (Belsky \& Jaffee, 2006). This theory does accept the idea that overcrowding, poverty, and family violence hinder the mothers' ability to give appropriate attention and 
nurturance to their infants. Having a mother who provides little or no appropriate emotional responsiveness during infancy and childhood has severe ramifications for children's psychological development (Cicchetti \& Valentino, 2006).

Neighborhood and social organizational theory. Researchers working in the neighborhood and social organizational theory field look closely at the aspects of the neighborhood environment that relate to child development (Brooks-Gunn, 2010; Leventhal \& Brooks-Gunn, 2000). Social organizational theory suggests that neighborhood structural factors, such as poverty, residential instability, employment, and ethnic heterogeneity, are essential to explaining behavior through their ability to influence and/or change neighborhood organization (formal and informal institutions; Leventhal \& Brooks-Gunn, 2000; Sampson, 1992; Sampson et al., 1997). Risk factors in the current study directly relevant to this theory include family financial troubles, unemployment, residential mobility, and neighborhood violence. Protective factor neighborhood influences included in this study involve concrete access to financial and housing support and neighborhood cohesion. Studies including neighborhood characteristics have found that the higher aggregate mean of socioeconomic status (SES) in neighborhoods (rather than individual SES) is linked to greater school achievement, and lower neighborhood SES and resident instability to increases in multiple child behavior problems (Leventhal \& Brooks-Gunn, 2000).

Five outcome domains were included in this study, incorporating eight child and 
parenting outcomes. Child and parenting outcomes previously reported in the literature to be good indicators of healthy child development were of the most interest here. A summary of study outcomes and specific research questions follows.

\section{Key Outcome Domains}

The outcome of child welfare involvement was included, as indicated by self-report by a HS/HFO home visitor in regular contact with the family. Two additional child outcomes in the study included positive screening for developmental delay or off-track development and child health and well-being. To better understand risk and protective factors in relation to parenting outcomes and provide insight into the parent-child home environment, three indicators of parenting approaches and bonding were chosen. Belief

in corporal punishment practices, maternal responsiveness and acceptance, and parenting stress were included in this domain. Engagement in an appropriate supportive learning environment in the home and with their parents is also key to children's continued healthy development. The home learning environment was assessed in two ways. The first included assessing the level of engagement and developmentally-appropriate and supportive learning activities, and the second was the frequency and type of parent play activities with the child.

\section{Research Questions}

As stated earlier, many factors have been linked to negative child development and parenting outcomes (Belsky \& Jaffee, 2006; Burchinal et al., 2008; Cicchetti \& Valentino, 2006; Delgado et al., 2007; Lee \& Guterman, 2010; Simon et al., 2013; Stith et al., 2009). Positive influences in the form of multiple levels of protective factors 
including individual, family and community influences may buffer the risk for maltreatment and other negative child and parenting outcomes even in the face of high levels of risk. Based on the research described earlier, the following predictions are made:

Hypothesis 1: Parents with high risk factor index scores and high protective factor index scores will be less likely to have child abuse or neglect reports, compared to similar risk families with low protective index scores.

Hypothesis 2: Parents with high risk factor index scores and high protective factor index scores will be more likely to have children with on-time or typical development (language, gross/fine motor, cognitive, and socialemotional), compared to similar risk families with low protective index scores.

Hypothesis 3: Parents with high risk factor index scores and high protective factor index scores will be more likely to have children with higher scores on child health and well-being indictors compared to similar risk families with low protective index scores.

Hypothesis 4: Parents with high risk factor index scores and high protective factor index scores will be more likely to demonstrate positive parenting approaches, compared to similar risk families with low protective index scores.

Hypothesis 5: Parents with high risk factor index scores and high protective factor index scores will be will be more likely to provide a developmentally 
supportive learning home environment compared to similar risk families with low protective index scores.

\section{Exploratory Research Questions Across All Study Outcomes}

In addition, two exploratory research questions guided additional inquiry for this study.

Question 1: Of the 12 individual risk factors in the study, which factors provide a unique contribution to explaining outcomes?

Question 2: Of the 10 individual protective factors in the study, which factors provide a unique contribution to explaining outcomes?

The following methods chapter will describe the selection and description of participants for this study, measures documentation, and planned analytic approaches. 


\section{Chapter 3. Methods}

This is a secondary data analysis utilizing data collected in the ongoing randomized controlled trial of the Healthy Start/Healthy Families Oregon (HS/HFO) home visitation program (Green, 2009). The original randomized HS/HFO study (referred to as the "Primary Study") evaluates the impact of the HS/HFO program on documented incidents of child maltreatment. The primary study began in 2009 in seven counties in Oregon and is funded by the Administration for Children, Youth, and Families' Children's Bureau to continue through September, 2015 (Green, 2009). Of the 36 HS programs operating at the time of the grant proposal, seven met criteria for inclusion in the primary study, specifically that the program met state-established performance standards for the quality of program implementation and estimates indicated that the program would have a minimum of 25 unserved eligible applicants per year. Of the seven programs that met these criteria, four were medium-sized programs (300-1,000 first births per county) and three were large programs (1,000+ first births). Four served primarily urban areas or mixed urban/rural, while three were primarily rural. All programs were overseen by the Oregon Commission on Children and Families (OCCF) State HS staff and a state HS Steering Committee comprised of local representatives, but were administered and delivered locally by subcontract agencies.

By design for the seven counties participating in the primary study, mothers in the HS/HFO program group started by receiving weekly home visiting services. An established HS/HFO system of well-defined levels determines the frequency of visits and level of services based on a family's needs and resources (Oregon Commission on 
Children and Families [OCCF], 2012). Four levels of service are provided and intended to continue until the child's third birthday. All families at Level 1 are intended to receive weekly visits for at least 6 months. Level 2 includes visits every other week, Level 3 monthly visits, and Level 4 visits every three months.

Data were collected at initial home visit/intake, and at regular intervals every 6 months until the child turned age 3 . As a part of the primary study $(n=2,664)$, a telephone survey was conducted between December 2011 and January 2013 with a random sample of 806 of the currently enrolled program families $(n=405)$ and control families $(n=401)$ when children turned 12 months of age. This study utilized data collected at all intervals (screening and follow-up) for the program families participating in the 12-month parent phone survey.

\section{Eligibility, Screening, and Recruitment}

First-time mothers were approached by screening staff in hospitals, clinics, and other locations where first birth families could be identified, usually in the prenatal period. Mothers were asked if they were interested in learning more about the HS/HFO program. Eligibility for the HS/HFO program was determined using the New Baby Questionnaire (NBQ), a risk screening tool adapted to be self-administered by parents in English or Spanish (Duggan et al., 2000; Green et al., 2009). Parents completed the NBQ and were considered eligible for HS/HFO services if they screened positive on either substance abuse or depression items or had any two of the other NBQ risk items. If eligible, parents were asked if they would like to participate in home visiting services if space was available. For ethical reasons, infants who were medically fragile, those with a 
positive toxicology screen at delivery, or those with another immediate safety concern, were eligible for the HS/HFO program and were not included in the study.

Random assignment. Eligible and interested families were entered into an existing statewide web-based database programmed with a random-number generator to assign them to program services or no program services. When randomized to study group, program service families scheduled a first home visit and control group families were given standard resource and referral information that is currently provided for eligible families who cannot be served by HS/HFO. Preliminary analyses of screening procedures from previous years has shown that despite the voluntary nature of services, HS/HFO is reaching intended high-risk families, with participating families having an average of 3.4 NBQ risk factors at screening (Green et al., 2009). Figure 4 provides an overview of family participation from eligibility to the 12 month phone survey data collection. The bottom rounded rectangle represents the sample for the analyses for the current study. 


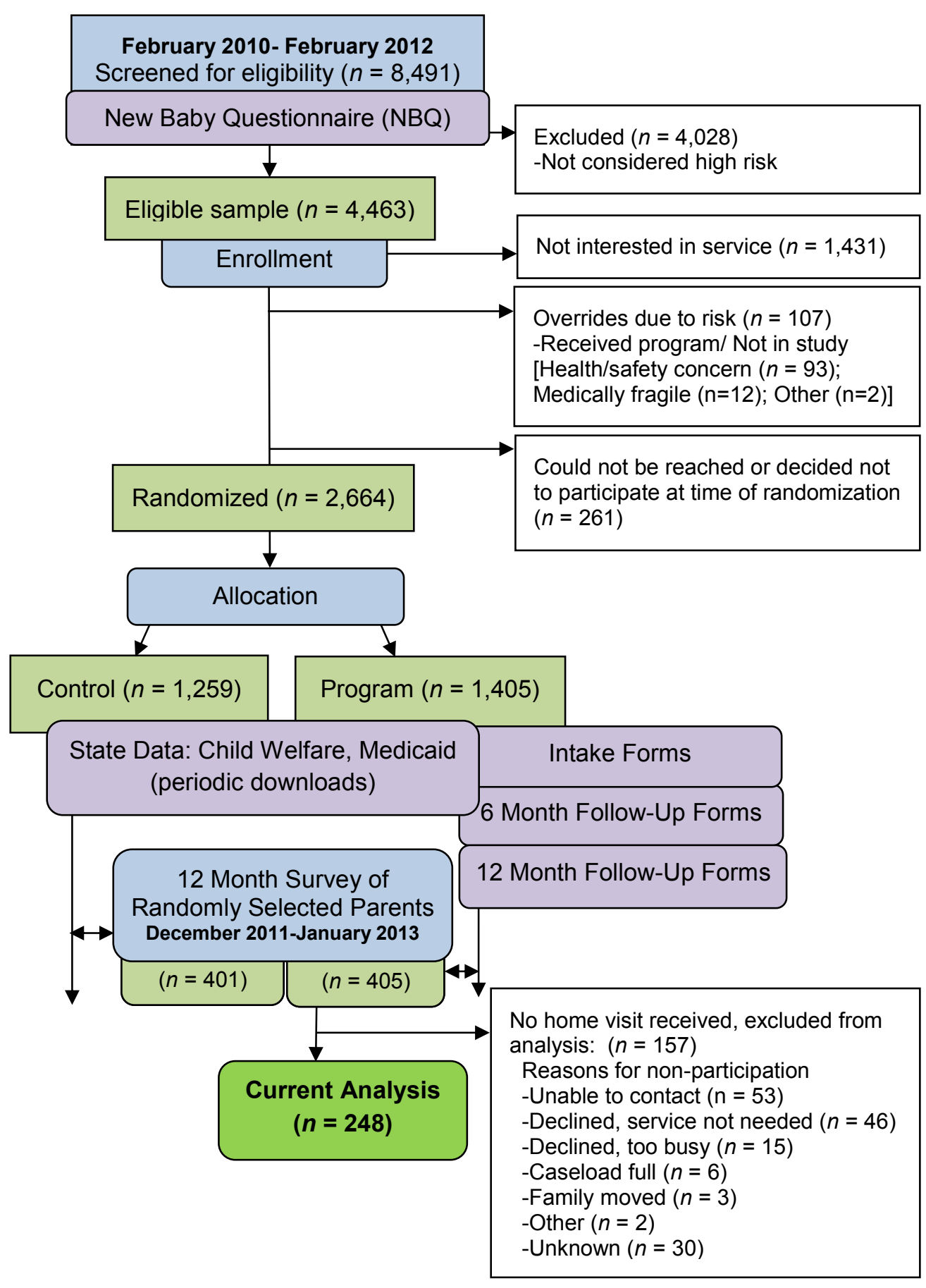

Figure 4. HS/HFO primary study and current analysis participant selection including total number of eligible, enrolled, and engaged participants. 


\section{Characteristics of the Sample}

Four hundred five families receiving the HS/HFO program who were randomly selected to participate in the 12-month phone survey study were eligible to be included in the sample for this study. Subsequently, for those program participants called on the phone survey, $38 \%(n=157)$ did not receive a home visit even though assigned to the program group. Due to screening families early in their pregnancy, some families who agreed to be in the program before their child was born chose not to participate when later called by the program. Reasons for non-participation for the 157 families in the program group who did not receive a home visit include the following: Unable to contact (53), family declined services stating they were not needed (46), family declined stating they were too busy (15), home visitor caseload was full (6), family moved (3), other (2), and unknown reason (30). Since the focus of the current inquiry is on factors linked to outcomes for families receiving program services, only those families with documented home visits were included. Also, non-participating families did not have key data gathered by the home visitor at 6 and 12 month intervals since they were not connected to HS/HFO services. Keeping those families that were active in the program maximized the availability of data for this project. In summary, the final sample of the current study included only families participating in the 12 month phone survey and who received at least one program home visit $(n=248)$.

Characteristics of the families in the sample can be found in Table 1. Sixty percent of the sample were White/Non-Hispanic, while a third of the sample were Hispanic, and $9 \%$ other race/ethnicity. Mother's average age was $22.8(S D=4.9)$, with $31 \%$ 
categorized as teen mothers, 19 or younger. The youngest teen mothers, aged 17 or younger, made up $11 \%$ of the sample. Households consisted predominately of single parents (77\%), with approximately a quarter having achieved less than a high

Table 1

Sample Characteristics for HS/HFO Program Study Families

(Received $\geq 1$ Home Visit; $N=248$ )

\begin{tabular}{|c|c|c|c|c|}
\hline \multirow[b]{2}{*}{ Characteristic } & \multicolumn{2}{|c|}{ Yes } & \multicolumn{2}{|c|}{ No } \\
\hline & $n$ & $\%$ & $n$ & $\%$ \\
\hline \multicolumn{5}{|l|}{ Age } \\
\hline Teen mother $\leq 19$ years & 75 & 31 & 167 & 69 \\
\hline Teen mother $\leq 17$ years & 27 & 11 & 214 & 89 \\
\hline Late prenatal care ${ }^{\mathrm{a}}$ & 61 & 25 & 182 & 75 \\
\hline $\begin{array}{l}\text { Premature infant } \\
\text { Not reported }(n=19)\end{array}$ & 19 & 9 & 210 & 91 \\
\hline \multicolumn{5}{|l|}{ Race $^{b}$} \\
\hline White/Non-Hispanic & 136 & 60 & -- & -- \\
\hline Hispanic/Latina & 71 & 31 & -- & -- \\
\hline $\begin{array}{l}\text { Other race/ethnicity }{ }^{\mathrm{c}} \\
\text { Race not reported }(n=21)\end{array}$ & 20 & 9 & -- & -- \\
\hline Non-English speaking at home & 47 & 22 & 169 & 78 \\
\hline Single status & 190 & 77 & 57 & 23 \\
\hline Federal financial support ${ }^{\mathrm{d}}$ & 89 & 38 & 144 & 62 \\
\hline Trouble paying for basic needs & 205 & 83 & 41 & 17 \\
\hline Both parents unemployed & 86 & 35 & 160 & 65 \\
\hline Less than HS education & 63 & 26 & 184 & 74 \\
\hline Maternal depression & 67 & 27 & 178 & 73 \\
\hline \multirow[t]{2}{*}{ Frequent mobility $^{\mathrm{e}}$} & 53 & 22 & 192 & 78 \\
\hline & Mean & $S D$ & & \\
\hline Mother's age & 22.8 & 4.9 & & \\
\hline $\begin{array}{l}\text { Number of NBQ baseline risk } \\
\text { factors }\end{array}$ & 3.1 & 1.2 & & \\
\hline
\end{tabular}

Note. Not all rows add to 248 due to missing data. ${ }^{\text {a Late }}$ was considered more than 12 weeks or not at all. ${ }^{\mathrm{b}}$ Percentages are for reported race/ethnicity. ${ }^{\mathrm{c}}$ Includes African American $(n=1)$, Asian/Pacific Islander $(n$ $=4)$, American Indian/Alaska Native $(n=2)$, and multi-racial/other $(n=13) .{ }^{\mathrm{d}}$ Temporary Assistance for Needy Families (TANF)/cash assistance used or needed. ${ }^{e}$ Homeless episode or $\geq 2$ moves in 12 months. ${ }^{\mathrm{f}} \mathrm{NBQ}=$ New Baby Questionnaire screen for 10 risk factors; range 1-10. 
school/GED education. Families had an average of three baseline risk factors upon screening at enrollment as measured by the NBQ screener. Financial stress was also common for families, with $83 \%$ reporting trouble paying for basic expenses and $35 \%$ stating that both parents were unemployed. Twenty-seven percent of mothers had an indicator for depression, while $22 \%$ reported frequent mobility (homeless or two or more moves in the past 12 months). Families received an average of 16 HS/HFO program home visits in the first 6 months of program participation; home visits ranged from $1-31$ in this 6 month time frame. Additional comparisons on selected characteristics, predictors, and outcome variables by race/ethnicity can be found in Appendix C.

\section{Data Collection}

As described, family risk factor data were collected at study recruitment. Within one month of program entry, parents completed the HS Parent Survey I, and home visitors and parents completed the intake questionnaire and Kempe Family Stress Inventory (KFSI). Every 6 months thereafter (starting with the child's 6-month birthdate), a variety of standardized and other measures were completed by both the home visitor and the parent, until the child's third birthday (Table 2). Data from family screening at enrollment through the child's first birthday were utilized in the current study. 
Table 2

Healthy Start/Health Families Oregon (HS/HFO) Data Collection Details

\begin{tabular}{|c|c|c|c|}
\hline HS/HFO Measurement Protocol & Respondent & Timing & Location \\
\hline New Baby Questionnaire $^{a}$ & Parent & Eligibility/Enrollment & $\begin{array}{l}\text { Hospital, } \\
\text { medical offices }\end{array}$ \\
\hline HS Family Intake Survey & Home Visitor & Within 30 days of enrollment & Family Home \\
\hline Kempe Family Stress Inventory & $\begin{array}{l}\text { Home Visitor - } \\
\text { Interview of Parent }\end{array}$ & Within 30 days of enrollment & Family Home \\
\hline HS Parent Survey I & Parent & Within 30 days of enrollment & Family Home \\
\hline $\begin{array}{l}\text { HS Family Update (ASQ/ ASQ- } \\
\text { SE) }\end{array}$ & $\begin{array}{l}\text { Home Visitor / } \\
\text { Parent }\end{array}$ & 6 and 12 month birthdays & Family Home \\
\hline HS Parent Survey II-A & Parent & 6 and 12 month birthdays & Family Home \\
\hline HS Parent Survey II-B & Parent & 6 and 12 month birthdays & Family Home \\
\hline HOME inventory & Home Visitor & 12 month birthday & Family Home \\
\hline HS Parent Phone Survey & $\begin{array}{l}\text { Research Staff - } \\
\text { Interview of Parent }\end{array}$ & 12 month birthday & Phone interview \\
\hline Home Visitation Exposure & Home Visitor & Periodic download & NA \\
\hline
\end{tabular}

Note. ${ }^{\text {a }}$ NBQ screens families in the hospital, clinic, or location of new mothers on 10 risk indicators. Families are offered services if they screen positive for substance use or depression. They are also offered services if they have $\geq 2$ of the following; maternal age (17 or younger), single parent status, lack of early prenatal care and/or comprehensive prenatal care (fewer than five total prenatal visits), parent not completing high school or GED, unemployment, financial problems, or family relationship problems. HS = Healthy Start. ASQ = Ages and Stages Questionnaire. ASQ-SE = Ages and Stages-Social/Emotional. $\mathrm{HOME}=$ Home Observation Measure of the Environment.

Study measures are regularly transmitted to the research field office from all programs.

Regular processing and ongoing monitoring of screening, attrition, and program implementation/visits are also done.

It is important to note that the majority of the measures in the HS/HFO Primary Study are available for the program group only (not the comparison group). This includes all intake forms, and periodic forms and screenings at 6 month and 12 month follow-up intervals (Figure 4). Therefore, the current study includes only HS/HFO 
program participants receiving intervention services (treatment group). Thus, findings will be limited to understanding how risk and protective factors operate on study outcomes within a group of first time parents receiving home visitation.

\section{Model Development}

For the current inquiry, the empirical literature was reviewed to identify key protective factors, risk factors, and optimal child development related outcomes important in the study of maltreatment and maltreatment prevention programs (Bishop \& Leadbeater, 1999; Burchinal et al., 2008; Chu et al., 2011; Green et al., 2009; Quality Improvement Center on Early Childhood [QIC-EC], 2009; Ross \& Vandivere, 2009; Stith et al., 2009; Wolfe, 2011). Once key constructs were identified, the entire HS/HFO study measures protocol was reviewed to determine available data that reflected these key constructs. Thus, the current study was limited to available measures in the HS/HFO protocol. The majority of the constructs were captured well in the existing battery of measures, including a number of widely-used outcomes related to parenting and child development.

\section{Measures}

The following sections provide details on outcome measures, protective factors, and risk factors chosen for this work. Tables 3 through 5 highlight all study variables including measures. Every attempt was made to utilize protective factor and risk factor predictor data collected as early in the study recruitment process as possible. Baseline (before services begin) and intake data (within 1 month of recruitment) were given priority for predictor data, however 6 month data were used if earlier data were missing. 
In four instances, 12 month phone survey data were used for predictors as noted in the measures description section. The majority of outcome data was collected at 12 months after the child's birth. Because loss to follow-up is greater at the 12 month data collection, 6 month outcome data were included if 12 month data were not available.

Outcome measures. Outcomes measures from the ongoing HS/HFO study were reviewed for relevance given current literature, guidelines or expert opinion as to the key child and family outcomes, and predictors used for maltreatment research (Heller, Larrieu, D’Imperio, \& Boris, 1999; QIC-EC, 2009; Ross \& Vandivere, 2009). The current study incorporated a number of widely used and validated measures in the field of child development, with indicators for quality of the parent-child relationship, and child health and development. Twelve month data were used for outcome analyses. Table 3 provides an overview of the five outcome domains and the eight specific family and child outcome measures in this study. 
Table 3

Summary of Child and Family Outcomes and Measures in Study

\begin{tabular}{|c|c|c|}
\hline $\begin{array}{l}\text { Outcome Domain } \\
\text { (Data Type) }\end{array}$ & Outcome Measure & Collection Method \\
\hline $\begin{array}{l}\text { Child Welfare } \\
\text { Involvement } \\
\text { (Dichotomous) }\end{array}$ & $\begin{array}{l}\text { Child welfare involvement: open cases, } \\
\text { investigations, out of home placements, child } \\
\text { welfare report by home visitor, reports by } \\
\text { others }\end{array}$ & Home visitor (forms) \\
\hline $\begin{array}{l}\text { Developmental } \\
\text { Delay/Off -Track } \\
\text { Development Screen } \\
\text { (Dichotomous) }\end{array}$ & $\begin{array}{l}\text { Ages \& Stages Questionnaire (ASQ) } \\
\text { Ages \& Stages Questionnaire, } \\
\text { Social/Emotional (ASQ-SE) } \\
\text { Off-track development }\end{array}$ & $\begin{array}{l}\begin{array}{l}\text { Home visitor \& parent } \\
\text { (forms) }\end{array} \\
\text { Home visitor (forms) \& } \\
\text { parent (phone survey) }\end{array}$ \\
\hline $\begin{array}{l}\text { Child Health \& Well } \\
\text { Being } \\
\text { (Continuous) }\end{array}$ & $\begin{array}{l}\text { Immunization, well-child care, passive smoke } \\
\text { exposure, overall health and nutrition } \\
\text { Breast feeding }\end{array}$ & $\begin{array}{l}\text { Home visitor \& parent } \\
\text { (forms) } \\
\text { Parent (phone survey) }\end{array}$ \\
\hline $\begin{array}{l}\text { Parenting Approach \& } \\
\text { Bonding } \\
\text { (Continuous-Scale) }\end{array}$ & $\begin{array}{l}\text { Home Observation Measure of the } \\
\text { Environment (HOME); Responsivity and } \\
\text { Acceptance subscales }\end{array}$ & Home visitor (forms) \\
\hline (Continuous-Scale) & $\begin{array}{l}\text { Adult-Adolescent Parenting Inventory } \\
\text { (AAPI)-Corporal Punishment subscale }\end{array}$ & Parent (phone survey) \\
\hline (Continuous-Scale) & Parenting Stress Index-Short Form (PSI-SF) & Parent (phone survey) \\
\hline $\begin{array}{l}\text { Supportive Development } \\
\text { (Continuous-Scale) }\end{array}$ & $\begin{array}{l}\text { Home Observation Measure of the } \\
\text { Environment (HOME); Organization, } \\
\text { Learning, Involvement, and Variety subscales }\end{array}$ & Home visitor (forms) \\
\hline (Continuous-Scale) & Parent-Child Activities Scale & Parent (phone survey) \\
\hline
\end{tabular}

Child welfare involvement. Every 6 months, HS/HFO home visitors were asked to report on family child welfare involvement on six specific items on update forms. The home visitor reported on knowledge of families in the following areas (1) family receives child welfare services, (2) home visitor has made a maltreatment report on the family, (3) there has been a child welfare investigation, (4) there has been a child welfare case opened, (5) there have been children removed from the home, and, (6) there are other child welfare reports on the family. If the home visitor marked the item No or Don't 
Know, this was coded No (0). If there was a Yes response to any of these six items at six months or 12 months, the child welfare involvement variable was coded Yes (1). Although Oregon Administrative State Child Welfare data were requested early in the proposal stage of this study, State maltreatment data were not available during the data collection or analysis phase of this work.

Developmental delay /off-track development screener. The child's developmental status was tracked at 6 months and 12 months on a variety of measures and questionnaire items, with both home visitor and parent reporting on the child's behavior (Table 4). The Ages and Stages Questionnaires (ASQ) and the ASQ-Social-Emotional (ASQ-SE) were used to monitor children's development at 6 and 12 month (four potential places for a positive screen for potential delay). These instruments have been shown to be reliable for screening to identify those children who are in need of further evaluation for delays and those who have typical development. If children screen positive on this measure, referral and further testing is needed to confirm if there is a delay or not. The ASQ screened five developmental areas (communication, gross motor, fine motor, problem solving, personal-social) and the ASQ-SE screens seven behavioral areas (self-regulation, compliance, communication, adaptive, autonomy, affect, and interaction with people; Nickel \& Squires, 2000; Squires, Bricker, \& Twombly, 2002). Sample items on the 6 month ASQ screener include, "Does your baby pick up a toy and put it in his mouth?" and "Does your baby like to be picked up or held?" The response choices for parents are as follows: Yes, Sometimes, or Not Yet. Home visitors worked with parents to complete 
Table 4

Description of Developmental Delay or Off Track Development Screening Measures and Items

\begin{tabular}{ll}
\hline Cognitive Functioning Items & Respondent \\
\hline ASQ Screen, 6 months & Parent, Home Visitor \\
ASQ-SE Screen, 6 months & Parent, Home Visitor \\
Any diagnosed developmental delays ${ }^{a} 6$ months & Home Visitor \\
ASQ Screen, 12 months & Parent, Home Visitor \\
ASQ-SE 12 Screen, 12 months & Parent, Home Visitor \\
Any diagnosed developmental delays ${ }^{a}$ 12 months & Home Visitor \\
Off-track development ${ }^{b}$ 12 months & Parent \\
\hline Coding for Developmental Delay/Off-Track & Positive response on any of \\
Development Screen, outcome variable $=1$ & the 7 items
\end{tabular}

Note. ASQ = Ages and Stages Questionnaire, ASQ-SE = Ages and Stages-Social/Emotional. ${ }^{a}$ The home visitor is asked to report any delays noticed overall when the child is 6 months and 12 months old. ${ }^{b}$ Parents are asked (on a phone survey when the child turns 12 months old) if they have ever been told or if they ever thought that their child was off-track in their development.

these measures as needed. Scoring instructions on the ASQ and ASQ-SE screener forms provided details to home visitors including how to adjust scores if one or more items were missing, adding items, recording subscale area scores, and using a chart to transfer total scores. The chart provided cut-offs for scores that indicated the child's development as falling into one of three categories (1) on schedule, (2) development requires learning activities, and (3) monitoring and further assessment with a professional is recommended. The Home Visitor was asked to fill out a HS/HFO form after the ASQ and ASQ-SE administration was complete, indicating the child's developmental status: normal, delays, or other. If the home visitor marked these forms with a potential delay code at either time 
frame, the variable was coded Yes (1). Again, a positive response does not indicate a definitive delay, only that a child would need to go for further evaluation and testing to assess for actual delay.

Home visitors were also asked to report at six and 12 months on HS/HFO forms if they knew whether the child had a diagnosed developmental delay. Also, on their child's 12 month birthday, parents were asked on a phone survey to report on their child's developmental status. The response choices for parents were Yes (1) or No (0), on the following question:

Have you been told (or have you ever thought) that your child may need services to help with his/her development, or that your child is not quite "on track" with where s/he should be with walking, talking, or other development? In summary, the developmental delay or off-track screen variable for this study was coded Yes (1) if a child received a positive screen for delay on either of the ASQ and ASQ-SE measures at six months or 12 months, a home visitor report of delay at six or 12 months, or the parent reported a potential development problem on the 12 month phone survey.

Child health and well-being. A continuous child health and well-being scale was created by calculating the mean of six items as indicators of child health status at one year (Table 5). Positive indicators of health included home visitor report of immunizations being up to date, which was coded: Yes (1) and Some or No (0). Wellchild visits up to date and no passive smoke exposure were coded as follows: Yes (1), No (0), and Don't Know was coded as missing. Home visitor report of child's overall health 
and overall nutrition were also included as part of this measure. Response choices included poor, fair, good, and very good. Since these indicators were highly skewed with most responses in only the good and very good categories, a code of 1 was given if the home visitors rated the child in the very good category. A code of 0 was given for any category below very good. On their child's 12 month birthday, parents were asked about the length of time they breastfed their child with the response choices, still breastfeeding, number of weeks/months they breastfed, and never breastfed. Based on guidelines for

optimal

Table 5

Description of Individual Items in Child Health and Well Being Outcome Measure

\begin{tabular}{|c|c|c|}
\hline Item & Respondent & Measure \\
\hline Are the child's immunizations up to date? ${ }^{\mathrm{a}}$ & Home Visitor & $\begin{array}{l}\text { HS/HFO Family } \\
\text { Update }^{\text {b }}\end{array}$ \\
\hline Has the child received regular well-child checkups? & Home Visitor & $\begin{array}{l}\text { HS/HFO Family } \\
\text { Update }^{\text {b }}\end{array}$ \\
\hline $\begin{array}{l}\text { Does the child receive passive smoke exposure } \\
\text { (frequently exposed to smoke at home or elsewhere)? }\end{array}$ & Home Visitor & $\begin{array}{l}\text { HS/HFO Family } \\
\text { Update }^{\text {b }}\end{array}$ \\
\hline How would you rate the child's health, overall? & Home Visitor & $\begin{array}{l}\text { HS/HFO Family } \\
\text { Update }^{\text {b }}\end{array}$ \\
\hline How would you rate the child's nutrition, overall? & Home Visitor & $\begin{array}{l}\text { HS/HFO Family } \\
\text { Update }^{\text {b }}\end{array}$ \\
\hline $\begin{array}{l}\text { If you breastfed, how old was your baby when s/he } \\
\text { completely stopped breastfeeding or being fed breast }^{\text {milk? }^{c}}\end{array}$ & Parent & $\begin{array}{l}12 \text { Month Phone } \\
\text { Survey }\end{array}$ \\
\hline
\end{tabular}

Note ${ }^{a}$ Home visitor has access to State records on immunization data. ${ }^{\mathrm{b}}$ The home visitor is asked to report on this when the child is 6 and 12 months old. ${ }^{c}$ Parent question on phone survey when child turns 12 months old. HS/HFO = Healthy Start/Healthy Families Oregon program.

early childhood health and growth from the American Academy of Pediatrics (American Academy of Pediatrics [AAP], 2012), having breastfed for six or more months was 
considered protective and coded Yes (1) for this item in the scale. Less than six months of breastfeeding or never breast fed was coded $N o(0)$.

\section{Parenting approaches and bonding.}

Corporal Punishment. The eight items on the Adult Adolescent Parenting Inventory--Corporal Punishment Subscale (AAPI-CP; Bavolek \& Keene, 2001) were used to assess parent perceptions and acceptance of harsh punishment, specifically hitting and spanking. Parents responded about their agreement with statements on a 5-response Likert scale from 5 (strongly agree) to 1 (strongly disagree). Selected scale items included the following: "spanking teaches children right from wrong," "children can learn good discipline without being spanked (reverse code)," "hitting a child out of love is different than hitting a child out of anger," "it's OK to spank as a last resort," and "a good spanking lets children know that parents mean business." Higher scores on the AAPI-CP have been related to other measures of harsh discipline and items showed good internal consistency (Cronbach's alpha = .79; Conners, Whiteside-Mansell, Deere, Ledet, \& Edwards, 2006). In the current study, AAPI-CP items showed similar psychometrics with a Cronbach alpha coefficient of .77.

Parent responsiveness and acceptance. The Home Observation Measure of the Environment (HOME, Infant-Toddler version; Bradley \& Caldwell, 1984) was collected by home visitation staff at the child's first birthday. Six subscales (45 items) captured the child in his/her home environment, as a receiver of information from objects, events, and people within the immediate family surroundings (Bradley, 1993). Responsivity (11 items) and Acceptance (8 items) subscales were combined for the responsive and 
accepting parenting approach outcome measure. These scales were thought to best capture the idea of providing a reinforcing and responsive environment for a child as observations include physical affection, positive approaches to discipline, and nonrestricted access to the home environment. Examples of parent observation items from the Responsivity subscale included "spontaneously praises child," "voice conveys positive feelings toward child," and "responds verbally to child's vocalizations or verbalizations," coded as Yes (1) or No (0). A subset of items from the Acceptance subscale includes the following: "parent does not express overt annoyance with or hostility to child," "parent does not scold or criticize child during visit," and "parent does not interfere with or restrict child 3 times during visit." For this subscale, each item was coded with Agree (1) or Disagree (0); the mean score was calculated for the 19 items. Higher Responsivity and Acceptance subscale scores were considered better for parent and child functioning. Numerous studies provided evidence for both construct and scale validity (Bradley, 1993; Bradley \& Caldwell, 1984; Stevens \& Bakeman, 1985). In the current study, the combined Responsivity and Acceptance subscales showed good internal consistency with a Cronbach alpha coefficient of .69.

Parenting Stress. The Parenting Stress Index (Abidin, 1995) and Parenting Stress Index- Short Form (PSI-SF, Haskett, Ahern, Ward, \& Allaire, 2006) have been widely used in the child maltreatment literature, and utilized with similar risk groups with strong psychometric properties (Reitman, Currier, \& Stickle, 2002; Whiteside-Mansell, et al., 2007). Using the PSI-SF, the two subscales in this study were comprised of 12 selfreport items on a 5-point Likert scale and asked parents about how much each item 
currently disturbs them in relation to their parenting role. Responses ranged from 5 (strongly agree) to 1 (strongly disagree). The five items on the Parenting Stress Subscale related to stress due to having a child included "giving up things," "feeling trapped," "unable to do new things," "not doing things they like," "and problems in relationships." The General Stress seven item subscale included these items: "can't handle things," "things bother you," "feel alone," "go to party/bad time," "less interested," "enjoy less," and "unhappy about a recent purchase." Mean items for a PSI-SF Total score for two subscales were calculated, with higher scores equated to higher stress. High internal consistency for the PSI-SF General and Parenting Stress subscales has been shown in prior research (Cronbach's alpha $=.88$ and .95 , respectively; Reitman et al., 2002). Good internal consistency for the 12 items on the PSI-SF was found for this sample $($ Cronbach's alpha $=.77)$.

\section{Supportive development.}

Supportive learning environment. Four HOME subscales were used at the child's 12 month birthday to assess the extent to which parents provided a developmentally supportive environment for their children (Bradley \& Caldwell, 1984; Stevens \& Bakeman, 1985). Twenty-six items comprised the Organization (5 items), Learning Materials (9 items), Involvement (6 items), and Variety (5 items) Subscales, each rated as a Yes (1) or No (0) by the home visitor during home observation. Table 6 includes sample items for subscales for this measure. The mean of four subscales incorporating the supportive development outcome measure were calculated (Cronbach's alpha $=.79$ ). Higher scores indicate greater levels of developmentally appropriate, supportive, and 
engaging activities for children in the home. As noted earlier, numerous studies provided evidence of the HOME's robust psychometric qualities (Bradley, 1993).

Table 6

Example Items for the The Home Observation Measure of the Environment (HOME) Four Subscales Comprising the Supportive Development Outcome for This Study

\begin{tabular}{l}
\hline Example Items for the HOME by Subscale \\
\hline Organization \\
Child is taken to grocery store at least once a week. \\
Child is taken regularly to doctor's office or clinic. \\
Child's play environment is safe. \\
\hline Learning Materials \\
Parent provides toys for child to play with during visit. \\
Cuddly toy or role-playing toys. \\
Simple eye-hand coordination toys. \\
Involvement \\
Parent keeps child in visual range, looks at often. \\
Parent consciously encourages developmental advance. \\
Parent provides toys that challenge child to develop new skills. \\
\hline Variety \\
Parent reads stories to child at least 3 times weekly. \\
Family visits relatives or receives visits once a month or so. \\
Child has 3 or more books of his/her own. \\
\hline Note. Items from The Home Observation Measure of the Environment (HOME) \\
(Bradley \& Caldwell, 1984).
\end{tabular}

Parent child activities. The Parent-Child Activities Scale (PCAS) was used as a measure of the frequency of developmentally-supportive parent-child interactions at 12 months (Love et al., 2002). The PCAS asks parents to report on their level of activity with their child in the last month on five items. The response format is a 6-choice Likert scale ranging from not at all (0) to more than once a day (5) on the following items: songs/nursery rhymes, tell stories, play outside, play chasing/peek-a boo games, and go 
on outings. Higher scores indicate greater levels of parent-child activity and engagement. The PCAS has shown good internal consistency in relevant studies (Cronbach's alpha = .71; Love et al., 2002). The mean of items was used and showed adequate internal consistency (Cronbach's alpha $=.56)$.

\section{Predictors}

Protective factor predictors. Ten multi-level individual parent, family, and neighborhood factors measures were used in this study (Table 7). Factors were not meant Table 7

Protective Factor Predictors and Measures ${ }^{a}$

\begin{tabular}{|c|c|c|}
\hline Level $^{b}$ & Protective Factor & Measure \\
\hline \multirow{4}{*}{$\begin{array}{l}\text { Individual- } \\
\text { Parent }\end{array}$} & Social support & Duke-UNC Social Support Scale $^{c}$ \\
\hline & Number of supports & New Baby Questionnaire \\
\hline & Parenting confidence & Parenting Ladder Measure \\
\hline & $\begin{array}{l}\text { Expectations of infant } \\
\text { milestones/behavior }\end{array}$ & Kempe Family Stress Inventory \\
\hline \multirow{5}{*}{ Family } & Family functioning & Protective Factors Survey $^{\mathrm{d}}$ \\
\hline & Access to housing support & Parent Intake Form \\
\hline & Access to financial support & Parent Intake Form \\
\hline & HS/HFO program visits & Home Visitation Fidelity Measures \\
\hline & Other home visit programs/ classes & $\begin{array}{l}\text { Additional Home Visiting } \\
\text { Programs and/or Parenting Classes }\end{array}$ \\
\hline $\begin{array}{l}\text { Neighbor- } \\
\text { hood }\end{array}$ & Neighborhood cohesion & Neighborhood Cohesion Scale $^{d}$ \\
\hline
\end{tabular}

to be exclusive to one level of influence, for instance access to concrete financial and housing support spans the individual and family domain, and even potentially the 
neighborhood level regarding availability of services in the community. In general, when a protective factor was dichotomized, this response format was followed: the presence of the item was coded as being a positive or protective influence (code 1), and the absence of the factor was coded as a lack of protection on that variable (code 0 ).

Social support. Social support was assessed for families at program entry using two measures. The first is included on the HS/HFO Parent Survey I Form, the Duke-UNC Functional Social Support Scale (Broadhead, Gehlbach, de Gruy, \& Kaplan, 1988). The measure asked parents how they felt about the level of support they received from other people, gauging support on a 5-choice Likert response scale from 5 (as much (support) as I would like) to 1 (much less (support) than I would like). The 10 items for three subscales on the DUKE-UNC Scale included, (a) Emotional- love and affection from others, chances to talk, chances to do things, people who care; (b) Tangible - talk about money, useful advice, transportation help, household chore help; and (c) Parenting child care help, advice on raising children. The mean of items was calculated for this measure, with higher scores being indicative of increased levels of social support. The Duke-UNC Social Support Scale has been shown to be valid and reliable (Cronbach's alpha $=.81$; Broadhead et al., 1988), with similar internal consistency in our sample $($ Cronbach's alpha $=.84)$.

Number of supports. The second measure of social support gathered at program entry was asked on the NBQ and states: "How many people do you know that you could turn to for support, or talk to about problems, concerns, or things that are bothering you?" 
The response choices were $0,1,2$, or more than 2 . More than two supports was considered protective (1) and $0-2$ less protective $(0)$.

Parenting confidence. The Parenting Ladder was a retrospective measure used to assess pre-post changes in parent's perspectives on parenting confidence and knowledge (Pratt, McGuigan, \& Katzev, 2000). Mothers were asked at six months to think back to the time of their child's birth and rate how they felt about their knowledge of how children grow and develop, their confidence that they knew what was right for their child, and their ability to help their child learn. They rated themselves on a 4-point scale (ladder graphic with multiple rungs) with response choices from 0 (need some help) on the last rung of the ladder, to 4 (doing great) on the top step of the ladder. Mean scores on the three retrospective items were used for this measure with higher scores indicating higher confidence. In a study of this measure, home visitor report of mother's knowledge of infant behavior was significantly correlated with mothers' retrospective pretest score on the "knowledge of how children grow and develop" item $(\mathrm{r}=.27, p<.01$; Pratt, et al., 2000). Our sample showed strong internal consistency for the items on this measure $($ Cronbach's alpha $=.85)$.

Expectations of infant milestones and behavior. The KFSI is an interview instrument used by the home visitors to gather information on stressful past and present life experiences, using observation, conversation, and probes (Kempe, 1976; Korfmacher, 2000). The KFSI includes home visitor ratings of parents on a three level rating system (no problems, problems, or many problems) for 10 present and past potentially concerning behaviors that can negatively influence family functioning (Kempe, 1976). 
Parents were interviewed with the KFSI within one month of study enrollment. One of the areas included expectations of their infant's milestones and behavior. Having no problems with expectations was considered protective (code 1), while having problems or many problems with expectations of infant milestones was considered not protective (code 0 ). The KFSI has been found to be a valid measure if used with appropriate training, and reliability data for the measure as a whole has been promising and emerging (Korfmacher, 2000; Orkow, 1985), however single item analyses would not be appropriate.

Family functioning. The Family Functioning subscale of the Protective Factors Survey (PFS) was used to measure the quality of family relationships and support using five items including talking about problems, taking time to listen, listening to both sides, pulling together in times of stress, and being able to solve problems (Counts, Buffington, Chang-Rios, Rasussen, \& Preacher, 2010). A Likert 5-item scale was used ranging from 0 (never) to 4 (always). Mean scores were calculated, with higher scores evidencing better family functioning. This measure was administered on the parent phone survey at the child's 12 month birthday. Previous studies show good internal consistency (Cronbach's alpha $=.89$; Counts et al., 2010; Protective Factors Survey [PFS], 2009), and our study provided similar findings (Cronbach's alpha $=.86$ ). Recent content validity data showed that higher family functioning scores were associated with greater scores on positive constructs such as optimism and positive affect (Institute for Educational Research \& Public Service, 2013). 
Access to concrete housing and financial support. Family access to concrete supports for housing or financial assistance was assessed at study entry. The HS/HFO intake and update surveys included questions about which services (Housing, Temporary Aid to Needy Families, or other cash assistance) the family had currently used or still needed prior to enrollment, and if any member of the family used or lacked a needed service. The response format for each service on the form included, service currently used, service not needed, and family lacks needed service. For this variable, service currently used and service not needed were collapsed and coded 1 . This meant that the family did not need or did not lack current housing or financial support. Those families who reported lacking the needed service were coded 0 . Housing and financial supports were each counted as separate dichotomous protective factors.

HS/HFO program visits and other home visiting programs and classes. The total number of HS/HFO family home visits (as reported by home visitors) received within the first 6 months of program participation was used to gauge level of program exposure. Also, on the parent phone survey at the child's 12 month birthday, families were asked about their participation in home visiting program services, community programs, or parenting classes in the past year. They were asked to specify if their participation in a home visiting program was the HS/HFO program or a different agency. They were also asked this question: “In the first year of the baby's life, have you participated in any parenting education classes or parenting support groups?" An additional home visiting or parenting class protective factor dichotomous variable was created using this information as follows: the families reporting participation in an additional home visiting program 
outside the HS/HFO program or participation in a parenting class or support group of any kind were coded 1 and those that reported no participation in programs outside the HS/HFO program or no parenting classes or support groups were coded 0 . Numbers of HS/HFO home visits and family participation in additional programs or classes were included as two separate protective factors.

Neighborhood cohesion. The six item Neighborhood Cohesion Scale included items on liking the neighborhood, and neighbors being trustworthy, caring, willing to help, able to get along, and sharing the same values (Mujahid, Diez Roux, Morenoff, \& Raghunathan, 2007). The mean was calculated, based on a 5-choice Likert scale ranging from 5 (strongly agree) to 1 (strongly disagree) for 6 items. Higher scores indicated higher levels of positive neighborhood attributes and connection. These data were collected on the parent phone survey, 12 months post service commencement. Good internal consistency for the scale items is reported in the field (Mujahid et al., 2007; Cronbach's alpha $=.74)$ and in this sample $($ Cronbach's alpha $=.86)$.

Risk factor predictors. Twelve multi-level risk factors were included in this study (Table 8). Eight of the twelve baseline risk factors included in this model were collected on the New Baby Questionnaire (NBQ) when families were first screened for eligibility for the study (Green et al., 2009). As with some of the protective factors, many risk factors have multiple levels of influence even though they are organized into one of the individual parent, family, and neighborhood categories below. In general, risk factors that were dichotomous followed this response format, presence (1) the family had the risk factor, and absence (0) the family did not have the risk factor. Many of the risk 
factors are dichotomous in nature and data on internal consistency was not appropriate for reporting on a single item measure.

Table 8

Risk Factor Predictors and Measures

\begin{tabular}{|c|c|c|}
\hline Level $^{\mathrm{a}}$ & Risk Factor & Measure \\
\hline \multirow{7}{*}{$\begin{array}{l}\text { Individual- } \\
\text { Parent }\end{array}$} & Young age $(<19)$ & New Baby Questionnaire \\
\hline & Late prenatal care & New Baby Questionnaire \\
\hline & Single status & New Baby Questionnaire \\
\hline & Depression (PHQ-2) & New Baby Questionnaire \\
\hline & Low education & New Baby Questionnaire \\
\hline & Drug/abuse issues & Kempe Family Stress Index \\
\hline & $\begin{array}{l}\text { Caregiver family history of } \\
\text { maltreatment }\end{array}$ & Kempe Family Stress Index \\
\hline \multirow{4}{*}{ Family } & Unemployment & New Baby Questionnaire \\
\hline & Financial stress & New Baby Questionnaire \\
\hline & Troubled family relationships & New Baby Questionnaire \\
\hline & Frequent mobility $^{\mathrm{b}}$ & Homelessness/Moves \\
\hline Neighborhood & Neighborhood violence $^{\mathrm{b}}$ & Neighborhood Safety Scale \\
\hline \multicolumn{3}{|c|}{ 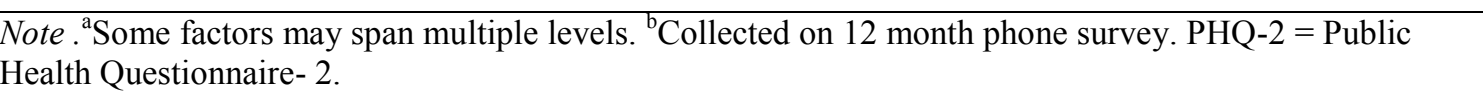 } \\
\hline \multicolumn{3}{|c|}{ Young age. Age of mother was used as an individual-level risk factor in this } \\
\hline \multicolumn{3}{|c|}{ model, and is gathered on the NBQ at study recruitment (Green et al., 2009). Age was } \\
\hline \multicolumn{3}{|c|}{ used as a continuous variable when possible. When dichotomized, the teen mother risk } \\
\hline \multicolumn{3}{|c|}{ factor was defined as 19 years old or younger. } \\
\hline \multicolumn{3}{|c|}{ Late prenatal care. Mothers were asked about their prenatal care on the NBQ } \\
\hline during eligibility & eening. Late prenatal care (st & $g$ after the first trimester or no \\
\hline
\end{tabular}


factor: "For this pregnancy, how far along were you when you first saw a health care provider (like a doctor) for prenatal care (not including any visit that was only for a pregnancy test)?" The response format included 0-12 weeks, more than 12 weeks, or not at all. This variable was dichotomized to include 0-12 weeks (coded 0), and more than 12 weeks or not at all (coded 1).

Single status. Mothers were asked if they were currently married on the NBQ. Those that were unmarried were coded 1 , those that were married were coded 0 . Single status was considered a risk factor in this study.

Depression. The well-validated measure of parental depression, the Public Health Questionnaire-2 (PHQ-2), asked mothers about feelings in the past month including, (a) often feeling down, depressed or hopeless, and (b) bothered by having little interest or pleasure in doing things (Herrenkohl et al., 2008; Kroenke, Spitzer, \& Williams, 2003). This variable was coded as a dichotomous variable for which mothers were coded as having the presence of the risk factor (coded 1) if they answered positively on both screener items and as having the absence of the risk factor (coded 0) if they answered in the negative to either or both items.

Low education. The NBQ asked participants to report on their education level as follows: What is the highest level of school you have completed? The three response choices on how far they had gone in school were, (a) less than a high school education (no high school diploma or GED), (b) completed high school or GED, or, (c) education beyond high school/GED. As low education is considered a risk factor in this study, this dichotomous variable was coded as presence of the risk factor (1) if parents reported less 
than high school, and absence (0) if they reported completion of high school or schooling beyond high school.

Drug abuse/issues. As discussed earlier, the KFSI interview style measure required home visitors to use a rating system (no problems, problems, or many problems) to code for potential family problems in a variety of areas (Kempe, 1976). Current substance abuse issues for either the primary caregiver or the second parent figure were combined for this sample and coded as a dichotomous variable. If home visitors reported any problems for either parent for substance abuse issues, it was considered as present as a risk factor (1), and no reported problems was coded as absent as a risk factor (0).

Caregiver family history of maltreatment. Parental information on family history of childhood maltreatment (Wolfe, 2006), gathered as part of the Kempe Family Stress Inventory (KFSI), was also included in this study. The KFSI is shown to be a valid and reliable measure of histories of abuse and neglect (Kempe, 1976; Korfmacher, 2000). Interviewers probed about the childhood histories of primary caregiver and secondary parent figure regarding their experiences with physical/sexual abuse, emotional abuse/neglect, and removal from parental care, rating parents as having had no problems, problems, or many problems in this area. Using data for both parents, a single dichotomous variable was created by coding the absence of this risk factor (no problems, coded 0 ), and combining problems or many problems for any of the three maltreatment areas as presence of the risk factor (coded 1). In short, if problems were noted by the home visitor on any of the three KFSI maltreatment items for either parent, it indicated the presence of risk for this factor. 
Unemployment. At study enrollment, both parents were asked on the NBQ to describe their current employment situation (after they returned from maternity/paternity leave) and given the choices of employed full-time ( $35 \mathrm{hrs} / \mathrm{wk}$ or more), employed parttime, seasonally employed, not employed, or other. If there was a spouse or partner with the mother, or the mother was not partnered, and not employed was chosen by both or the only employment indicated was seasonal, this variable was coded as presence of this risk factor (1). If either of the parents marked full or part time employment, this was considered current employment or absence of the risk factor (0).

Financial stress. Families were asked at enrollment on the NBQ screener how often they had trouble paying for basic living expenses (rent, food, etc.). A dichotomous variable was created coding 1 for those families that reported trouble most of the time or some of the time and 0 for those that reported never having trouble.

Troubled family relationships. The NBQ troubled relationships variable was also dichotomized for this study. Families reported on the level of problems they had in current family relationships. Those families with some problems or serious problems in their current family relationships were coded as having the presence of the risk factor (1), and those reporting few problems or minor problems as having the risk factor not present $(0)$.

Frequent mobility. Parent report of their residential mobility was assessed and calculated as a dichotomous variable using two items on the phone survey at 12 months following entry to services. Frequent mobility was calculated based on answers to number of homeless episodes and number of moves in the past 12 months. Having been 
to a homeless shelter overnight one or more times or having 2 or more moves in the past year was defined as presence of high mobility as a risk factor (1), while no homeless episodes and 0 or 1 move in the last year was coded as low mobility or absence of this risk factor (0).

Neighborhood violence. Neighborhood violence was assessed using three items on the Neighborhood Safety Scale on the phone survey at 12 months, asking parents to rate their neighborhood experiences in the past 12 months (Mujahid et al., 2007). Parents were asked to rate how they felt on a 5-point Likert scale from 1 (strongly agree) to 5 (strongly disagree) on the following items: "I feel safe walking in my neighborhood, day or night," "violence is a problem in my neighborhood," and, "my neighborhood is safe from crime." Mean scores of the 3 items were calculated where higher scores indicated greater feelings of the neighborhood being unsafe or violent. Good internal reliability results from our sample (Cronbach's alpha $=.74$ ) have echoed those of studies in the field (Cronbach's alpha $=.77$; Mujahid et al., 2007)

\section{Analytic Approach}

Data handling and all statistical analyses were carried out using SPSS software (IBM SPSS Statistics Version 21). Univariate descriptive analysis, bivariate correlations, and scale reliability tests were performed for all predictor and dependent variables as appropriate. Tests of normality, linearity, and homogeneity of variance were performed on all variables and calculated risk and protective factor indices (Tabachnik \& Fidell, 2007). In addition, correlation analysis was done on the PFI and RFI, race, and the eight 
dependent variables for the models. Comparisons using means testing and Chi-square analysis for dichotomous pairs were performed as appropriate.

Mean calculations for scales were performed in SPSS using at least $70 \%$ of the total valid items for a given scale (e.g., the mean of at least 8 of 10 valid items). Also, due to the small numbers of participants in the African American $(n=1)$, Asian/Pacific Islander $(n=4)$, American Indian/Alaska Native $(n=2)$, or Multi-racial/other $(n=13)$ race/ethnicity groups, these participants were grouped with the larger Hispanic/Latina group $(n=71)$ and referred to as persons of color in these analyses. Subsequently, race/ethnicity was coded as a dichotomous variable as follows: $0=$ White/Non-Hispanic $(n=136)$ and $1=$ persons of color $(n=91)$.

Attrition and missing data. In many home visiting programs, high staff engagement and initial enrollment are seen prenatally, however after the child is born, family follow-through with actual services can be problematic. In a recent study of engagement of families in a home visiting program in North Carolina, Alonso-Marsden and colleagues (2013) reported that $34 \%$ of those who initially agreed to program participation did not receive an initial home visit, similar to the $38 \%$ in this sample. As noted earlier, although some families originally were interested in program services, later they declined or could not be reached when it was time to schedule a visit to their homes. For these families in our sample, no data were collected after initial eligibility screening. In addition, as data collection time points moved farther from study entry (6 and 12 months), missing data increased and created subsequent analytic challenges 
(Easterbrooks et al., 2013). Staff error and failure to report data were also likely reasons why data was not available for some families at different intervals.

To better understand the potentially important differences between those families that received home visits, and those who did not receive visits, comparisons were made on multiple baseline characteristics between these two groups. Appendix A provides details on all tests in this comparison cluster. The majority of tests were not significant for these analyses; however, two differences were noted between groups. A Chi-square test for independence (with Yates Continuity Correction) indicated a significant association between maternal depression and receipt of home visit services, $X^{2}(1, n=$ $400)=21.8, p<.001, \mathrm{phi}=.24$. A higher proportion of mothers with depression indicators received home visitation services than did not receive services, compared to non-depressed mothers. In addition, a significant association between race/ethnicity and home visit status was also found (Chi-square; $X^{2}(2, n=384)=12, p=.002$, Cramer's $V$ $=.17$ ). A greater proportion of Hispanic/Latino families compared to the White/NonHispanic and other race/ethnicity groups received home visits.

Potential bias due to patterns of missing data at follow-up was also explored by comparing the characteristics of those families with complete outcome data and those with missing outcome data. Outcomes where data were missing at greater than $20 \%$ were chosen for this sub-analysis due to a greater conceivable threshold for bias. Appendix B provides details on comparisons for the three outcome variables meeting this criteria, including the significance levels for appropriate tests. There were few differences; mothers with completed data tended to be older and have more troubled family 
relationships compared to those with missing outcomes. Being careful not to generalize study results to younger mothers is important given this finding. Looking across overall comparisons, however, it was reasonable that the group with intact data for this study provided an adequate sample to perform planned analyses without additional missing data manipulations.

Development of indices. Two summative indices were developed using the 10 protective factors and 12 risk factors. An overall Protective Factor Index (PFI) and Risk Factor Index (RFI) were generated by adding the dichotomized scores for the absence (0) or presence (1) of factors. Scores on indices had the potential to range from 0 to 10 and 0 to 12, respectively. Following Jessor and associates' (1995) methods for non-binary categorical data (e.g., Likert-type scale scores), dichotomization of scores on each of the measures of protection or risk was done to yield the highest or lowest $35 \%$ of participants on a given measure, thus maximizing the likelihood that the factor was present. The lower $65 \%$ was coded not to have the factor present. An extreme score (top 35\%) on a measure was given a 1 , while a score of 0 indicated no protection or no risk on the particular measure. Tables 10 and 11 provide details on the parameters for indication of protection or risk for each factor. When a continuous variable did not have a clear cut point at the $65 \% / 35 \%$ split for absence/presence, the closest cumulative percentage scores to $65 \%$ were used.

Mean scores for participants with data for at least 7 of 10 protective factors, and 8 of 12 risk factors were calculated for each participant. Higher scores on the PFI indicated greater levels of protection, while higher scores on the RFI indicated greater levels of 
risk. To develop interpretable summary scores on both indices, the mean was multiplied by the number of items in the total index, 10 for the PFI and 12 for the RFI. The calculated PFI and RFI were used as predictor variables in main effects and interaction effects regression models.

Protective Factor Index. Table 9 provides details on the corresponding percentage of the sample with each of the 10 protective factors present given the coding parameters previously stated. Protective Factor Index (PFI) scores ranged from 1-9 with a median of $5($ Mean $=5.2, S D=1.6, n=236)$. There was a wide range of percentages of families with any given protective factor (ranging from $22 \%$ to $83 \%$ ). 
Table 9

Summary of Protective Factors at Baseline with Parameters for Protective Factor Index (PFI)

\begin{tabular}{|c|c|c|c|c|}
\hline \multirow[b]{2}{*}{ Protective Factor } & \multirow[b]{2}{*}{$N$} & \multicolumn{2}{|c|}{ Protective Factor Parameters $^{\mathrm{a}}$} & \multirow[b]{2}{*}{$\begin{array}{l}\% \text { with } \\
\text { Protective } \\
\text { Factor }\end{array}$} \\
\hline & & $\begin{array}{l}\text { Protective Factor } \\
\text { Not Present }\end{array}$ & $\begin{array}{l}\text { Protective Factor } \\
\text { Present } \\
(+1 \text { on index })\end{array}$ & \\
\hline Social support & 216 & $0=$ lower $63 \%$ & $1=\operatorname{top} 37 \%$ & 37 \\
\hline Number of supports & 242 & $0=2$ or less & $1=$ more than 2 & 76 \\
\hline Parenting confidence & 162 & $0=$ lower $78 \%$ & $1=$ top $22 \%$ & 22 \\
\hline Expectations infant milestones & 211 & $0=$ problems & $1=$ no problems & 62 \\
\hline Family functioning/resilency ${ }^{\mathrm{b}}$ & 245 & $0=$ lower $65 \%$ & $1=$ top $35 \%$ & 35 \\
\hline Access housing support & 233 & $0=$ problems & $1=$ no problems & 79 \\
\hline Access money support & 233 & $0=$ problems & $1=$ no problems & 83 \\
\hline HS/HFO program visits & 248 & $0=$ lower $68 \%$ & $1=$ top $32 \%$ & 32 \\
\hline Other HV programs/classes & 242 & $0=$ no & $1=$ yes & 54 \\
\hline Neighborhood cohesion $^{\mathrm{b}}$ & 245 & $0=$ lower $64 \%$ & $1=$ top $36 \%$ & 36 \\
\hline
\end{tabular}

Note. ${ }^{a}$ When continuous variables did not have a clear cut point at the $65 \% / 35 \%$ split for absence/presence, the closest cumulative percentage scores to $65 \%$ were used. ${ }^{b}$ Data collected on 12 month phone survey.

Risk Factor Index. Table 10 shows the 12 risk factors that comprise the Risk Factor Index (RFI) including the percentage of the sample with each factor present, given the parameters stated. RFI scores ranged from 1-11 with a median of $4.8($ Mean $=4.7, S D=$ $1.8, n=247$ ). The proportion of families reporting individual risk factors showed a similarly wide range as noted with the protective factors. 
Table 10

Summary of Risk Factors at Baseline with Parameters for Risk Factor Index (RFI)

Risk Factor Parameters

\begin{tabular}{lcllc}
\hline Risk Factor & N & $\begin{array}{l}\text { Risk Factor } \\
\text { Not Present }\end{array}$ & $\begin{array}{l}\text { Risk Factor Present } \\
(+1 \text { on index })\end{array}$ & $\begin{array}{l}\text { \% with } \\
\text { Risk Factor }\end{array}$ \\
\hline Young age & 242 & $0=20$ or older & $1=19$ or younger & 31 \\
Late prenatal care & 243 & $0=$ timely care & $1=$ lack of care & 25 \\
Single status & 246 & $0=$ married & $1=$ single & 77 \\
Depression & 245 & $0=$ none & $1=$ yes- 2 indicators & 27 \\
Low education & 247 & $0=$ HS or greater & $1=$ less than HS & 26 \\
Drug /abuse issues & 212 & $0=$ none & $1=$ yes on KFSI & 38 \\
CG maltreatment history & 141 & $0=$ none & $1=$ yes on KFSI & 48 \\
Unemployment & 246 & $0=$ no & $1=$ unemployed & 35 \\
Financial stress & 246 & $0=$ no difficulty & $1=$ difficulty & 83 \\
Troubled relationships & 243 & $0=$ no trouble & $1=$ trouble & 25 \\
Frequent mobility $^{\mathrm{b}}$ & 245 & $0=0$ or 1 move & $1=$ homeless $>2$ moves & 22 \\
Neighborhood violence $^{\mathrm{b}, \mathrm{c}}$ & 245 & $0=$ lower $66 \%$ & $1=$ top $34 \%$ & 34 \\
\hline
\end{tabular}

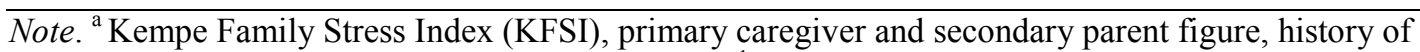
maltreatment in family when they were growing up. ${ }^{b}$ Data collected on 12 month phone survey. ${ }^{c}$ When continuous variables did not have a clear cut point at the $65 \% / 35 \%$ split for absence/presence, the closest cumulative percentage scores to $65 \%$ were used. $\mathrm{CG}=$ caregiver.

\section{Regression Analysis}

Similar to others' approaches to this type of data, primary research hypotheses as stated earlier were tested via regression main effect and interaction models (Hooper, Burchinal, Roberts, Zeisel, \& Neebe, 1998; Jessor et al., 1995). Hierarchical regression allows for estimating interaction or moderator effects (Cohen \& Cohen, 1983). Race was used as a dichotomized control variable in all models $(0=$ White/Non-Hispanic, $1=$ persons of color). Indices were centered in linear models (continuous outcomes) prior to computing the interaction terms, following Aiken and West (1991). Non-centered 
summary scores were used in the logistic models (dichotomous outcomes) for ease of interpretation of odds ratios.

In general, race, PFI, and RFI were entered in Step 1 of the linear regression procedures. At Step 2, cross-products or interactions of the centered PFI and the centered RFI were entered to examine whether protective factors moderate the effects of risk factors and to determine whether those moderator effects provided a significant additional increment in variance accounted for. Additional regression analyses and review of models were repeated for all study outcomes as follows: logistic regression for the child welfare involvement and developmental delay screening binary outcomes, and linear regression for the child health and well-being, parenting approaches (corporal punishment, parent bonding, and parenting stress), and learning environment (HOME 4 learning subscales and parent-child activities) continuous outcomes. Significant effects will be highlighted in results.

Overall, multivariate assumption checking by inspection of the normal probability plot (P-P) of the regression standardized residuals and scatterplots suggested that there were no major deviations from normality. A number of regression residuals scatterplots were slightly skewed however, they were still within acceptable range.

\section{Exploratory Analysis: Unpacking the PFI and RFI}

To better understand the individual associations of factors embedded in the summative PFI and RFI to outcomes, bivariate analyses were performed with all study outcome variables using the 12 risk factors and 10 protective factors in original form. Performing analyses on the original factor scaled data, prior to developing dichotomous 
threshold cut-offs for inclusion in the indices, provided further insights into how factors were related to outcomes outside the summative indices. Tests included correlation for continuous variables, chi-square for 2 X 2 dichotomous data comparisons, and mean comparisons as appropriate. Results of these bivariate analyses were reviewed for both significant $\mathrm{p}$-value and trend level factor associations with study outcomes. All significant or trend level $(p<.10)$ risk factor variables were entered into regression models for each of the study outcomes. The same procedure was followed for protective factor variables. Race was also included in all models. Each predictor in the model that was not significant, with the greatest $p$ value $(>.10)$, was manually removed and then the regression procedure repeated with the remaining variables, until only significant $(p<$ $.05)$ predictors were in left in the model. This approach allowed for understanding which of the individual factors, if any, explained the most variance in the outcome, controlling for the other variables in the model. 


\section{Chapter 4. Results}

Results are organized into three main sections including the following: (a) study variable psychometrics including normality, univariate, bivariate, and scale reliability testing, (b) regression models with main and interaction effects organized by research question and outcomes, and (c) regression models used to unpack individual contributions of the risk and protective factors.

\section{Psychometrics on Study Variables}

Outcome and predictor variables. Normality was examined for each continuous variable. While a number of the continuous variables displayed greater than moderate skew, the residual was approximately normally distributed in the models. Given that multivariate assumptions of normality and equal variance were met in the majority of models, and the robustness of regression at this sample size, the results are not likely to be distorted by not meeting distributional assumptions. Univariate and psychometric analyses for all continuous outcome and predictor variables (Table 11) and univariate analyses of dichotomous outcome and predictor variables (Table 12) were performed. Additional tables detail the items that comprise the child welfare involvement (Table 13) and developmental delay screener (Table 14) variables. 


\section{Table 11}

Psychometric Properties for Continuous Predictor and Outcome Variables

\begin{tabular}{|c|c|c|c|c|c|c|c|}
\hline \multicolumn{3}{|l|}{ Variable } & \multirow[b]{2}{*}{$n$} & \multirow[b]{2}{*}{$M$} & \multirow[b]{2}{*}{$S D$} & \multirow[b]{2}{*}{$\alpha$} & \multirow[b]{2}{*}{ Range } \\
\hline Continuous & Type & Items & & & & & \\
\hline Child-Health and Well-Being ${ }^{\mathrm{a}}$ & $\mathrm{O}$ & 6 & 187 & .683 & .222 & -- & $0-1$ \\
\hline AAPI- Corporal Punishment & $\mathrm{O}$ & 8 & 245 & 1.870 & .779 & .77 & $1-4.14$ \\
\hline HOME-R/A & $\mathrm{O}$ & 19 & 142 & .912 & .098 & .69 & $.53-1$ \\
\hline Parenting Stress Index-Short Form ${ }^{b}$ & $\mathrm{O}$ & 12 & 245 & 1.896 & .673 & .77 & $1-4.25$ \\
\hline HOME- ORG/LRN/INV/VAR & $\mathrm{O}$ & 26 & 142 & .921 & .104 & .79 & $.54-1$ \\
\hline Parent Child Activities Scale & $\mathrm{O}$ & 5 & 245 & 3.812 & .652 & .56 & $2-5$ \\
\hline Neighborhood violence/safety & $\mathrm{RF}$ & 3 & 245 & 1.980 & .857 & .74 & $1-5$ \\
\hline Mother's age & $\mathrm{RF}$ & -- & 242 & 22.82 & 4.97 & -- & $15-41$ \\
\hline DUKE Social Support Scale ${ }^{c}$ & $\mathrm{PF}$ & 10 & 216 & 4.208 & .670 & .84 & $2.20-5$ \\
\hline PFS: Family Functioning Subscale & $\mathrm{PF}$ & 5 & 245 & 3.064 & .806 & .86 & $0-4$ \\
\hline Neighborhood Cohesion & $\mathrm{PF}$ & 6 & 245 & 3.827 & .755 & .86 & $1-5$ \\
\hline Parent Confidence (intake) ${ }^{\mathrm{d}}$ & $\mathrm{PF}$ & 3 & 162 & .85 & .56 & .85 & $0-2$ \\
\hline Number of home visits (6 months) & PF & -- & 248 & 16.1 & 6.9 & -- & $1-31$ \\
\hline
\end{tabular}

Note. $\mathrm{O}=$ outcome, $\mathrm{PF}=$ protective factor, $\mathrm{RF}=$ Risk factor, $\mathrm{AAPI}=$ Adult-Adolescent Parenting Inventory; R/A = HOME Responsivity and Acceptance subscales; ORG/LRN/INV/VAR = HOME Organization, Learning Materials, Involvement, and Variety Subscales. PFS = Protective Factors Survey.

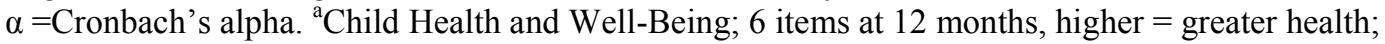
includes items as follows: immunizations up to date, well child check-ups, no passive smoke exposure, overall health rating very good, child's nutrition rating very good, breastfed $6 \mathrm{~m}$ or longer, $12 \mathrm{~m}$ data was used if available, $6 \mathrm{~m}$ data was used if no $12 \mathrm{~m}$ data were available. ${ }^{b}$ Parenting Stress Index-Short Form (PSI-SF): 12 items General Distress and Parenting Stress subscales, Cronbach alphas for General Stress, .68; Parenting Stress .65. ' Duke Social Support Scale includes 10 items: 3 subscales; Emotional, Tangible and Parenting Support. ${ }^{\mathrm{d}}$ Parenting Ladder Measure at 6 months (retrospective items about confidence when baby was born). 
Table 12

Percentages and Definitions for Dichotomous Predictors and Outcome Variables

\begin{tabular}{|c|c|c|c|c|c|}
\hline \multicolumn{2}{|l|}{ Variable } & \multirow[b]{2}{*}{ Coding Definition } & \multirow[b]{2}{*}{$n$} & \multirow[b]{2}{*}{ No $(\%)$} & \multirow[b]{2}{*}{ Yes $(\%)$} \\
\hline Dichotomous & Type & & & & \\
\hline $\begin{array}{l}\text { Child welfare involvement; } \\
\text { HV Report }\end{array}$ & $\mathrm{O}$ & $0=$ no reports; $1=$ reports & 188 & $171(91)$ & $17(9)$ \\
\hline $\begin{array}{l}\text { Developmental Delay/ Off- } \\
\text { Track Development Screen }{ }^{\text {a }}\end{array}$ & $\mathrm{O}$ & $\begin{array}{l}0=\text { No delay } / \text { on track; } \\
1=\text { Delay } / \text { off track }\end{array}$ & 247 & $216(87)$ & $31(13)$ \\
\hline Prenatal care & $\mathrm{RF}$ & $\begin{array}{l}0=\text { timely care } \\
1=\text { lack of care }\end{array}$ & 243 & $182(75)$ & $61(25)$ \\
\hline Single status & RF & $\begin{array}{l}0=\text { married } \\
1=\text { single }\end{array}$ & 247 & $57(23)$ & $190(77)$ \\
\hline Financial stress & $\mathrm{RF}$ & $\begin{array}{l}0=\text { no difficulty } \\
1=\text { difficulty paying }\end{array}$ & 246 & $41(17)$ & $205(83)$ \\
\hline Unemployment & RF & $\begin{array}{l}0=\text { no } \\
1=\text { parents unemployed }\end{array}$ & 246 & $160(65)$ & $86(35)$ \\
\hline Low education & $\mathrm{RF}$ & $\begin{array}{l}0=\mathrm{HS} / \mathrm{GED} \text { or greater; } \\
1=\text { less than } \mathrm{HS} / \mathrm{GED}\end{array}$ & 247 & $184(74)$ & $63(26)$ \\
\hline Troubled relationships & $\mathrm{RF}$ & $\begin{array}{l}0=\text { no trouble } \\
1=\text { yes trouble }\end{array}$ & 243 & $182(75)$ & $61(25)$ \\
\hline Depression $^{\mathrm{b}}$ & RF & $\begin{array}{l}0=\text { none } \\
1=\text { Yes for } 2 \text { indicators }\end{array}$ & 245 & $178(73)$ & $67(27)$ \\
\hline Drugs/abuse issues & $\mathrm{RF}$ & $\begin{array}{l}0=\text { none } \\
1=\text { Yes, either parent } 2 \text { items }\end{array}$ & 212 & $131(62)$ & $81(38)$ \\
\hline $\begin{array}{l}\text { Caregiver family history } \\
\text { maltreatment }\end{array}$ & RF & $\begin{array}{l}0=\text { no } \\
1=\text { Yes, either parent } 6 \text { items }\end{array}$ & 141 & $73(52)$ & $68(48)$ \\
\hline Residential mobility & $\mathrm{RF}$ & $\begin{array}{l}0=\text { Low } \\
1=\text { Homeless or } \geq 2 \text { moves }\end{array}$ & 245 & $192(78)$ & $53(22)$ \\
\hline Supportive people at intake & $\mathrm{PF}$ & $\begin{array}{l}0=0 / 1 / 2 \\
1=>2\end{array}$ & 242 & $58(24)$ & $184(76)$ \\
\hline Milestones/behavior & $\mathrm{PF}$ & $\begin{array}{l}0=\text { problems } \\
1=\text { no problems }\end{array}$ & 211 & $81(38)$ & $130(62)$ \\
\hline Access to services/housing & $\mathrm{PF}$ & $\begin{array}{l}0=\text { no access } / \text { need; } 1= \\
\text { access } / \text { no need }\end{array}$ & 233 & $49(21)$ & $184(79)$ \\
\hline Access to services/money & $\mathrm{PF}$ & $\begin{array}{l}0=\text { no access } / \text { need } \\
1=\text { access } / \text { no need }\end{array}$ & 233 & $40(17)$ & $193(83)$ \\
\hline $\begin{array}{l}\text { Other home visit program or } \\
\text { parenting class }\end{array}$ & $\mathrm{PF}$ & $\begin{array}{l}0=\text { no; } \\
1=\geq 1 \text { other home visiting } \\
\text { program or parenting class }\end{array}$ & 242 & 111(46) & $131(54)$ \\
\hline
\end{tabular}

Note. ${ }^{a}$ Developmental delay or off track development screen indicated at between $6 \mathrm{~m}-12 \mathrm{~m}$ based on any positive response to 7 items (ASQ 6 or 12m, SE-ASQ 6 or 12m, HV report 6 or $12 \mathrm{~m}$ or parent self-report $12 \mathrm{~m}) ; 0=$ no; $1=$ yes delay/off track. ${ }^{\mathrm{b}}$ Public Health Questionnaire-2 (PHQ-2): 2 items; 1 : past month bothered by feeling down, depressed or hopeless and, 2: bothered by having little interest or pleasure in doing things. 


\section{Table 13}

Composition of Home Visitor Report of Family Child Welfare Involvement Outcome

\begin{tabular}{lccccc}
\hline Child Welfare Involvement & \multicolumn{3}{c}{ Yes } & \multicolumn{2}{c}{ No } \\
Child welfare services & $N$ & $n$ & $\%$ & $n$ & $\%$ \\
\cline { 3 - 7 } Home visitor report & 188 & 8 & 4.3 & 180 & 95.7 \\
Investigation & 188 & 5 & 2.7 & 183 & 97.3 \\
Open case & 187 & 9 & 4.8 & 179 & 95.2 \\
Removal & 187 & 5 & 2 & 182 & 97.3 \\
Other reports on family & 188 & 1 & .5 & 187 & 99.5 \\
Any reports at 6 or 12 months & 187 & 3 & 1.6 & 184 & 98.4 \\
\hline
\end{tabular}

Note. Includes reports at 6 or 12 months made by home visitor.

Table 14

Composition of Developmental Delay or Off Track Development Screener Outcome

\begin{tabular}{|c|c|c|c|c|c|}
\hline & & \multicolumn{2}{|c|}{ Yes } & \multicolumn{2}{|c|}{ No } \\
\hline Cognitive Functioning Items & Reporter & $N$ & $\%$ & $\mathrm{~N}$ & $\%$ \\
\hline ASQ 6 months & Parent \& HV & 3 & 1.7 & 176 & 98.3 \\
\hline ASQ 12 months & Parent \& HV & 13 & 10.1 & 116 & 89.9 \\
\hline ASQ-SE 6 months & Parent \& HV & 4 & 2.4 & 163 & 97.6 \\
\hline ASQ-SE 12 months & Parent \& HV & 5 & 4.0 & 121 & 96.1 \\
\hline Any delays noted 6 months ${ }^{a}$ & $\mathrm{HV}$ & 3 & 1.7 & 177 & 98.3 \\
\hline Any delays noted 12 months $^{a}$ & $\mathrm{HV}$ & 3 & 2.3 & 130 & 97.7 \\
\hline Off-track development 12 months $^{b}$ & Parent & 16 & 6.5 & 229 & 93.5 \\
\hline Overall: Any positive response to 7 items & Parent \& HV & 31 & 12.6 & 216 & 87.4 \\
\hline
\end{tabular}

Note. ASQ $=$ Ages and Stages Questionnaire, $\mathrm{SE}=$ Social/Emotional. ${ }^{a}$ The home visitor is asked to report any delays noticed overall when the child is 6 months and 12 months old. ${ }^{b}$ Parents are asked about on/offtrack development on a phone survey when the child turns 12 months old. HV = Home visitor. 
Statistical properties of the indices. The tests for normality showed that the risk and protective factor indices did not violate assumptions of normality. Indices score histograms with a normal distribution curve overlay and normal probability displays (Normal Q-Q Plot) provide graphic representation of normality testing (Appendix D). Based on similar approaches, indices were expected to show a negative, weak, or moderate correlation (so as to not share too much variance) since they represent relatively discrete constructs (Jessor et al., 1995). The relationship between the Protective Factor Index (PFI) mean score and Risk Factor Index (PFI) mean score was investigated using the Pearson product-moment correlation coefficient. As expected there was a small, negative correlation between the two indices, $r=-.145, n=235, p=.026$. The mean PFI score was 5.22 (SD 1.56) with a score range of $1-9(n=236)$. The mean RFI was 4.66 (SD 1.79) with a range of $1-11(n=247)$.

Table 16 provides bivariate analyses results for the PFI, RFI, race, and study outcomes. For continuous variables, Pearson product-moment correlation coefficients with significance levels are shown. For the dichotomous variables (race, child welfare involvement, and developmental delay/off-track development screener), the Chi-square test for independence was performed (Phi value and Chi-square significant test values are shown in Table 15). Using an interpretation of correlation coefficients based on guidance from Cohen (1988), both indices showed small or medium significant correlations in the expected direction with a number of study outcomes. The PFI showed a significant negative correlation to parenting stress $(r=-.195, p<.01)$, and a positive correlation with HOME - responsivity and acceptance scores $(r=.179, p<.05)$. The RFI showed a 
negative correlation with both of the HOME subscale outcomes, responsivity and acceptance, and supportive learning environment $(r=-.279$ and $-.280, p<.01$, respectively.).

Table 15

Summary of Bivariate Analyses for Predictors (PFI, RFI, Race) and Study Outcomes ${ }^{a}$

\begin{tabular}{lccccccccccc}
\hline & 1 & 2 & $3^{\mathrm{b}, \mathrm{c}}$ & $4^{\mathrm{b}}$ & $5^{\mathrm{b}}$ & 6 & 7 & 8 & 9 & 10 & 11 \\
\hline 1. PFI & - & $-.145^{*}$ & $-.168^{*}$ & $-.145^{*}$ & .097 & .046 & -.066 & $.179^{*}$ & $-.195^{* *}$ & .102 & .084 \\
2. RFI & -- & -.075 & $.367^{* *}$ & .023 & $-.237^{* *}$ & -.088 & $-.279^{* *}$ & $.186^{* *}$ & $-.280^{* *}$ & -.042 \\
3. PC b c c $^{\mathrm{b}, \mathrm{c}}$ & & & -- & $-.141^{*}$ & -.037 & .069 & .100 & .011 & .068 & .119 & $-.188^{* *}$ \\
4. $\mathrm{CW}^{\mathrm{b}}$ & & & & -- & -.076 & -.108 & -.004 & $-.285^{* *}$ & .022 & $-.233^{* *}$ & .107 \\
5. DD & & & & & -- & .026 & .003 & .009 & $.167^{* *}$ & -.133 & -.049 \\
6. HWB & & & & & -- & -.037 & $.250^{* *}$ & -.031 & $.323^{* * *}$ & -.034 \\
7. AAPI-CP & & & & & & -- & -.127 & $.222^{* *}$ & -.130 & $-.132^{*}$ \\
8. HOME-2 & & & & & & & -- & -.020 & $.686^{* * *}$ & $.162^{\S}$ \\
9. PSI-SF & & & & & & & & -- & -.096 & $-.134^{*}$ \\
10. HOME-4 & & & & & & & & & -- & .070 \\
11. PCAS & & & & & & & & & & - \\
\hline
\end{tabular}

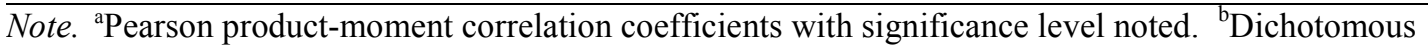
variables $\mathrm{PC}, \mathrm{CW}$, and $\mathrm{DD}$ show Phi value based on Chi-square test for independence (with Yates Continuity Correction). ${ }^{\mathrm{c}} \mathrm{PC}=$ persons of color $(\operatorname{coded} 1)$; Race is a categorical variable: $0=$ White/NonHispanic, 1 = persons of color; Hispanic/Latina, African American, Asian/Pacific Islander, American Indian/Alaska Native, or Multi-racial. PFI = Protective Factor Index, higher scores on the PFI indicate more protective factors. RFI $=$ Risk Factor Index, higher scores on the RFI indicate more risk factors. $\mathrm{CW}=$ child welfare involvement $(0 /$ no, $1 /$ yes $)$. $\mathrm{DD}=$ developmental delay $(0 /$ no; $1 /$ yes $)$. HWB $=$ HealthWell Being Scale, 6 items. AAPI-CP $=$ Adult-Adolescent Parenting Inventory-Corporal Punishment subscale. HOME-2 = Home Observation Measure of the Environment, 2 subscales, Responsivity and Acceptance Subscales. PSI-SF = Parenting Stress Inventory-Short Form. HOME-4 = Home Observation Measure of the Environment, 4 subscales, Organization, Learning Materials, Involvement, and Variety Subscales. PCAS $=$ Parent Child Activities Scale. ${ }^{*} p<.05 .{ }^{* *} p<.01 .{ }^{* *} \mathrm{p}<.001{ }^{\S}$ Trend level $p<.10$.

Higher RFI was associated with lower health and well-being scores $(r=-.237, p<.01)$ and higher parenting stress $(r=.186, p<.01)$.

Table 16 provides mean PFI and RFI comparisons for the three dichotomous variables: race, child welfare involvement, and developmental delay screening. PFI 
scores were lower for those with child welfare involvement $(M=4.5, S D=1.8)$

compared to those without involvement, $M=5.3, S D=1.5 ; t(184)=1.99, p<.05$. Also,

RFI scores were higher for those with child welfare involvement $(M=6.7, S D$ 1.8)

compared to those with no involvement, $M=4.5, S D=1.6 ; t(185)=-5.4, p<.001$.

Mean PFI scores were higher for White/Non-Hispanic $(M=5.4, S D=1.5)$ compared to

persons of color, $(M=4.9, S D=1.6 ; t(215)=2.5, p<.01$.

Table 16

Independent Samples T-Test Comparing PFI and RFI Mean Scores by Child Welfare

Involvement, Developmental Delay Screen, and Race/Ethnicity Groups

\begin{tabular}{|c|c|c|c|c|c|c|}
\hline \multirow[t]{2}{*}{ Dichotomous Variable } & \multicolumn{4}{|c|}{ PFI } & \multicolumn{2}{|c|}{ RFI } \\
\hline & $n$ & Mean & SD & $n$ & Mean & SD \\
\hline \multicolumn{7}{|l|}{ Child Welfare Involvement ${ }^{\mathrm{a}}$} \\
\hline No reports & 169 & $5.27 *$ & 1.51 & 170 & $4.48 * * *$ & 1.63 \\
\hline Reports & 17 & 4.50 & 1.78 & 17 & 6.73 & 1.79 \\
\hline \multicolumn{7}{|l|}{ Developmental Delay Screen ${ }^{b}$} \\
\hline No Delay & 206 & 5.16 & 1.55 & 215 & 4.63 & 1.79 \\
\hline Delay & 30 & 5.61 & 1.60 & 31 & 4.75 & 1.75 \\
\hline \multicolumn{7}{|l|}{ Race/Ethnicity ${ }^{\mathrm{c}}$} \\
\hline White/Non-Hispanic & 130 & $5.44 * *$ & 1.54 & 136 & 4.83 & 1.70 \\
\hline Persons of color & 87 & 4.90 & 1.59 & 91 & 4.56 & 1.91 \\
\hline
\end{tabular}

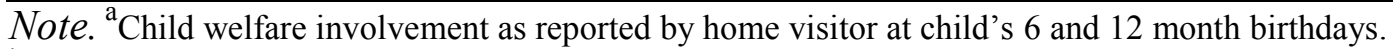

${ }^{\mathrm{b}}$ Home visitor report of delay at 6 months and 12months, ASQ/ASQ-SE at 6 months and 12 months, and parent report of off-track development on 12 month phone survey. ${ }^{\mathrm{c}}$ Race coding, White/Non-Hispanic $=0$, Hispanic/Latina, African American, Asian/Pacific Islander, American Indian/Alaska Native, or Multi-racial $=1$. PFI $=$ Protective Factor Index, higher scores on the PFI indicate more protective factors. RFI $=$ Risk Factor Index, higher scores on the RFI indicate more risk factors. ${ }^{*} p<.05 .{ }^{* *} p<.01 .{ }^{* * *} p<.001 .{ }^{\S}$ Trend level $p<.10$.

\section{Main and Interaction Effects Models Using Logistic and Linear Regression}

Main effect and interaction regression models were developed for child and parent outcomes in this study. For the six linear models, race was entered as a binary variable (0 
$=$ White/Non-Hispanic and $1=$ persons of color), and the centered values for the PFI and RFI were entered in Step 1. The centered PFI X RFI values were entered as an interaction term in Step 2. For the two logistic models, the binary coded race variable and the PFI and RFI were entered in Step 1. The interaction term PFI X RFI was entered in Step 2.

No interaction models were significant for these analyses. A number of main effects models were significant for the Risk Factor Index (RFI) and one for the Protective Factor Index (PFI) in expected directions. Regression main effects and interaction effects model results are presented in tables and text below by outcome. Also, race was tested as an interaction term with both the PFI and the RFI with no interaction effects, therefore, the results are not shown.

Child welfare involvement. The main effects model to predict child welfare involvement by home visitor report with race, PFI, and RFI in the model was significant $\left[X^{2}(3, N=172)=30.40, p<.001\right]$ (Table 17). The model explained between $16.2 \%$ (Cox and Snell $R^{2}$ ) and $34.1 \%$ (Nagelkerke $R^{2}$ ) of the variance in child welfare involvement. The RFI was a strong predictor of child welfare involvement, recording an odds ratio of $2.2(95 \% \mathrm{CI}, 1.5-3.2)$. Families were 2.2 times more likely to have child welfare involvement with the addition of each risk factor. The Protective Factor Index showed a trend toward significance in the expected direction, where families with higher PFI scores were less likely to have child welfare reports by home visitors $(p=.086)$. The interaction term in the model was not significant and will not be interpreted here. 
Table 17

Logistic Regression Predicting Analyses Predicting Child Welfare Involvement

\begin{tabular}{|c|c|c|c|c|}
\hline \multirow{2}{*}{ Variable } & \multicolumn{4}{|c|}{ Child Welfare Involvement } \\
\hline & $B$ & $S E B$ & Odds Ratio & $95 \% C I$ \\
\hline \multicolumn{5}{|l|}{ Main Effects Model ${ }^{\mathrm{a} * * *}$} \\
\hline Race $^{\mathrm{b}}$ (1=persons of color) & $-1.654^{*}$ & .792 & .191 & {$[.040, .904]$} \\
\hline Protective Factor Index (PFI) & $-.367^{\S}$ & .208 & .700 & {$[.466,1.05]$} \\
\hline Risk Factor Index (RFI) & $.770 * * *$ & .193 & 2.16 & [1.48. 3.15] \\
\hline Constant & \multicolumn{4}{|c|}{-4.43} \\
\hline$X^{2}$ & \multicolumn{4}{|c|}{$30.40 * * *$} \\
\hline$d f$ & \multicolumn{4}{|c|}{3} \\
\hline \multicolumn{5}{|l|}{ Interaction Model $^{\mathrm{C} * * *}$} \\
\hline Race $^{b}(1=$ persons of color $)$ & $-1.777^{*}$ & .849 & .169 & {$[.032, .893]$} \\
\hline Protective Factor Index (PFI) & .420 & .815 & 1.52 & {$[.308 .7 .51]$} \\
\hline Risk Factor Index (RFI) & $1.39 *$ & .695 & 4.03 & {$[1.03,15.75]$} \\
\hline $\begin{array}{l}\text { Protective Factor Index (PFI) } \\
\text { X Risk Factor Index (RFI) }\end{array}$ & -.128 & .131 & .880 & {$[.680,1.14]$} \\
\hline Constant & \multicolumn{4}{|c|}{-8.25} \\
\hline$X^{2}$ & \multicolumn{4}{|c|}{$31.31 * * *$} \\
\hline$d f$ & \multicolumn{4}{|c|}{4} \\
\hline \multicolumn{5}{|c|}{$\begin{array}{l}\text { Note. }{ }^{a} \text { Main effects model summary: } X^{2}(3, n=172)=30.40, \mathrm{p}=.000 .{ }^{b} \text { Race is a categorical variable } \\
0=\text { White/Non-Hispanic, } 1=\text { Hispanic/Latino, African American, Asian/Pacific Islander, American } \\
\text { Indian/Alaska Native, or Multi-racial (persons of color). }{ }^{\mathrm{c}} \text { Interaction effects model summary: } X^{2} \\
(4, n=172)=31.31, p=.000 \text {, interaction term not significant. CI = confidence interval. } \\
{ }^{*} p<.05 .{ }^{* *} p<.01 .{ }^{* * *} p<.001 .{ }^{\S} \text { Trend } p<.10 .\end{array}$} \\
\hline
\end{tabular}

The race variable here points to a lower likelihood of child welfare involvement for persons of color, and a higher likelihood of involvement for White/Non-Hispanic families. To interpret an odds ratios less than 1 as times less likely, 1 is divided by the Odds Ratio (e.g., For Main effects race variable, 1/.191 = 5.2). Persons of color were five times less likely to have child welfare involvement report when controlling for the 
other variables in the model. Additional post hoc tests were performed to better understand the relationship of race to child welfare involvement. Overall, there was a $9.8 \%(n=17)$ incidence of home visitor report of child welfare involvement in portion of the sample where data were available $(n=174)$. Comparing groups, results show a trend toward significance with Whites/Non-Hispanic and other race/ethnicity groups having a higher proportion of families with child welfare involvement compared to the Hispanic/Latina group $\left[X^{2}(2, n=174)=5.18, p=.075 ;\right.$ phi $\left.=.173\right]$. Table 18 shows the breakdown by race/ethnicity and child welfare involvement reports.

Table 18

Number and Percentage of Race/Ethnicity Groups and Child Welfare Involvement

\begin{tabular}{lccrc}
\hline $\begin{array}{l}\text { Child Welfare Involvement } \\
(N=174)\end{array}$ & \multicolumn{2}{c}{ No } & \multicolumn{3}{c}{ Yes } \\
\hline $\begin{array}{l}\text { Race/Ethnicity } \\
\text { White/Non-Hispanic }\end{array}$ & 93 & 87 & 14 & 13 \\
Hispanic/Latino & 51 & 98 & 1 & 2 \\
Other race/ethnicity & 13 & 87 & 2 & 13 \\
\hline
\end{tabular}

Note. ${ }^{\text {a }}$ Based on home visitor report at 6 and 12 months.

Further breakdown shows the specific race/ethnicity groups that had child welfare involvement reports were the following: 14 White/Non-Hispanic, 1 Hispanic, 1 American Indian, and 1 other race/ethnicity.

Developmental delay or off track development screeners. The logistic regression model main and interaction effects models to predict developmental delay with independent variables race, PFI, and RFI were not significant (Table 19). 
Table 19

Logistic Regression Predicting Analyses Predicting Screening Positive for a Possible Developmental Delay

\begin{tabular}{|c|c|c|c|c|}
\hline \multirow{2}{*}{ Variable } & \multicolumn{4}{|c|}{ Developmental Delay or Off-Track Development } \\
\hline & $B$ & $S E B$ & Odds Ratio & $95 \% C I$ \\
\hline \multicolumn{5}{|l|}{ Main Effects Model ${ }^{\mathrm{a}}$} \\
\hline $\operatorname{Race}^{\mathrm{b}}(1=$ persons of color $)$ & -.058 & .417 & .943 & {$[.417,2.14]$} \\
\hline Protective Factor Index (PFI) & .185 & .131 & 1.203 & {$[.930,1.56]$} \\
\hline Risk Factor Index (RFI) & .040 & .115 & .728 & {$[.831,1.30]$} \\
\hline Constant & & & -2.997 & \\
\hline$X^{2}$ & & & 2.208 & \\
\hline$d f$ & & & 3 & \\
\hline \multicolumn{5}{|l|}{ Interaction Model $^{\mathrm{c}}$} \\
\hline $\operatorname{Race}^{\mathrm{b}}(1=$ persons of color $)$ & -.058 & .417 & .943 & {$[.417,2.15]$} \\
\hline Protective Factor Index (PFI) & .168 & .367 & 1.180 & {$[.576,2.43]$} \\
\hline Risk Factor Index (RFI) & .020 & .414 & 1.020 & {$[.453,2.29]$} \\
\hline $\begin{array}{l}\text { Protective Factor Index } \\
\text { (PFI) X Risk Factor Index } \\
\text { (RFI) }\end{array}$ & .004 & .074 & 1.004 & {$[.868,1.16]$} \\
\hline Constant & & & -2.903 & \\
\hline$X^{2}$ & & & 2.21 & \\
\hline$d f$ & & & 4 & \\
\hline \multicolumn{5}{|c|}{$\begin{array}{l}\text { Note. Odds ratio }=\operatorname{Exp}(\mathrm{B}) .{ }^{\mathrm{a}} \text { Main effects model summary: } X^{2}(3, n=248)=2.208, p=.530{ }^{\mathrm{b}} \text { Race is a } \\
\text { categorical variable: } 0=\text { White/Non-Hispanic, } 1=\text { Hispanic/Latina, African American, Asian/Pacific } \\
\text { Islander, American Indian/Alaska Native, or Multi-racial (persons of color). }{ }^{\mathrm{c}} \text { Interaction effects model } \\
\text { summary: } X^{2}(4, n=248)=2.21, p=.697 . \mathrm{CI}=\text { confidence interval. }{ }^{*} p<.05 .{ }^{* *} p<.01 .{ }^{* * *} p<.001 . \\
{ }^{{ }_{\text {Thend }}} p<.10 .\end{array}$} \\
\hline
\end{tabular}

Child health and well-being. The main effects linear model was significant, accounting for $5.9 \%$ of the variance in child health and well-being (Table 20). The RFI was significant $(\beta=-.230, p=.003)$ while race and PFI were not significant predictors in 
the main effects model, $\quad F(3,169)=3.55, p=.016$. This result indicates that high numbers of risk factors predict lower levels of child health and well-being.

Table 20

Hierarchical Multiple Regression Main Effects and Interaction Effects Analyses Predicting Child Health and Well-Being

\begin{tabular}{|c|c|c|}
\hline \multirow[b]{2}{*}{ Predictor } & \multicolumn{2}{|c|}{$\begin{array}{l}\text { Child Health \& Well } \\
\text { Being }\end{array}$} \\
\hline & $\Delta R^{2}$ & $\beta$ \\
\hline Main Effects Model $^{\mathrm{a}} *$ & .059 & \\
\hline $\operatorname{Race}^{\mathrm{b}}(1=$ persons of color $)$ & & .056 \\
\hline Protective Factor Index (PFI) & & .022 \\
\hline Risk Factor Index (RFI) & & $-.230 * *$ \\
\hline 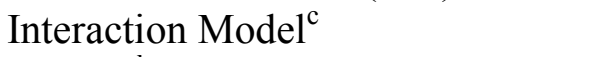 & .00 & \\
\hline $\operatorname{Race}^{\mathrm{b}}(1=$ persons of color $)$ & & .056 \\
\hline Protective Factor Index (PFI) & & .023 \\
\hline Risk Factor Index (RFI) & & $-.228 * *$ \\
\hline $\begin{array}{l}\text { Protective Factor Index (PFI) X } \\
\text { Risk Factor Index (RFI) }\end{array}$ & & .015 \\
\hline Total $R^{2}$ & .059 & \\
\hline$n$ & 172 & \\
\hline \multicolumn{3}{|c|}{$\begin{array}{l}\text { Note. }{ }^{\mathrm{a}} \text { Main effects model summary: } F(3,169)=3.55, p=.016 .{ }^{\mathrm{b}} \text { Race is a categorical variable: } 0= \\
\text { White/Non-Hispanic, } 1=\text { Hispanic/Latina, African American, Asian/Pacific Islander, American }\end{array}$} \\
\hline
\end{tabular}

\section{Parenting Approaches and Bonding}

Corporal punishment. The same predictor variables as previously used were entered into a linear regression model to predict corporal punishment perceptions/behavior. The main and interaction effects models were not significant (Table 21). 
Table 21

Hierarchical Multiple Regression Main Effects and Interaction Effects Analyses Predicting Corporal Punishment

\begin{tabular}{|c|c|c|}
\hline \multirow[b]{2}{*}{ Predictor } & \multicolumn{2}{|c|}{ Corporal Punishment } \\
\hline & $\Delta R^{2}$ & $\beta$ \\
\hline Main Effects Model $^{\mathrm{a}}$ & .021 & \\
\hline $\operatorname{Race}^{\mathrm{b}}(1=$ persons of color $)$ & & .082 \\
\hline Protective Factor Index & & -.065 \\
\hline Risk Factor Index & & -.091 \\
\hline 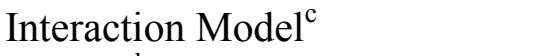 & .006 & \\
\hline $\operatorname{Race}^{\mathrm{b}}(1=$ persons of color $)$ & & .083 \\
\hline Protective Factor Index & & -.061 \\
\hline Risk Factor Index & & -.084 \\
\hline $\begin{array}{l}\text { Protective Factor Index X } \\
\text { Risk Factor Index }\end{array}$ & & .076 \\
\hline Total $R^{2}$ & .026 & \\
\hline$n$ & 216 & \\
\hline $\begin{array}{l}\text { Note. }{ }^{\mathrm{a}} \text { Main effects model summary } \\
0=\text { White/Non-Hispanic, } 1=\text { Hispa }\end{array}$ & $\begin{array}{l}\text { 3) }=1.4 \\
\text { a, Africa }\end{array}$ & $\begin{array}{l}{ }^{\mathrm{b}} \text { Race } \\
\text { in, Asia }\end{array}$ \\
\hline
\end{tabular}

Responsiveness and acceptance. The linear main effects model with race, PFI, and RFI predictors was significant, accounting for $9.7 \%$ of the variance on the Home Observation Measure of the Environment (HOME) -Responsivity and Acceptance subscales, $F(3,127)=4.6, p=.004$ (Table 22). This model suggests that higher RFI scores predict lower scores on the HOME Responsivity and Acceptance subscales $(\beta=-$ $.256, p=.003)$. A trend for the PFI was also evident, suggesting that higher PFI predicts higher HOME Responsivity and Acceptance subscale scores $(\beta=.144, p=.098)$. 
Table 22

Hierarchical Multiple Regression Main Effects and Interaction Effects Analyses

Predicting HOME Responsivity and Acceptance Subscales

\begin{tabular}{|c|c|c|}
\hline \multirow[b]{2}{*}{ Predictor } & \multicolumn{2}{|c|}{$\begin{array}{c}\text { HOME - Responsivity and } \\
\text { Acceptance }\end{array}$} \\
\hline & $\Delta R^{2}$ & $\beta$ \\
\hline Main Effects Model ${ }^{\mathrm{a}} * *$ & .097 & \\
\hline $\operatorname{Race}^{\mathrm{b}}(1=$ persons of color $)$ & & .016 \\
\hline Protective Factor Index & & $.144^{\S}$ \\
\hline Risk Factor Index & & $-.256 * *$ \\
\hline Interaction $\mathrm{Model}^{\mathrm{C} *}$ & .001 & \\
\hline $\operatorname{Race}^{\mathrm{b}}(1=$ persons of color $)$ & & .016 \\
\hline Protective Factor Index & & .142 \\
\hline Risk Factor Index & & $-.260 * *$ \\
\hline $\begin{array}{l}\text { Protective Factor Index X } \\
\text { Risk Factor Index }\end{array}$ & & -.037 \\
\hline Total $R^{2}$ & .099 & \\
\hline$n$ & 130 & \\
\hline $\begin{array}{l}\text { Note. }{ }^{\mathrm{a}} \text { Main effects model summary: } \\
0=\text { White/Non-Hispanic, } 1=\text { Hispani } \\
\text { Indian/Alaska Native, or Multi-racial } \\
F(4,126)=3.5, p=.010 \text {; interaction } \\
{ }^{\S} \text { Trend } p<.10 .\end{array}$ & $\begin{array}{l}3,127)=4.6 \\
\text { atino, Africa } \\
\text { ersons of colo } \\
\text { m not signifi }\end{array}$ & $\begin{array}{l}{ }^{b} \text { Race is a } \\
\text { an, Asian } / \mathrm{P} \\
\text { ction effect } \\
.05 . * * p<\end{array}$ \\
\hline
\end{tabular}

Parenting Stress. The main effects model accounted for $6.6 \%$ of the variance in parenting stress, with both RFI and PFI significant in the model in expected directions $F$ $(3,213)=5.03, p=.002$ (Table 23). Results indicate higher PFI scores predictor lower parenting stress, and higher RFI scores predict greater parenting stress $(\beta=-.162$ and .167 , respectively, both $p<.05)$. 
Table 23

Hierarchical Multiple Regression Main Effects and Interaction Effects Analyses

Predicting Parenting Stress

\begin{tabular}{|c|c|c|}
\hline \multirow[b]{2}{*}{ Predictor } & \multicolumn{2}{|c|}{$\begin{array}{l}\text { Parenting Stress Index- } \\
\text { Short Form }\end{array}$} \\
\hline & $\Delta R^{2}$ & $\beta$ \\
\hline Main Effects Model ${ }^{\mathrm{a} * *}$ & .066 & \\
\hline $\operatorname{Race}^{\mathrm{b}}(1=$ persons of color $)$ & & .053 \\
\hline Protective Factor Index & & $-.162 *$ \\
\hline Risk Factor Index & & $.167^{*}$ \\
\hline Interaction Model $^{\mathrm{c} * *}$ & .004 & \\
\hline $\operatorname{Race}^{\mathrm{b}}(1=$ persons of color $)$ & & .053 \\
\hline Protective Factor Index & & $-.159 *$ \\
\hline Risk Factor Index & & $.173^{*}$ \\
\hline $\begin{array}{l}\text { Protective Factor Index X } \\
\text { Risk Factor Index }\end{array}$ & & .064 \\
\hline Total $R^{2}$ & .070 & \\
\hline$n$ & 216 & \\
\hline \multicolumn{3}{|c|}{$\begin{array}{l}\text { Note. }{ }^{\mathrm{a}} \text { Main effects model summary: } F(3,213)=5.03, p=.002 .{ }^{\mathrm{b}} \text { Race is a categorical variable: } \\
0=\text { White/Non-Hispanic, } 1=\text { Hispanic/Latina, African American, Asian/Pacific Islander, American }\end{array}$} \\
\hline $\begin{array}{l}\text { Indian/Alaska Native, or Multi-racial } \\
F(4,212)=4.01, p=.004 \text {; interactior } \\
{ }^{\text {T }} \text { Trend } p<.10 .\end{array}$ & $\begin{array}{l}\text { ons of colc } \\
\text { n not signi }\end{array}$ & $\begin{array}{l}\text { action eff } \\
<.05 . * *\end{array}$ \\
\hline
\end{tabular}

\section{Supportive Development}

Supportive learning environment. The main effects model is significant, accounting for $9.4 \%$ of the variance in the 4 supportive learning and development related subscales on the HOME measure $F(3,127)=4.41, p=.006$ (Table 24). In the main effects model, higher RFI scores predict lower scores on the four HOME Supportive Environment subscales $(\beta=-.260, p=.003)$. 
Table 24

Hierarchical Multiple Regression Main Effects and Interaction Effects Analyses

Predicting HOME Supportive Learning Materials- 4 Subscales

\begin{tabular}{|c|c|c|}
\hline \multirow[b]{2}{*}{ Predictor } & \multicolumn{2}{|c|}{$\begin{array}{c}\text { HOME Supporting } \\
\text { Learning Materials - } 4 \\
\text { Subscales }\end{array}$} \\
\hline & $\Delta R^{2}$ & $\beta$ \\
\hline Main Effects Model ${ }^{a} * *$ & .094 & \\
\hline $\operatorname{Race}^{\mathrm{b}}(1=$ persons of color $)$ & & .112 \\
\hline Protective Factor Index & & .083 \\
\hline Risk Factor Index & & $-.260 * *$ \\
\hline Interaction $\mathrm{Model}^{\mathrm{C} *}$ & .001 & \\
\hline $\operatorname{Race}^{\mathrm{b}}(1=$ persons of color $)$ & & .112 \\
\hline Protective Factor Index & & .085 \\
\hline Risk Factor Index & & $-.257 * *$ \\
\hline $\begin{array}{l}\text { Protective Factor Index X } \\
\text { Risk Factor Index }\end{array}$ & & .033 \\
\hline Total $R^{2}$ & .095 & \\
\hline$n$ & 130 & \\
\hline $\begin{array}{l}\text { Note. }{ }^{a} \text { Main effects model summary: } \\
0=\text { White/Non-Hispanic, } 1=\text { Hispani } \\
\text { Indian/Alaska Native, or Multi-racial } \\
F(4,126)=3.32, p=.013 \text {; interactiol } \\
{ }^{\S} \text { Trend } p<.10 .\end{array}$ & $\begin{array}{l}127)=4.4 \\
\text { na, Africa } \\
\text { ns of col } \\
\text { not signi }\end{array}$ & $\begin{array}{l}\text { 6. }{ }^{b} \text { Race is } \\
\text { an, Asian } / \mathrm{F} \\
\text { action effe } \\
<.05 . * * p\end{array}$ \\
\hline
\end{tabular}

Parent-Child Activities. The main effects model accounted for $4.1 \%$ of the variance on the Parent Child Activities scale $F(3,213)=2.99, p=.032$ (Table 25). Race was significant in this model, with the White/Non-Hispanic ethnicity group having higher scores on the Parent-Child Activities Scale compared with persons of color $(\beta=-1.84, p$ $=.008)$. Neither the RFI nor the PFI were significant in the main effects model. 
Table 25

Hierarchical Multiple Regression Main Effects and Interaction Effects Analyses

Predicting Parent Child Activities

\begin{tabular}{|c|c|c|}
\hline \multirow[b]{2}{*}{ Predictor } & \multicolumn{2}{|c|}{ Parent Child Activities } \\
\hline & $\Delta R^{2}$ & $\beta$ \\
\hline Main Effects Model ${ }^{a} *$ & $.041 *$ & \\
\hline $\operatorname{Race}^{\mathrm{b}}(1=$ persons of color $)$ & & $-.184 * *$ \\
\hline Protective Factor Index & & .046 \\
\hline Risk Factor Index & & -.049 \\
\hline Interaction $\mathrm{Model}^{\mathrm{c}} *$ & .004 & \\
\hline $\operatorname{Race}^{\mathrm{b}}(1=$ persons of color $)$ & & $-.184 * *$ \\
\hline Protective Factor Index & & .043 \\
\hline Risk Factor Index & & -.055 \\
\hline $\begin{array}{l}\text { Protective Factor Index X } \\
\text { Risk Factor Index }\end{array}$ & & -.062 \\
\hline Total $R^{2}$ & .044 & \\
\hline$n$ & 216 & \\
\hline $\begin{array}{l}\text { Note. }{ }^{\text {a }} \text { Main effects model summary: } \\
0=\text { White/Non-Hispanic, } 1=\text { Hispani } \\
\text { Indian/Alaska Native, or Multi-racial } \\
F(4,212)=2.46, p=.047 \text {; interactio } \\
{ }^{\S} \text { Trend } p<.10 .\end{array}$ & $\begin{array}{l}213)=2.9 \\
\text { no, Africa } \\
\text { ons of colo } \\
\text { not signi }\end{array}$ & $\begin{array}{l}\text { 2. }{ }^{b} \text { Race is } \\
\text { an, Asian/P } \\
\text { cction effec } \\
<.05 .{ }^{* * p}\end{array}$ \\
\hline
\end{tabular}

\section{Unpacking the PFI and RFI Predictors: Risk Factor and Protective Factor}

\section{Predictors}

Exploratory bivariate and regression analyses were undertaken to better understand the contributions of individual risk or protective factors as predictors of outcomes on their own, outside the indices' cumulative influence. Bivariate analysis of all risk and protective factors in their original scale form evidenced varying significant and trend level associations with study outcomes (Appendices E and F). All predictors showing bivariate correlations with $p$ values $<.10$ were entered into regression models, and removed manually one by one based on which predictor showed a $p$ value $>.05$ at that 
step. For example, age would be removed next if it had a significance value of .17 and single status had a significance value of .12. This step was performed manually with individual factors being removed until the remaining predictors in the model were all significant at the $p<.05$ level. The summary of each final model by research outcome and factor type (risk or protective) follows. Tables also footnote which individual factors showed an initial bivariate relationship $(p<.10)$ but were removed from the model during the described regression procedure.

Child welfare involvement. Six risk factors were significantly correlated with child welfare involvement $(p<.10)$ and were entered into the logistic regression model. Table 26 shows the final model with mother's age and caregiver history of maltreatment in their family of origin explaining between 19\% (Cox and Snell $\left.R^{2}\right)$ and $35 \%$ (Nagelkerke $R^{2}$ ) of the variance in child welfare involvement, $X^{2}(1, n=110)=24.4, p<$ .001. The strongest predictor of home visitor report of child welfare involvement was parental family history of maltreatment, with an odds ratio of 27.81 . This indicated that parents who had a prior history of maltreatment in their families were over 27 times more likely to have a reported child welfare event than those who did not have a family history of maltreatment, controlling for other factors in the model. Results also indicated that younger mothers were 1.3 times more likely to have a child welfare involvement report compared to older mothers. 
Table 26

Logistic Regression Models with Factors Predicting Child Welfare Involvement

\begin{tabular}{|c|c|c|c|c|c|c|c|}
\hline \multicolumn{6}{|l|}{ Child Welfare Involvement } & \multicolumn{2}{|c|}{$95 \% \mathrm{CI}$} \\
\hline & $\mathrm{B}$ & S.E. & Wald & $d f$ & OR & \multicolumn{2}{|c|}{ Lower Upper } \\
\hline \multicolumn{8}{|l|}{ Risk Factor Model $^{\mathrm{a}}$} \\
\hline Mother's age & -.241 & .108 & 4.96 & 1 & $.786^{*}$ & .636 & .972 \\
\hline $\begin{array}{l}\text { Caregiver family } \\
\text { history /maltreatment }\end{array}$ & 3.326 & 1.09 & 9.32 & 1 & $27.81 * *$ & 3.289 & 235.2 \\
\hline \multicolumn{8}{|l|}{ Protective Factor Model ${ }^{\mathrm{b}}$} \\
\hline Housing support ${ }^{\mathrm{c}}$ & -1.104 & .555 & 3.960 & 1 & $.332 *$ & .112 & .983 \\
\hline $\begin{array}{l}\text { Race/ethnicity } \\
(1=\text { persons of color })\end{array}$ & -1.645 & .782 & 4.427 & 1 & $.193 *$ & .042 & .894 \\
\hline
\end{tabular}

Note. ${ }^{2}$ Drug issues, residential mobility, single status, and race were not significant in the final model. Model significance: $X^{2}(1, n=110)=24.4, p=<.001$. ${ }^{\mathrm{b}}$ There were no other protective factors in this model. Model significance: $X^{2}(1, n=169)=9.34, p=.009$. ${ }^{\mathrm{c}} 0=$ access needed $/ 1=$ have access or no access needed. ${ }^{\mathrm{d}}$ Race is a categorical variable: $0=$ White/Non-Hispanic, $1=$ Hispanic/Latina, African American, Asian/Pacific Islander, American Indian/Alaska Native, or Multi-racial (persons of color). $\mathrm{OR}=$ Odds ratio. $\mathrm{CI}=$ Confidence interval. $\mathrm{POC}=$ persons of color. ${ }^{*} p<.05 . * * p<.01 . * * * p<.001$. ${ }^{\S}$ Trend $p<.10$.

The model including two individual protective factors was significant, $X^{2}(1, n=$ $169)=9.34, p=.009$. Families lacking housing support was predictive of having reports of child welfare involvement $(\beta=-1.104, p=.047)$. Families without concrete housing support were 3 times more likely to have a child welfare report than those who did not lack support for housing. Also, as noted in earlier findings, White/Non-Hispanic families were 5 times more likely to have a child welfare involvement report by home visitor compared to persons of color $(\beta=-1.65, p=.035)$.

Developmental delay/off-track development screeners. Only one variable qualified and was entered into each of the risk and protective factor logistic regression 
models for the developmental delay/off track development screening outcome (Table 27). Mothers having the protective factor of no problems with expectations of infant milestones and behavior accounted for between 3.7\% (Cox and Snell $\left.\mathrm{R}^{2}\right)$ and 6.6\% (Nagelkerke $\mathrm{R}^{2}$ ) of the variance in developmental delay screener status. Interestingly, these families were over 3.6 times more likely to screen positive for a potential developmental delay by home visitor or be reported as off-track on development by a parent. Mother's increased age was associated with slightly greater likelihood of screening positive for a potential developmental delay or off track development designation with an odds ratio of 1.079 (95\% C.I. $1.005-1.158)$.

Table 27

Logistic Regression Models with Factors Predicting Developmental Delay or Off Track Development Screener

Developmental Delay /Off-Track Development Screener

\begin{tabular}{|c|c|c|c|c|c|c|c|}
\hline & \multirow[b]{2}{*}{ B } & \multirow[b]{2}{*}{ S.E. } & \multirow[b]{2}{*}{ Wald } & \multirow[b]{2}{*}{$d f$} & \multirow[b]{2}{*}{ OR } & \multicolumn{2}{|c|}{$95 \% \mathrm{CI}$} \\
\hline & & & & & & Lower & Upper \\
\hline $\begin{array}{l}\text { Risk Factor Model } \\
\text { Mother's age }\end{array}$ & .076 & .036 & 4.46 & 1 & $1.079 *$ & 1.005 & 1.158 \\
\hline $\begin{array}{l}\text { Protective Factor Model } \\
\text { Expectations of infant } \\
\text { milestones }^{c}\end{array}$ & 1.296 & .513 & 6.39 & 1 & $3.654^{*}$ & 1.338 & 9.979 \\
\hline
\end{tabular}

Child health and well-being. Hierarchical linear multiple regression was used to assess risk and protective factors in separate models to predict child health and wellbeing (see table 28). In the risk factor model, three of five potential factors remained 
significant in the final model, accounting for $10.7 \%$ of the variance, $F(3,175)=6.99, p$ $<.001$. Mother's age recorded the higher beta value $(\beta=.210, p=.004)$ compared to neighborhood violence $(\beta=-.159, p=.031)$ and residential mobility $(\beta=-.150, p=.043)$. Increased maternal age, lower neighborhood violence, and less residential mobility were associated with higher scores on the 6-item child and health and well-being measure.

Three factors entered the protective factor prediction model, two remained significant, and one was trend level, accounting for $8.3 \%$ of the variance in the child health and well-

Table 28

Regression Models for Factors Predicting Child Health and Well Being Scores

\begin{tabular}{|c|c|c|}
\hline \multirow[b]{2}{*}{ Predictor Variables } & \multicolumn{2}{|c|}{ Child Health Well-Being Scores $^{\mathrm{a}}$} \\
\hline & Total $R^{2}$ & $\beta$ \\
\hline \multicolumn{3}{|l|}{ Risk Factor } \\
\hline Model $^{\mathrm{b}}$ & $.107 * * *$ & \\
\hline Mother's age & \multicolumn{2}{|r|}{$.210^{*}$} \\
\hline Mobility $^{\mathrm{c}}$ & \multicolumn{2}{|r|}{$-.150 * *$} \\
\hline Neighborhood violence & \multirow{2}{*}{\multicolumn{2}{|c|}{$-.159 *$}} \\
\hline$n=178$ & & \\
\hline \multicolumn{3}{|l|}{ Protective Factor } \\
\hline Model $^{\mathrm{d}}$ & \multicolumn{2}{|l|}{$.083 * *$} \\
\hline Number of home visits (6 months) & \multicolumn{2}{|r|}{$.203 * *$} \\
\hline Neighborhood cohesion & \multicolumn{2}{|r|}{$.180^{*}$} \\
\hline Expectations of infant milestones ${ }^{\mathrm{e}}$ & \multicolumn{2}{|r|}{$.145^{\S}$} \\
\hline \multicolumn{3}{|l|}{$n=168$} \\
\hline \multicolumn{3}{|c|}{$\begin{array}{l}\text { Note. }{ }^{\mathrm{a}} \text { Includes a mean score of } 6 \text { child health and well-being items. }{ }^{\mathrm{b}} \text { Risk factor predictors } \\
\text { single-status and unemployment did not remain significant in the model. Model summary: } F \\
(3,175)=6.99, p<.001 \text {. }{ }^{\mathrm{c}} \text { Coded as } 0=\text { no homeless events or } 1 \text { move; } 1=\text { homeless event } \\
\text { or } \geq 2 \text { moves. }{ }^{\mathrm{d}} \text { No other protective factors were in this model. Model summary: } F(3,165)= \\
4.99, p=.002 .{ }^{\mathrm{e}} \text { Coded as } 0=\text { problems, } 1=\text { no problems. }{ }^{*} p<.05 .{ }^{* *} p<.01 .{ }^{* *} p<.001 . \\
{ }^{8} \text { Trend } p<.10 \text {. }\end{array}$} \\
\hline
\end{tabular}

being outcome, $F(3,165)=4.99, p=.002$ (Table 28). Both increased numbers of HS/HFO home visits $(\beta=.203, p=.008)$ and higher neighborhood cohesion $(\beta=.180, p=$ 
.018) predicted higher child health scores. In addition, there was a trend for mothers with no problems with expectations of infant milestones and behavior to show greater health and well-being scores $(\beta=.145, p=.056)$.

\section{Parenting Approaches}

Corporal punishment. The risk factors of drug issues and parental family history of maltreatment met criteria for entry into the regression model predicting corporal punishment however, the model was borderline significant in the expected directions, $F$ $(2,136)=2.49, p=.087$ (Table 29). In the individual protective factor prediction model, one of two factors remained significant accounting for $2.7 \%$ of the variance on the

Table 29

Regression Models for Protective Factors Predicting AAPI- Corporal Punishment Scores
Risk Factor Model $^{\mathrm{b}}$
Drug Issues ( $0=$ no) Caregiver family history of maltreatment $n=138$


Corporal Punishment subscale, $F(1,240)=6.55, p=.011$. Families having reported participation in an additional home visiting program or parenting class showed lower acceptance of corporal punishment beliefs $(\beta=-.163, p=.023)$.

Responsiveness and acceptance. The risk factors unemployment and low education remained in the regression model accounting for $11.4 \%$ of the variance in HOME Responsivity and Acceptance scores, $F(2,137)=8.77, p<.001$ (Table 30). The model suggests that high school, GED or greater education $(\beta=-.239, p<.01)$ and parental employment $(\beta=-.194, p<.01)$ were associated with higher scores on being responsive and accepting of the child. Although three protective factors met entry criteria Table 30

Hierarchical Regression Model with Factors Predicting HOME Responsivity and Acceptance Subscale Scores

HOME Responsivity and Acceptance Subscales

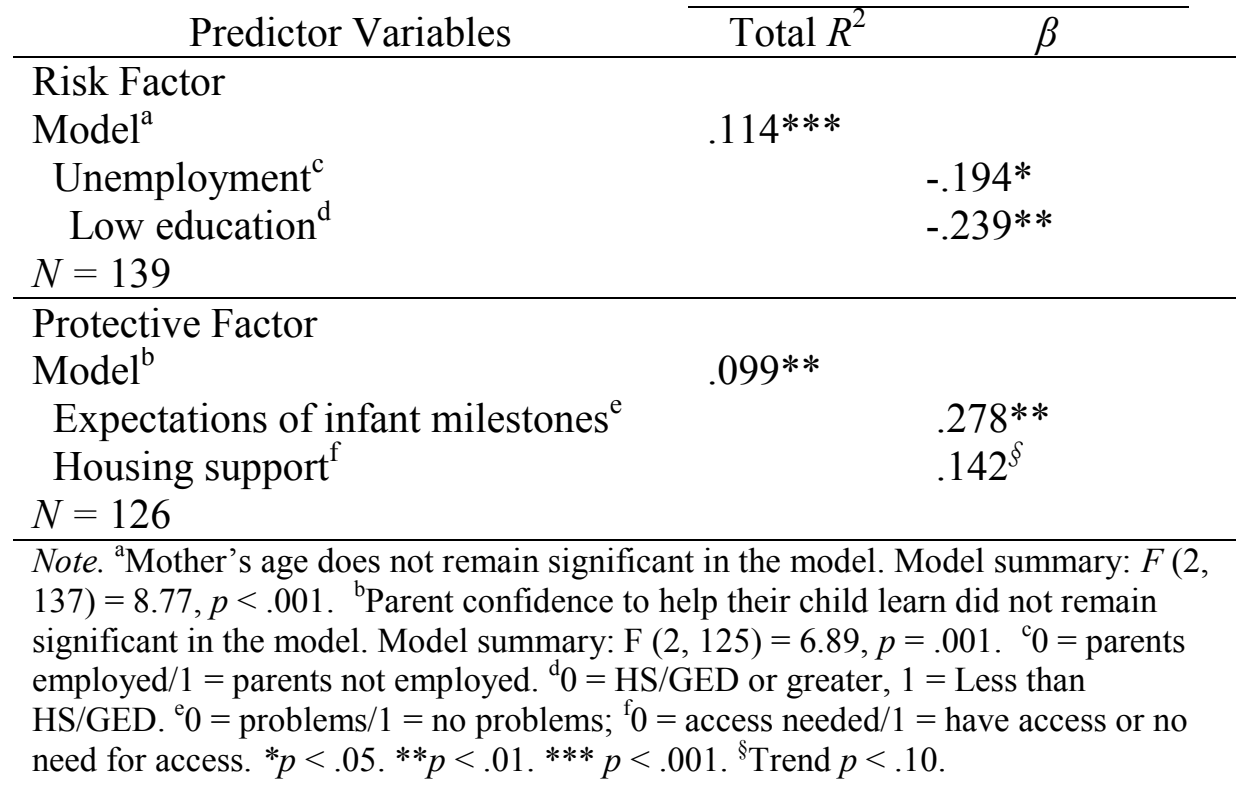


for entry into the model, two remained significant in the final model: having no issues with expectations of infant milestones and behavior and access to housing support remained significant, and predicted $9.9 \%$ of the variance in HOME Responsivity and Acceptance Subscale scores, $F(2,125)=6.89, p=.001$ (Table 30). Expectations of infant milestones and behavior had the largest beta $(\beta=.278, p=.001)$, while housing support showed a trend toward significance $(\beta=.142, p=.098)$.

Parenting stress. Of the four risk factors entered into the regression model predicting parenting stress, depression and drug use issues remained significant after elimination of the other two, accounting for $5.9 \%$ of the variance in the Parenting Stress Index-Short Form, $F(2,204)=6.36, p=.002$ (Table 31). Depression evidenced a higher Table 31

Hierarchical Regression Model for Factors Predicting Parenting Stress IndexShort Form Scores

\begin{tabular}{|c|c|c|}
\hline \multirow[b]{2}{*}{ Predictor Variables } & \multicolumn{2}{|c|}{$\begin{array}{l}\text { Parenting Stress Index- } \\
\text { Short Form }\end{array}$} \\
\hline & Total $R^{2}$ & $\beta$ \\
\hline \multicolumn{3}{|l|}{ Risk Factor } \\
\hline Model $^{\mathrm{a}}$ & \multirow[t]{3}{*}{$.059 * *$} & \\
\hline Depression $^{\mathrm{b}}$ & & \multirow{3}{*}{$\begin{array}{l}.193^{* *} \\
.127^{\xi}\end{array}$} \\
\hline Drug use issues ${ }^{b}$ & & \\
\hline$N=137$ & & \\
\hline \multicolumn{3}{|l|}{ Protective Factor } \\
\hline Model $^{\mathrm{c}}$ & $.114 * * *$ & \multirow{5}{*}{$\begin{array}{l}-.251 * * * \\
-.169 *\end{array}$} \\
\hline Social support & & \\
\hline PFS: Family Functioning & & \\
\hline Subscale & & \\
\hline \multicolumn{2}{|l|}{$N=214$} & \\
\hline \multicolumn{3}{|c|}{$\begin{array}{l}\text { Note. }{ }^{\mathrm{a}} \text { Maltreatment history and mobility were not significant in the model. } \\
\text { Model summary: } F(2,204)=6.36, p=.002 .{ }^{\mathrm{b}} 0=\text { no } / 1=\text { yes. } \\
F(2,204)=6.4, p<.001 \mathrm{PFS}=\text { Protective Factor Scale. } \\
{ }^{*} p<.05 .{ }^{* *} p<.01 .{ }^{* * *} p<.001 .{ }^{\S} \text { Trend } p<.10 .\end{array}$} \\
\hline
\end{tabular}


beta value $(\beta=.193, p=.005)$, while parental drug use issues trended toward significance $(\beta=.127, p=.065)$. This result suggests that maternal depression is a strong predictor of parenting stress, perhaps one of the strongest of the risk factors in the index we tested. A parental drug abuse issue was also associated with higher parenting stress (trend level). Social support, family functioning, and neighborhood cohesion were entered into the protective factors regression model. The final model was significant, with Social Support (DUKE-UNC scale) and the Protective Factor Scale: Family Functioning Subscale accounting for $11.4 \%$ of the variance in the Parenting Stress Index Short Form (PSI-SF) $F(2,204)=6.4, p<.001$ (Table 31$)$. Both beta values were negative in the expected direction, pointing to higher protections with support and healthy family functioning being linked to lower parenting stress. Social support provided the higher beta value $(\beta=$ $-.251, p<.001)$ compared to family functioning $(\beta=-.169, p<.05)$ in this protective factor model.

\section{Supportive Development}

Supportive learning environment. The model is significant with unemployment accounting for $9 \%$ of the variance in the four HOME - Learning environment related subscales $F(1,138)=13.65, p<.001$ (Table 32). Those parents that were employed had higher scores on the four HOME Learning Subscales $(\beta=-.300, p<.001)$. Three protective factor predictors accounted for $16.4 \%$ of the variance on the four HOME Subscales, $F(3,118)=7.70, p<.001$ (Table 32). Expectations of infant milestones had the highest beta value $(\beta=.251, p=.004)$. Participating in additional home visiting or parenting classes and reporting no current need for additional access to housing support 
was associated with higher learning environment HOME scores, reporting significant beta values in this model $(\beta=.238, p<.01$ and $.196, p<.05$, respectively).

Table 32

Hierarchical Regression Model for Factors Predicting HOME- Organization, Learning Materials, Involvement, and Variety Subscale Scores

\begin{tabular}{|c|c|c|}
\hline \multirow[b]{2}{*}{ Predictor Variables } & \multicolumn{2}{|c|}{$\begin{array}{c}\text { HOME - } 4 \text { Subscale } \\
\text { Scores }\end{array}$} \\
\hline & Total $R^{2}$ & $\beta$ \\
\hline \multicolumn{3}{|l|}{ Risk Factor } \\
\hline Model $^{\mathrm{a}}$ & $.090 * * *$ & \multirow{3}{*}{$-.300 * * *$} \\
\hline Unemployment $^{\mathrm{b}}$ & & \\
\hline$N=139$ & & \\
\hline \multicolumn{3}{|l|}{ Protective Factor } \\
\hline Model $^{\mathrm{c}}$ & $.164 * * *$ & \\
\hline Expectations of infant milestones ${ }^{\mathrm{d}}$ & & $.251 * *$ \\
\hline Additional home visiting/parenting classes ${ }^{\mathrm{e}}$ & & $.238 * *$ \\
\hline Housing support ${ }^{\mathrm{f}}$ & & $.196^{*}$ \\
\hline \multicolumn{3}{|l|}{$N=122$} \\
\hline $\begin{array}{l}\text { Note. }{ }^{\mathrm{a}} \text { Low education did not remain significant in the } \mathrm{I} \\
138)=13.65, p<.001 .{ }^{\mathrm{b}} 0=\text { parents employed } / 1=\text { pare } \\
\text { help child learn was not significant in this model. Mode } \\
<.001 .{ }^{\mathrm{d}} 0=\text { problems, } 1=\text { no problems. }{ }^{\mathrm{e}} 0=\text { no additio } \\
\text { classes, } 1=\text { additional home visiting or classes. }{ }^{\mathrm{f}} 0=\text { aco } \\
\text { need for access. }{ }^{*} p<.05 .{ }^{* *} p<.01 .{ }^{* * *} p<.001 .{ }^{\S} \text { Tree }\end{array}$ & $\begin{array}{l}\text { model; Mode } \\
\text { not employed } \\
\text { ummary: } F( \\
\text { home visitin } \\
\text { needed, } 1= \\
p<.10\end{array}$ & $\begin{array}{l}\text { Summary: } F(1, \\
{ }^{\circ} \text { Confidence to } \\
118)=7.70, p \\
\text { programs or } \\
\text { ve access or no }\end{array}$ \\
\hline
\end{tabular}

Parent child activities. Education and race predicted $5.6 \%$ of the variance on the Parent-Child Activities Scale, $F(2,223)=6.61, p=.002$ (Table 33). Having a high school education/GED or greater is linked to higher scores on this measure $(\beta=-.145, p=$ .028). The result also suggests that White/Non-Hispanic families had higher scores comparatively than persons of color $(\beta=-.165, p=.013)$. Post hoc independent-samples t-test did show a significant difference in scores by race/ethnicity $t(224)=2.8, p=.005$ (two-tailed): White/Non-Hispanic $(M=3.92, S D=.57)$ and persons of color $(M=3.67$, 
$S D=.75$ ). The magnitude of the difference in the means was very small (eta squared $=$

.033). Family functioning and race/ethnicity remained in the final protective factor predictors model accounting for $6.2 \%$ of the Parent Child Activities Scale, $F(2,223)=$ 7.35, $p=.001$ (Table 33). Higher levels of family functioning were associated with higher scores on the Parent-Child Activities scale $(\beta=.163, p=.013)$. Race showed similar results as in the individual risk factor model $(\beta=-.183, p=.005)$.

Table 33

Hierarchical Regression for Factors Predicting Parent-Child Activities Scale

\begin{tabular}{|c|c|c|}
\hline \multirow[b]{2}{*}{ Predictor Variables } & \multicolumn{2}{|c|}{$\begin{array}{c}\text { Parent-Child } \\
\text { Activities Scale }\end{array}$} \\
\hline & Total $R^{2}$ & $\beta$ \\
\hline \multicolumn{3}{|l|}{ Risk Factor } \\
\hline Model $^{\mathrm{a}}$ & $.056^{* *}$ & \\
\hline Race/Ethnicity ${ }^{\mathrm{b}}$ (1=persons of color) & & $-.165 * *$ \\
\hline Low Education ${ }^{c}$ & & $-.145 * * *$ \\
\hline$N=225$ & 226 & \\
\hline \multicolumn{3}{|l|}{ Protective Factor } \\
\hline Model $^{\mathrm{d}}$ & $.062 * *$ & \\
\hline Race/Ethnicity ( $1=$ persons of color) & & $-.183 * *$ \\
\hline PFS: Family Functioning Subscale & & $.163 *$ \\
\hline$N=225$ & & \\
\hline
\end{tabular}

Note. ${ }^{\mathrm{b}}$ No other risk factors were entered in this model. Model summary: F (2, $223)=6.61, p=.002 .^{\mathrm{b}} 0=\mathrm{HS} / \mathrm{GED}$ or greater, $1=$ Less than HS/GED. ${ }^{\mathrm{c}}$ Race is a categorical variable: $0=$ White/Non-Hispanic, $1=$ Hispanic/Latina, African American, Asian/Pacific Islander, American Indian/Alaska Native, or Multiracial (persons of color). ${ }^{\mathrm{d}}$ Parent confidence to help child learn was not significant in the model. Model summary: $F(2,223)=7.35, p=.001 . \mathrm{PFS}=$ Protective Factor Scale. ${ }^{*} p<.05 . * * p<.01 . * * * p<.001 .{ }^{\S}$ Trend $p<.10$.

\section{Summary of Results}

Table 34 provides the summary of results for all regression models main effects (RFI, PFI, and race), interaction effects (main effects and RFI X PFI), and individual risk 
and protective factor models in an abbreviated form for ease of interpretation. RFI was significant in 5 of the 8 main effects regression models with RFI, PFI, and race. Higher scores on the RFI were associated with a greater likelihood of child welfare involvement reports and lower scores on the health and well-being scale. Higher RFI scores were associated with lower scores on both of the Home Subscale measures (Responsivity/ Acceptance and Supportive Learning Environment Subscales) and higher parenting stress. All of these results are in the expected direction given the literature and discussion in this paper. The PFI was significant in 1 of the 8 models, showing lower PFI linked to higher levels of parenting stress. Two PFI trends showed that higher PFI scores were associated with less likelihood of child welfare involvement and with greater HOMEResponsivity and Acceptance Subscores.

In the follow-up analyses, nine individual risk factors predicted outcomes, while eight protective factors predicted outcomes. No single risk or protective factor emerged across all or most dependent variable outcomes, suggesting that cumulative risk and protective indices have utility in this work. For instance, if one risk factor was strong across $75 \%$ of the outcomes, argument could be made for a single risk model that is as good as the index in prediction, however, these results may suggest that the cumulative score is better at indicating underlying risk than the individual factors on their own.

Selected results from the individual factor models are presented here, for an overview of all model findings, see Table 34 and the discussion section. Specifically, lack of access to housing support was predictive of child welfare involvement and White/Non-Hispanic race predicted child welfare involvement in the protective 
Table. 34

Summary of Regression Model Significant Predictors and Direction for All Outcomes, (a) Main Effects (PFI, RFI, Race) and Interaction Effects (PFI, RFI, Race and PFIX RFI), and (b) Backwards Removal with Individual Risk Factors and Individual Protective Factors

\begin{tabular}{|c|c|c|c|c|c|c|}
\hline & \multicolumn{3}{|c|}{ Main Effects } & \multirow{2}{*}{$\begin{array}{l}\begin{array}{c}\text { Inter- } \\
\text { action } \\
\text { Term }\end{array} \\
\text { PFI X } \\
\text { RFI }\end{array}$} & \multicolumn{2}{|c|}{ Individual Factors $^{b}$} \\
\hline Outcome & $\begin{array}{l}\text { Risk } \\
\text { Factor } \\
\text { Index } \\
\text { (RFI) }\end{array}$ & $\begin{array}{l}\text { Protective } \\
\text { Factor } \\
\text { Index } \\
(\mathrm{PFI})\end{array}$ & $\begin{array}{l}\text { Race }^{\mathrm{a}} \\
(1= \\
\text { POC })\end{array}$ & & Risk Factors & Protective Factors \\
\hline $\begin{array}{l}\text { Child Welfare } \\
\text { Involvement }\end{array}$ & Sig + & Trend - & Sig - & $\mathrm{NS}$ & $\begin{array}{l}\text { Caregiver FMH + } \\
\text { Age - }\end{array}$ & $\begin{array}{l}\text { Housing support - } \\
\text { Race }^{\text {a }} \text { - }\end{array}$ \\
\hline $\begin{array}{l}\text { Developmental } \\
\text { Delay }\end{array}$ & NS & $\mathrm{NS}$ & NS & NS & Age + & Milestones + \\
\hline $\begin{array}{l}\text { Health \& } \\
\text { Well-Being }\end{array}$ & Sig - & $\mathrm{NS}$ & NS & NS & $\begin{array}{l}\text { Age }+ \\
\text { NB Violence - } \\
\text { Mobility }^{c} \text { - }\end{array}$ & $\begin{array}{l}\text { Home visits }+ \\
\text { NB Cohesion }+ \\
\text { Milestones (Trend) }+\end{array}$ \\
\hline $\begin{array}{l}\text { Corporal } \\
\text { Punishment }\end{array}$ & NS & $\mathrm{NS}$ & NS & NS & $\mathrm{NS}$ & HV /classes - \\
\hline $\mathrm{HOME}-\mathrm{R} / \mathrm{A}$ & Sig - & Trend + & NS & NS & $\begin{array}{l}\text { Unemployment }^{\mathrm{d}} \text { - } \\
\text { Low Education }^{\mathrm{e}} \text { - }\end{array}$ & $\begin{array}{l}\text { Milestones }+ \\
\text { Housing (Trend)+ }\end{array}$ \\
\hline $\begin{array}{l}\text { Parenting } \\
\text { Stress Index- } \\
\text { Short Form }\end{array}$ & Sig + & Sig - & NS & NS & $\begin{array}{l}\text { Depression }+ \\
\text { Drug Use }(\text { Trend })+\end{array}$ & $\begin{array}{l}\text { Social Support - } \\
\text { Family Functioning - }\end{array}$ \\
\hline $\begin{array}{l}\text { HOME - } 4 \\
\text { subscales }\end{array}$ & Sig - & NS & NS & NS & Unemployment $^{\mathrm{d}}-$ & $\begin{array}{l}\text { Milestones }+ \\
\text { HV /classes }+ \\
\text { Housing support }+\end{array}$ \\
\hline $\begin{array}{l}\text { Parent Child } \\
\text { Activities } \\
\text { Scale }\end{array}$ & NS & NS & Sig - & NS & $\begin{array}{l}\text { Low Education - } \\
\text { Race }^{\text {a }} \text { - }\end{array}$ & $\begin{array}{l}\text { Family Functioning + } \\
\text { Race }^{\text {a }} \text { - }\end{array}$ \\
\hline \multicolumn{7}{|c|}{$\begin{array}{l}\text { Note. }{ }^{\mathrm{a}} \text { Race is a categorical variable: } 0=\text { White/Non-Hispanic; } 1=\text { Persons of color (POC), } \\
\text { Hispanic/Latina, African American, Asian/Pacific Islander, American Indian/Alaska Native, or Multi- } \\
\text { racial. Race was tested as an interaction term with both the PFI and the RFI with no interaction effects (no } \\
\text { results shown). }{ }^{\mathrm{b}} \text { Individual factors that showed a bivariate level association }(\mathrm{p}<.10) \text { with outcome were } \\
\text { entered in each model, and removed one at a time if they did not remain significant in the model, until only } \\
\text { significant predictors were left in the model. }{ }^{\mathrm{c}} 0=\mathrm{Low} \text { mobility, } 1=\geq 2 \text { moves or homeless episode. }{ }^{\mathrm{d}} 0= \\
\text { employed, } 1=\text { unemployed. }{ }^{\mathrm{e}} 0=\text { Greater than } \mathrm{HS} / \mathrm{GED}, 1=\text { less than HS/GED. Sig }=\text { significance testing } p \\
<.05 \text { level. Trend }=\text { significance testing } p<.10 . \mathrm{NS}=\text { Not significant. HV }=\text { Home Visiting. FMH }= \\
\text { Family Maltreatment History. HOME- } 4 \text { subscales }=\text { Organization, Learning Materials, Involvement, and } \\
\text { Variety Subscale Scores. NB }=\text { Neighborhood. R/A }=\text { Responsivity and Acceptance subscales. }\end{array}$} \\
\hline
\end{tabular}


factor regression. For the same outcome, caregiver family history of maltreatment and young age were predictors in the risk factor model. Along with other variables, appropriate expectations of infant milestones and behavior proved predictive in four of the protective factor models, including a greater likelihood for a delay screen, better scores on child health and well-being and more favorable scores on both the HOME outcomes of parent responsiveness and acceptance, and supportive learning materials. Risk factors associated with lower scores on parent responsiveness and acceptance included unemployment and low education, while infant milestones knowledge and housing support protective factors were predictive of higher scores. Maternal depression and parental drug use issues were associated with higher levels of parenting stress, where families with better social support and family functioning protections had lower parenting stress. Further review of these findings with implications for research for each individual factor model follows in the discussion section. 


\section{CHAPTER 5. Discussion}

The secondary data analysis conducted in this dissertation provides new information on factors associated with parent and child outcomes in a group of first time mothers with multiple stressors, many of whom also have protective factors. Discussion in this section first focuses on a summary of results for the five specific parenting and child outcome domains with a focus on ways practice, policy, and future research may be approached based on findings. Suggestions for practice-based work for social service, counseling practitioners, and related agencies working with families are provided. Overall implications for policy and future research are also highlighted. Particular attention is given to the areas of program development for maltreatment prevention and social work practice for improving family and child well-being. Finally, the section concludes with a discourse of study limitations, a critical look at how studies like this can improve, and some brief conclusions about how knowledge gained can inform and drive future investigations.

\section{Summary of Findings: Implications by Study Outcome}

Regression analyses were performed using interaction models to better understand the combination of forces, both positive and negative, that when linked, have the potential to create an environment of protection for children growing up in stressful situations. For most outcomes, predictor relationships were in expected directions, however, there was no support for the protective or buffering models where protection would moderate the effects of risk on outcomes. The RFI measure had utility in predicting the child outcomes of maltreatment and health and well-being. In addition, 
both the RFI and the PFI predicted parenting stress, with the RFI also predicting multiple aspects of the home environment including parent responsiveness, acceptance, and supportive learning activities. When unpacking the indices and examining the ability of single risk or protective factors to predict outcomes, no single factor emerged as predictive across the entire set of the child and parenting outcomes, which provides support for the value of the indices.

Child welfare involvement. As expected and seen in previous literature, families in our study with many risks factors were more likely to have child welfare involvement reports from home visitors than families with fewer risk factors. Similarly, HS/HFO home visitation program evaluation data (Green et al., 2009) showed that regardless of which specific risk factors are present, as the number of risk factors increase, the likelihood of maltreatment increases. For example, families with just one risk factor were 6 times more likely to have a case of maltreatment, compared to those with no risk factors; those with four risk factors were 13 times more likely to have a founded maltreatment report, compared to those with no risk factors (Figure 5; Green et al., 2009). Also, families with six risk factors were more than 30 times more likely to have a founded report. 


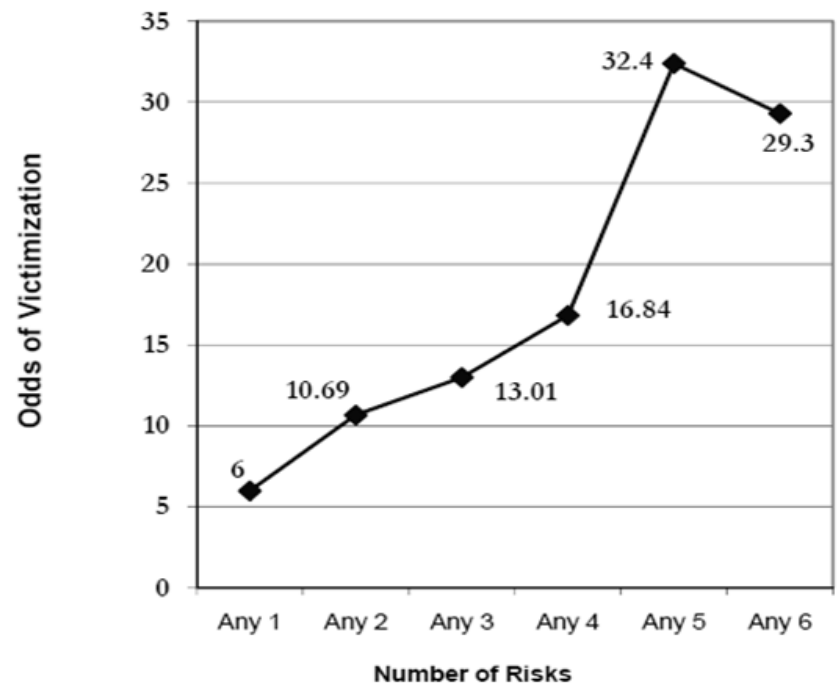

Figure 5. Risk factors and odds of victimization in 2009 HS/HFO evaluation study. Adapted from "Oregon's Healthy Start Maltreatment Prevention Report 2007-2008. A report to the Oregon Commission on Children and Families," by B. L. Green, C. H. Lambarth, J. M. Tarte, \& A. M. Snoddy, A. M., 2009, Portland Oregon, Northwest Professional Consortium (NPC) Research. Reprinted with permission.

For the Green and colleagues' (2009) evaluation sample, risk factors strongly linked to abuse included single parent status and primary caregivers with less than a high school education/GED. Additionally, there was a trend toward families experiencing financial hardship and maternal depression to have increased odds of abuse (Green et al., 2009).

Our study results showed that $9 \%$ of the sample had home visitor reported child welfare involvement. Oregon data from 2009-2011 shows a substantiated victim maltreatment rate of $1.34 \%$ or 13.4 per 1000 (ODHS, 2012). The higher levels of selfreports in the study may be due to visibility or surveillance bias on the part of the home visitor as previously discussed, or may be measuring something different than would capture families with substantiated cases. Home visitor report of child welfare involvement was the only maltreatment data available for this work at the time of data analysis. From home visitor report data, information on the type of abuse, perpetrator, 
and overlap of abuse categories is impossible to discern. When Oregon State Administrative child maltreatment data (e.g., substantiated cases) becomes available for the HS/HFO program participants, further investigations on these models, and additional comparisons of home visitor report to State reports will be of interest.

Another finding from the current study reflecting recent literature on child maltreatment was that families with young mothers, or having either parent with a family history of maltreatment in their family of origin, were at greater risk for child welfare reports. This is consistent with the published literature on the intergenerational transmission of child maltreatment behavior (Valentino, Nuttall, Comas, Borkowski, \& Akai, 2012) and young mothers' maltreatment behavior (Shipman \& Zeman, 2001). Community and program work with young parents from abusive origins has focused on breaking these cycles; these results confirm that such efforts are crucial for both decreasing child maltreatment rates, and subsequent reduction in short-term and longterm residual suffering.

For cumulative protection measured by the PFI, although there was a trend for families with more protective factors to have less child welfare involvement, high cumulative risks determined through the RFI were more strongly linked with child welfare involvement. The single protective factor of having adequate housing support (have current access or do not need access) was associated with lower likelihood of child welfare reports. In short, those families stating they are in need of current housing supports were more likely to have child welfare involvement. Perhaps these families were the most economically challenged of the group, and/or disconnected from adequate 
resources. Also, housing supports may be one of the most challenging family needs to meet in home visiting programs. These findings can help child welfare systems and family service workers better understand family needs and provide appropriate services and supports to families. Screening families into programs with risk tools before abuse occurs is a standard practice in many programs, however, using age, parental histories of family maltreatment, and inadequate access to housing in assessments could target support more effectively and could be the focus of future research.

Another finding was that persons of color were less likely to have child welfare reports when compared to White/Non-Hispanic families in this sample. Given the thinking regarding child-welfare and racial/ethnicity disproportionality stated in the literature, which documents disparities in child welfare involvement by race/ethnicity (Hill, 2006), further exploration was done into this finding. Persons of color in our sample included a collapsed category of all groups except White/Non-Hispanic, with White/Non-Hispanic being the comparator. This was done because the small number $(n=20)$ of families in categories other than White/Non-Hispanic and Hispanic would have limited the ability to use them in study comparisons. Breakdown of the percentages within race/ethnicity groups with maltreatment reports for the entire sample with those families with data $(n=174)$ was as follows: White/Non-Hispanic $(13 \%)$, Hispanic/Latino $(2 \%)$, and all other race/ethnicity (13\%). Looking at the percentages within race/ethnicity groups for only those families with a reported child welfare report $(n=$ 17), $82 \%$ were White/Non-Hispanic, $6 \%$ Hispanic/Latino and $12 \%$ other race/ethnicity. Even though the White/Non-Hispanic group comprised $61 \%$ of the sample, a greater 
proportion of this group had child welfare reports than other race/ethnicity groups. Hispanic/Latino families comprised $31 \%$ of the families, while they had a $6 \%$ representation in child welfare reports in this sample. Other race/ethnicity groups comprised about $9 \%$ of study participants, with $12 \%$ having home visitor child welfare involvement reports.

Our sample showed different proportions of White/Non-Hispanic and other race families receiving home visitor reports of child welfare involvement than those data reported by the State for substantiated reports (ODHS, 2012). Caucasian/Non-Hispanic families made up approximately $60 \%$ of the State's substantiated child maltreatment reports in 2011, while the State population for this group at that time was $66.9 \%$ (ODHS, 2012). Hispanic groups made up $20 \%$ of the Oregon State population in 2011, while $16.9 \%$ had administrative child maltreatment reports. Other races (not Caucasian or Hispanic) included $12.8 \%$ of the population in Oregon, and showed $8.4 \%$ of the substantiated child maltreatment reports (ODHS, 2012). A percentage of the State data had no reported race or ethnicity. Of course, variations may be due in part to different maltreatment measurement methods (home visitor report vs. State administrative data), and that the families in the HS/HFO group from seven counties were different in other ways (e.g. higher risk levels) to the total Oregon population.

That said, there is a trend in this sample toward a significantly lower proportion of child welfare involvement reports for Hispanic families compared to White/NonHispanic and other race/ethnicity groups. Moreover, it may be because the HS/HFO program model is committed to culturally sensitive practices, including development of 
study materials and measures in Spanish and hiring native Spanish speaking home visitors, and that these efforts may increase the programs' efficacy in serving Spanish speaking program families.

Developmental delay and off-track development screening. The PFI and RFI were not useful in predicting positive screens on developmental delay or off-track development. Only two single factors proved to predict a positive screen for delay: older mothers and those having appropriate expectations of children's milestones and behavior. These are interesting findings, and have multiple interpretations. An older mother and a mother who has proper expectations of developmental milestones may be more apt to have her child checked for delays, or be more aware of potential off-track behavior, and therefore be more likely to report developmental issues. Further, the developmental delay outcome combined information gathered on two versions of the parent and home visitor completed Ages and Stages Questionnaires (ASQ/ASQ-SE), overall knowledge of delays reported by the home visitor, as well as 12 month phone data on parent self-report of off-track child development. Because these screens were gathered from different reporters and on different measures, the identification of possible delay may warrant further exploration on the specific measures on their own. In addition, information on percentages of children with a confirmed diagnosis of delay, and follow-up services are potential areas for exploration using the risk and protection framework. Overall, the low rate of positive developmental delay screens limits power to detect effects as well.

Child health and well-being. Higher levels of risk were linked to lower child health and well-being scores for children at 12 months old. Risks specific to lower scores 
included neighborhood violence, high residential mobility, and young maternal age. This result has many implications for future research and practice, where two factors linked to non-optimal child health for children were neighborhood-based influences. Young children thrive in safe and predictable spaces (Leventhal \& Brooks-Gunn, 2000). Frequent moves or episodes of homelessness, and proximity to potentially violent situations do not provide an environment rich in supports for optimal growth and development opportunities for infants and children. This finding enhances the argument that service efforts focused on working closely with young mothers to ensure stable housing, in safe neighborhoods, is essential for positive child health and well-being. Working to eliminate the barriers (i.e., financial stress, unemployment) to availability of affordable, long-term, and safe housing needs to be a priority for family service provision as well.

In addition, families more heavily engaged in the HS/HFO program, with a firm handle on expected infant behavior, or living in neighborhoods in which they felt connected, had children who had better health and well-being. The first two seem to fit well in that the HS/HFO model goal, like most home visiting programs, is to improve parent knowledge of child development and expected milestones and to keep families on track with health related routines like well-baby check-ups and immunizations (Avellar et al., 2012). More time with home visitors in the first six months of the program may be a protection against negative child health and well-being. Neighborhood factors again, this time as protective influences, show links to child health, where families who felt higher levels of cohesion with their neighbors and neighborhood reported higher health and 
well-being for their children. Much literature supports the view that living in safe, organized, and connected communities has direct links to improved health and well-being (Coulton et al., 2007; Stith et al., 2009).

\section{Parenting approaches and parent bonding.}

Corporal punishment. Level of risk and protective factors did not have any association with belief in the use of corporal punishment. Having participated in an extra home visiting program outside the HS/HFO program or taken a parenting class was related to less acceptance of harsh punishment behavior. This seems like a reasonable finding given the teachings of positive discipline in most home visiting programs and parenting classes $(\mathrm{OCCF}, 2012)$. Families in this sample are already getting exposure to positive discipline practices and handling parenting stress in the HS/HFO program. In further exploration of data from this study, those families receiving the highest numbers of home visits in the first 6 months of the HS/HFO program showed lower scores on this measure of corporal punishment, indicating less acceptance of the behavior though this result was not statistically significant. Program models like HS/HFO have shown reductions in harsh discipline (Mitchell-Herzfeld et al., 2005; Duggan et al., 2004). With the addition of other home visits or parenting classes that provide a similar discouragement of harsh parenting practices, perhaps this extra dose of program support reinforced the use of positive practices and the rejection of harsh ones. Since corporal punishment is a risk factor for maltreatment (Zolotor et al., 2008), programs that use teaching models to provide positive discipline strategies to parents will likely reduce maltreatment in those families. 
Parent responsiveness and acceptance. For infants to thrive, it is essential that they are connected to nurturing and protective caregivers. In this study, parents with higher numbers of risks showed lower maternal responsiveness and acceptance of their children. Scores were also lower in families with parental unemployment issues or where the mother had less than a High School or GED education. High levels of risk factors and stressors have been linked to disruptions in the parent-child bonding and attachment processes and increases in parental negative behavior toward their children, and in turn to increased likelihood for maltreatment (Cicchetti \& Valentino, 2006; Stith et al., 2009). Home visitors assisting parents with handling structural stressors, like access to employment and education, are important aspects of the HS/HFO program. Families stressed by multiple challenges, including anxiety and upset due to financial stress often cannot be fully present for their infants. Working with families to decrease risk factors, specifically to improve education, job skills, and employment opportunities would likely elevate levels of warmth and child connections.

Those families with high cumulative protective factors showed a trend toward increased responsiveness and acceptance of their children $(p=.098)$. Specifically, mothers who had realistic expectations of their child's behavior and no issues with housing showed greater responsiveness and acceptance of their children. Parents having reasonable knowledge-based expectations of their children's behavior increased their ability to have responsive, positive, and engaging maternal contact (Duggan et al., 2004). Again, the HS/HFO program offers extensive resources to parents about infant and child milestones. This result provides some potentially encouraging program effects regarding 
the link between increased knowledge of the infant/child's behavior and the creation of a responsive and nurturing home environment. In this study, not needing housing was linked to parents' ability to be present for their children. Programs and services need make sure to create or continue supports for stable and secure housing for families with young children.

Parenting stress. High levels of parenting stress have established associations with child maltreatment (Shipman \& Zeman, 2001). In this study, families with high levels of risk factors and low levels of protective factors had more parenting stress. Given the links of parenting stress to potential maltreatment, the utility of both indices for screening or targeting services warrants further investigation. Parents without the protection of social support and healthy family functioning had high levels of parenting stress. This has major implications for program development and service provision for families on the protection side. Focus is often on the identification of stressors and risk factors for families, and here we see the potential for families to benefit from efforts targeted to improve family functioning and social support systems. Home visiting that calls for using an approach to strengthening families is seen as warranted (Sar, Antle, Bledsoe, Barbee, \& Van Zyl, 2010). Here too, we see that families dealing with maternal depression and parental drug issues show increased parenting stress. Depression and drug abuse issues have shown negative impacts on parenting, as well as child development (Cicchetti \& Valentino, 2006). Twenty-seven percent of the mothers in this study had both PHQ-2 indicators of depression at study entry, and at least half of these women had not had their child yet at recruitment. Future work aimed at better 
understanding the prevalence of depression and other clinical issues in home visiting populations is essential for developing best practices for working with new mothers with depression, in the context of both maternal and family clinical support and child wellbeing (Ammerman, Putnam, Bosse, Teeters, \& Van Ginkel, 2010). This is potentially a sub-specialty in home visiting that could have major beneficial impacts for children and families.

\section{Home Learning Environment.}

HOME - Supportive Learning Environment. High RFI scores were associated with lower supportive learning environments for young children. The risk factor most strongly linked to this outcome was unemployment. Families with employment difficulties were assessed as providing less engaging learning environments. This may speak to the overwhelming nature of financial stress for families out of work, and at the same time, validation that program efforts focused on improving future goal planning, independence, and job placement are paramount for both parent and child optimal growth and development. Alternatively, families with a good grasp on what to expect from their child's behavior, who participated in additional home visiting or parenting classes outside the HS/HFO program, or who had no housing support issues provided a more positive, engaging learning environment for their children. It is also possible that the items on this measure may reflect some bias toward higher socioeconomic status, since many of the factors associated with lower scores on the subscales in this study were socioeconomically related (e.g., unemployment, low education, lack of housing support). In addition, further analysis looking at level of additional program exposure in addition to 
the influence of the HS/HFO program may shed light on how programs or services can work together to provide support and resources to families.

Parent child activities. Low maternal education was associated with less engagement in parent-child play behavior. Examining these results from a practice and program perspective that focuses on strengthening families, family functioning seems to consistently linked to better outcomes for children, here with increased developmentally appropriate play between parents and children (Horton, 2003; QIC-EC, 2009). Program efforts need to move toward models that work on building family skills and helping parents find supports to buffer other risks. Both the risk and protection models with individual factors indicated that White/Non-Hispanic groups participated in more parent child activities than persons of color. This finding warrants additional study, as parentchild interactions especially around play behavior can vary greatly by the norms established in different cultures (Vigil \& Hwa-Froelich, 2004).

\section{Implications for Practitioners Working with Children and Families}

Practitioners in many fields working to promote optimal health and development for parents and children can gain practice knowledge from the insights gained from this work. The previous section provided some ideas in this area by outcome, and this section summarizes these findings related to specific suggestions for how to use this information in the field with children and families. If using a screening tool, service workers can assess specific risks and target services accordingly. For instance, if a family has multiple stressors, focusing on the areas most challenging to the family and involving them in choices to move toward positive changes may increase engagement and enhance 
functioning. Table 35 provides specific examples of the kinds of approaches and specific work that could be done with families based on this information. In all cases, focusing on families with multiple stressors, with high levels of risk for negative parenting or child outcomes would be a priority. Practices suggested could be focused in areas where children and families gather, for instance, health clinics, child-care facilities, and community centers. Other practice focus locations and specific services are highlighted in the table. 
Table 35

Practice Implications Related to Services and Practice Approaches for Families with Multiple Stressors Based on Study Findings

\begin{tabular}{|c|c|c|}
\hline Point of Service & Focus Area & Practice Approach Suggestion Based on Findings \\
\hline $\begin{array}{l}\text { - Child welfare agency } \\
\text { - Community or home } \\
\text { visitation programs } \\
\text { - Counseling centers }\end{array}$ & $\begin{array}{l}\text { Reductions in } \\
\text { child welfare } \\
\text { involvement }\end{array}$ & $\begin{array}{l}\text { Facilitate support groups for parents with abusive origins } \\
\text { Work to improve access to concrete housing support } \\
\text { resources }\end{array}$ \\
\hline $\begin{array}{l}\text { - Pediatrician /health } \\
\text { clinics/ preschool- } \\
\text { based health } \\
\text { clinic/child-care } \\
\text { centers } \\
\text { - Community or home } \\
\text { visitation programs } \\
\text { - Counseling centers }\end{array}$ & $\begin{array}{l}\text { Increases in } \\
\text { child health } \\
\text { and well } \\
\text { being }\end{array}$ & $\begin{array}{l}\text { Work with families in the home to promote early } \\
\text { childhood development and to teach physical and } \\
\text { psychological milestones } \\
\text { Facilitate concrete housing support resources, focus on } \\
\text { stable and long-term options } \\
\text { Work with neighborhood groups to address safety } \\
\text { concerns and increase supports and connections with } \\
\text { neighbors }\end{array}$ \\
\hline $\begin{array}{l}\text { - Child welfare agency } \\
\text { - Community or home } \\
\text { visitation programs } \\
\text { - Child-care centers } \\
\text { - Counseling centers }\end{array}$ & $\begin{array}{l}\text { Improving } \\
\text { positive } \\
\text { parenting } \\
\text { approaches } \\
\text { and parent- } \\
\text { child bonding }\end{array}$ & $\begin{array}{l}\text { Offer classes/programs with a focus on teaching/modeling } \\
\text { positive discipline practices } \\
\text { Focus parent education on child development and teaching } \\
\text { physical and psychological milestones } \\
\text { Facilitate access to concrete housing support, job skills, } \\
\text { employment, education (completion of GED) }\end{array}$ \\
\hline $\begin{array}{l}\text { - Child welfare agency } \\
\text { - Community or home } \\
\text { visitation programs } \\
\text { - Counseling centers }\end{array}$ & $\begin{array}{l}\text { Reducing } \\
\text { parenting } \\
\text { stress }\end{array}$ & $\begin{array}{l}\text { Target services to those mothers at risk for post-partum } \\
\text { depression, and families with potential drug abuse issues } \\
\text { Facilitate support groups and counseling to bolster } \\
\text { protections to increase social support and healthy family } \\
\text { functioning }\end{array}$ \\
\hline $\begin{array}{l}\text { - Community or home } \\
\text { visitation programs } \\
\text { - Child-care centers } \\
\text { - Counseling centers }\end{array}$ & $\begin{array}{l}\text { Enhancing a } \\
\text { supportive } \\
\text { learning } \\
\text { environment }\end{array}$ & $\begin{array}{l}\text { Offer classes/programs with a focus on modeling parent- } \\
\text { child interaction/play behavior } \\
\text { Develop culturally sensitive programs for teaching parent- } \\
\text { child play activities and child development } \\
\text { Facilitate access to concrete housing support, job skills, } \\
\text { employment, education (completion of GED) } \\
\text { Hold support groups and provide counseling specific to } \\
\text { enhance healthy family functioning }\end{array}$ \\
\hline
\end{tabular}




\section{Implications for Policy}

Funding for home visitation programs in the U.S. has increased over the last decade to record levels. Taking a public health perspective on use of family screening tools to best deliver services is not a new concept, however for home visitation services the practice is controversial. Universal programs vs. targeted programs have been debated (Astuto \& Allen, 2009). Offering services to all mothers, at different levels of intensity based on specific risk and protective factor screenings, would make the program universal but also targeted effectively. This type of process would normalize services so that the seeking and receiving of supports at this crucial time in the families' lives would become non-stigmatizing (Astuto \& Allen, 2009). Inter-disciplinary alliances around this type of program between hospitals and clinics, social service agencies, child welfare, and local early childhood initiatives, and families would also improve the non-stigmatizing aspect of service delivery.

\section{Implications for Future Research}

Demonstration of main effects for risk and protective factors predictors in the current study has implications for future research and the development of prevention and intervention programs for child maltreatment, as well as reduction of parenting stress and improving parent-child engagement. The RFI measured the risks shown to predict maltreatment and parenting stress and could potentially be used as a tool for assessing the needs of new mothers in various settings. The RFI contains 8 of the 10 risk factors included in the NBQ, a successful risk screening tool used to categorize maltreatment risk level for new mothers being offered home visitation services (Green et al., 2009). Three 
risk factors added to the index in this study had predictive power: caregiver maltreatment history was a strong predictor of child welfare reports, and neighborhood violence and residential mobility predicted child health and well-being. The caregiver maltreatment history item for this study came from the KFSI. This inventory contains 10 items, and takes specialized training to administer. Potentially adding the one item about maltreatment history from family of origin to an existing brief screener may improve predictive power for the NBQ tool. Additionally, neighborhood violence can be measured with three brief items, and residential mobility with two items. All three factors could fit easily within the context of already existing brief screening instruments.

Future research employing multiple factor models outside the scope of the current study could involve the addition of other important factors in the model. For instance, broadening the single status factor to include more information about the engagement of the father of the child would be of interest. Currently, many mothers report not being married, however, they are living with a partner with variable supports to the family (e.g., financial or emotional). Cohabitation, depending on the engagement and health of the relationship can increase stressors for the family, or decrease them (Brown, 2004; Dunifon \& Kowaleski-Jones, 2002). Another area of study that would advance the current work includes the addition of risk factors (for negative outcomes) around violence exposure for mother and child on all ecological levels (Coulton et al., 2007). This would include extending the parental histories of maltreatment to include information on the perpetrator, chronicity, and severity. Also, inclusion of data on domestic violence histories for the parent's family of origin, as well as parent and child exposure to current 
and past partner abuse would be important. Finally, neighborhood level of violence exposure could be obtained by both parent self-report of witnessing violence and community crime statistics.

The PFI did not show any predictive ability related to child welfare involvement, however a trend was seen in the expected direction. This index could be used as a tool for directing services for specific families. For instance, high levels of social support and healthy family functioning predicted lower levels of parenting stress, a known link to child maltreatment. If programs used these protective factor measures as screens for families entering services, clinicians could better direct their efforts to increase social support and family counseling services to potentially decrease parenting stress and the potential for child maltreatment. Extending protective factors to capture information on the wider net of supports for the mother and baby would also be useful. This would include information about adults living in the home who have responsibility for care of the child, including domestic partners and extended family. Similarly, information on childcare access and quality, and parent satisfaction with childcare would be important to study especially in the context of financial stress and parenting stress (Cicchetti \&Valentino, 2006). Another area of potential protection for families living with multiple stressors is community connections to organizations such as a spiritual or religious group (Stith et al., 2009). Others have agreed about the need for a broad focus:

...more research is needed to further inform intervention and prevention efforts...maltreating parents exhibit a complex pattern of cognitive, affective, interpersonal, and behavioral processes that are in part derived from their 
own childhood relational experiences. Parental resources are further challenged by the influence of macrosystem factors as well as by poverty, community violence, and other aspects of the exosystem (Cicchetti \& Toth, 2006, p. 180).

Future research directly related to advancing the methods and knowledge base established by the current study could involve factor analysis or latent class analysis models providing a more precise way of categorizing types of risk or protective factor clusters that are linked to specific outcomes. In addition, looking at individual child factors in the risk factor domain may be informative. For instance, there is a large literature on child risk factors for child maltreatment such as the child medical factors of prematurity, low birth weight, and chronic conditions, as well as age and temperament (Sedlak et al., 2010; Sidebotham, et al., 2006). Incorporating these risks may provide additional insights into prediction of outcomes. Also, exploring the static or changing nature of risk and protective factors, where applicable, from baseline to 12 month followup would provide insight about both the nature of the risk factors, as well as potential HS/HFO program effects. For instance, a logical question to ask is: Do families with higher engagement in the HS/HFO program show reduced need for concrete housing support services, from baseline to follow-up? Also, are there changes for families at different program engagement levels or race/ethnicity groups in terms of financial stress, troubled relationships, depression, parenting confidence, or social supports over this time period, and how is this related to outcomes? 
As noted earlier, using the newly created RFI and PFI scores, study families had an average of 4.7 risk factors (potential up to 12 ) and 5.2 protective factors (potential up to 10). Attempts to categorize groups by number/types of risks or protections (e.g., clusters of risk and protection) and comparing outcomes with these grouping variables could be another step in this work. Additionally, use of qualitative methods like focus groups or interviews with program families and home visitors would provide valuable data for program course corrections and potentially new program insights. Also, working to better understand the needs of the hard to engage families could guide recruitment and retention practices to improve non-participation rates, and provide more families with needed services (Peacock, et al., 2013). Questions for the program model might include: Does the flexibility of the model contribute to its effectiveness?, In what ways can the model be modified in practice to best serve families and still show program effectiveness on important outcomes?, and, Are there program or service elements that are best kept intact, and others that need to be malleable to a family's unique needs?

\section{Overall Limitations of the Study}

Sample size and composition. The originally calculated sample size and subsequent power analyses for this work was calculated with a sample of approximately 400 families participating in the HS/HFO program. Because of the nature of communitybased research and recruitment strategies at prenatal visits in this study, a large proportion of those initially enrolled in the program did not receive a first home visit (38\%), thereby limiting the size of the available sample. In addition, there was a lack of racial diversity in the sample. To keep all families in the sample, a combined category 
for persons of color was developed and included all groups except White/Non-Hispanic families. Complete comparisons between the major racial/ethnic groups were not able to be performed in this study due to small numbers.

Retrospective selection of measures. The current study was also limited to the already existing screening and data collection procedures in an ongoing trial of intensive home visitation services for families at risk for child maltreatment. Measures and constructs were not chosen in a standard a priori approach, rather retrospectively guided by the empirical literature, and the perspectives of the author and early readers of the proposal, as well as what measures already existed in the HS/HFO measures protocol. Perceptions and behavior around spiritual beliefs or religious activity, as well as other activities that have shown links to family and caregiver coping in stressful environments, were not included in the HS/HFO study measures. Lacking here also was a more indepth look at childcare access and type, and parent satisfaction with childcare needs. In addition, although the program does collect some information on caregiver perception of culturally competent service provision, a closer look at cultural influences on coping behavior, parenting practices, and their links to maltreatment would enhance this work.

Generalizability. The study sample is limited to those families with multiple risk factors that are screened into the home visitation program, who actually received at least one home visit, in seven counties in Oregon, somewhat limiting generalizability of findings beyond this demographic and geographic profile. Attrition in the study creates other considerations for generalizability of results as well. A higher proportion of depressed mothers, when contacted to set up their home visit after initial recruitment, 
engaged in home visiting services than non-depressed mothers. Also, families with complete data for 12 month outcomes tended to be of older maternal age compared to those with missing outcome data at this time-point. Being careful not to generalize study results to younger mothers is important given this finding.

Variations in model development. The methodology for developing multiple indices, and approaches like factor analysis, summative scores, and at-risk range models have been discussed at length in the literature (Burchinal et al., 2000; Burchinal et al., 2006; Deater-Deckard, Dodge, Bates, \& Petit, 1998; Gutman, Sameroff, \& Cole, 2003; Gutman, Sameroff, \& Eccles, 2002; Hooper et al., 1998; Jessor et al., 1995; Sameroff \& Cole, 2003; Sameroff, Seifer, Barocas, Zax, \& Greenspan, 1987; Sameroff, et al., 1993). Given varying opinions, there is support in the literature for using a cumulative risk based approach when trying to predict early developmental outcomes (Hooper et al., 1998). The summative index approach has the advantage of simplicity, while also the disadvantage of losing potentially important information when equal weight is given to all factors in the model (Burchinal et al., 2000). Because no assumptions are made about the relative importance of any given risk or protective factor, each one is treated equally when categorized into presence or absence, and then summed. One way this criticism is combatted is to examine individual index factors by unpacking the items using additional analyses. Since index development using multiple potentially important factors is somewhat of an exploratory research exercise, taking apart the indices to better understand the unique contribution of each factor is an important step in gauging impact on outcomes. When unpacking the indices for the current study, one to three risk or 
protective factors in each of the models tended to be driving the RFI and PFI as predictors.

\section{Conclusion}

Indeed, a fundamental take-home message for the applied developmentalist or clinician must be that efforts to enhance parenting and child development should be targeted to more than a single course of influence, as it is invariably the cumulative impact of the multiple sources of influence...that determine the course of parenting, parentchild relations, and child development to a substantial degree (Belsky \& Jaffee, 2006, p. 74).

The number of new mothers who screen positive for needing HS/HFO services based on risk eligibility criteria far exceeds the ability for the current system to provide for each one, and unfortunately, this situation is not limited to Oregon. Research on home visiting models currently has the attention of policymakers in the U.S. President Obama has repeatedly endorsed the home visitation model as part of his approach to comprehensive education and effective and comprehensive early childhood programs (Astuto \& Allen, 2009). U.S. funding for such programs is increasing and movement has begun to push evidence-based home visiting programs forward (Avellar et al., 2012). For decades, the field of home visitation has been debating the kinds of program inputs that are essential to optimal child and family outcomes, from curriculum, to education level and training of the home visitor, to level of resource allocation in balancing inputs and outputs. Because this discussion is now national, the opportunity to elevate both the 
research base and the lives of many children and families is a potential reality. The current study adds to the knowledge base of using cumulative factor models in the prediction of child and parenting outcomes in families with multiple stressors, participating in home visitation services. The RFI specifically can be considered a theoretically identified and empirically supported risk factor tool. Careful attention to the specific risk factors and key protective factors found to be predictive of outcomes in the study models may enhance service delivery and ultimately improve child, parent, and family outcomes. More research on protective factors and promotion strategies that foster resilience in families living in difficult circumstances is warranted. Ultimately, a targeted service provision approach guided by key factors linked to important outcomes is especially timely in light of limited State and county resources. 


\section{References}

Abidin, R. R. (1995). Parenting Stress Index, 3rd ed: Professional manual, Odessa, FL: Psychological Assessment Resources, Inc.

Aiken, L. S., \& West, S. G. (Eds.). (1991). Multiple regression: Testing and interpreting interactions. Newbury Park, CA: Sage.

Alonso-Marsden, S., Dodge, K. A., O’Donnell, K. J., Murphy, R. A., Sato, J. M., \& Christopoulos, C. (2013). Family risk as a predictor of initial engagement and follow through in a universal nurse home visiting program to prevent child maltreatment. Child Abuse and Neglect, in press. Retrieved from http://dx.doi.org/10.1016/j.chiabu.2013.03.012

American Academy of Pediatrics. (2012). AAP reaffirms breastfeeding guidelines. Retrieved from http://www.aap.org/en-us/about-the-aap/aap-pressroom/pages/AAP-Reaffirms-Breastfeeding-Guidelines.aspx

Academic Pediatric Association and American Academy of Pediatrics Task Force on Childhood Poverty. (2013). APA and AAP strategic road-map. Retrieved from http://academicpeds.org/public_policy/pdf/APA_Task_Force_Strategic_Road_Ma pver3.pdf

Ammerman, R. T., Putnam, F. W., Bosse, N. R., Teeters, A.R., \& Van Ginkel, J. B. (2010). Maternal depression in home visitation: A systematic review. Aggression and Violent Behavior 15(3), 191-200.

Appleyard, K., Egeland, B., van Dulmen, M., \& Sroufe, L. (2005). When more is not better: The role of cumulative risk in child behavior outcomes. Journal of Child Psychology and Psychiatry, 46(3), 235-245.

Astuto, J., \& Allen, L. (2009). Home visitation in young children: An approach worth investing in? Social Policy Report, 23(4). Retrieved from http://www.mainechildcare.org/images/National_Report_on_the_Impact_of_Fami ly_Vistation_Programs.pdf

Avellar, S., Paulsell, D., Sama-Miller, E., \& Del Grosso, P. (2012). Home visiting evidence of effectiveness review (HomVEE): Executive summary. Washington, DC: Office of Planning, Research and Evaluation, Administration for Children and Families, U.S. Department of Health and Human Services.

Bandura, A. (1979). Social learning and personality development. New York, NY: Holt, Rinehart and Winston. 
Bandura, A. (2004). Health promotion by social cognitive means. Health Education \& Behavior, 31(2), 143-164.

Barth, R. P. (1991). An experimental evaluation of in-home child abuse prevention services. Child Abuse and Neglect, 15, 363-375.

Baumann, D. J., Dalgleish, L., Fluke, J., \& Kern, H. (2011). The decision-making ecology. Washington, DC: American Humane Society, 1-13.

Bavolek, S. J., \& Keene, R. G. (2001). Adult-Adolescent Parenting Inventory AAPI-2: Administration and development handbook. Retrieved from http://www.nurturingparenting.com/ValidationStudiesAAPI.html

Belsky, J. (1993). Etiology of child maltreatment: A developmental-ecological analysis. Psychological Bulletin, 114(3), 413-434.

Belsky, J., Bell, B., Bradley, R. H., Stallard, N., \& Stewart-Brown, S. L. (2006). Socioeconomic risk, parenting during the preschool years and child health age 6 years. European Journal of Public Health, 17(5), 508-513.

Belsky, J., \& Jaffee, S. R. (2006). The multiple determinants of parenting. In D. Cohen (Ed). Developmental psychopathology, risk disorder and adaptation (pp. 38-85). Hoboken, NJ: John Wiley and Sons.

Bishop, S., \& Leadbeater, B. (1999). Maternal social support patterns and child maltreatment: Comparison of maltreating and nonmaltreating mothers. American Journal of Orthopsychiatry, 69(2), 172-181.

Black, D. A., Heyman, R. E., \& Smith Slep, A. M. (2001). Risk factors for child physical abuse. Aggression and Violent Behavior, 6 (2-3), 121-188.

Black, M. M., Nair, P., Knight, C., Wachtel, R., Roby, P., \& Schuler, M. (1994). Parenting and early development among children of drug-abusing women: Effects of home intervention. Pediatrics, 94(4), 440-448.

Bowlby, J. (1977). The making and breaking of affectional bonds. I. Aetiology and psychopathology in the light of attachment theory: An expanded version of the Fiftieth Maudsley Lecture, delivered before the Royal College of Psychiatrists, 19 November 1976. British Journal of Psychiatry, 130(3), 201-210.

Bradley, R. H. (1993). Children's home environments, health, behavior, and intervention efforts: A review using the HOME inventory as a marker measure. Genetic, Social and General Psychology Monographs, 119, 437-490. 
Bradley, B. M., \& Caldwell, R. H. (1984). The HOME inventory and family demographics. Developmental Psychology, 20(2), 315-320.

Bretherton, I. (1992). The origins of attachment theory: John Bowlby and Mary Ainsworth. Developmental Psychology, 28(5), 759-775.

Broadhead, W., Gehlbach, S. H., de Gruy, F. V., \& Kaplan, B. H. (1988). The DukeUNC Functional Social Support Questionnaire: Measurement of social support in family medicine patients. Medical Care, 26(7), 709-723.

Bronfenbrenner, U. (1979). The ecology of human development: Experiments by nature and design. Cambridge, MA: Harvard University Press.

Bronfenbrenner, U. (1986). Ecology of the family as a context for human development: Research perspectives. Developmental Psychology, 22(6), 723-742.

Brooks-Gunn, J. (2010). The neighborhoods where young children grow up. In S. L. Kagan \& K. Tarrant (Eds). Transitions for young children: Creating connections across early childhood systems (211-240). Baltimore, MD: Paul H Brookes Publishing.

Brown, S. (2004). Family structure and child well-being: The significance of parental cohabitation. Journal of Marriage and Family, 66(2), 351-367.

Brown, J., Cohen, P., \& Johnson, J. (1998). A longitudinal analysis of risk factors of child maltreatment: Findings of a 17-year prospective study of officially recorded and self-reported child abuse and neglect. Child Abuse and Neglect, 22(11), 1065-1078.

Burchinal, M., Roberts, J. E., Zeisel, S. A., Hennon, E. A., \& Hooper, S. (2006). Social risk and protective child, parenting, and child care factors in early elementary school years. Parenting: Science and Practice, 6(1), 79-113.

Burchinal, M., Vernon-Feagans, L., \& Cox, M. (2008). Cumulative social risk, parenting, and infant development in rural low-income communities. Parenting: Science and Practice, 8(1), 41-69.

Burchinal, M. R., Roberts, J. E., Hooper, S., \& Zeisel, S. A. (2000). Cumulative and early cognitive development: A comparison of statistical risk models. Developmental Psychology, 36(6) 793-807.

Cabrera, N. J., Fagan, J., Wight, V., \& Schadler, C. (2011). Influence of mother, father, and child risk on parenting and children's cognitive and social behaviors. Child Development, 82(6), 1985-2005. 
Centers for Disease Control and Prevention. (2011). Child maltreatment prevention scientific information: Risk and protective factors. Retrieved from http://www.cdc.gov/violenceprevention/childmaltreatment/riskprotectivefactors.ht $\mathrm{ml}$.

Chu, A. T., Pineda, A. S., DePrince, A. P., \& Freyd, J. J. (2011). Vulnerability and protective factors for child abuse and maltreatment. In J. W. White, M. P. Koss \& A. E. Kazdin (Eds.), Violence against women and children, Vol 1: Mapping the terrain (pp. 55-75). Washington, DC: American Psychological Association.

Cicchetti , D., \& Cohen, D. (2006). Developmental psychopathology: Volume one: Theory and method (2nd ed). Hoboken, NJ: John Wiley and Sons.

Cicchetti, D., \& Lynch, M. (1993). Toward an ecological/transactional model of community violence and child maltreatment: Consequences for children's development. Psychiatry, 53, 96-118.

Cicchetti, D., Lynch, M., \& Manly, J. T. (1997). An ecological developmental perspective on the consequences of child maltreatment. Washington, DC: U.S. Department of Health and Human Services, National Center on Child Abuse \& Neglect.

Cicchetti, D., \& Valentino, K. (2006). An ecological-transactional perspective on child maltreatment: Failure of the average expectable environment and its influence on child development. In D. Cicchetti \& D. J. Cohen (Eds.) Developmental psychopathology: Volume one: Theory and method (2nd ed., pp. 129-201). Hoboken, NJ: John Wiley and Sons.

Cohen, J. W. (1988). Statistical power analysis for the behavioral sciences (2nd ed.). Hillsdale, NY: Lawrence Erlbaum Associates.

Cohen, J., \& Cohen, P. (Eds.). (1983). Applied multiple regression/correlation analysis for the behavioral sciences (2nd ed.). Hillsdale, NJ: Erlbaum.

Conners, N., Whiteside-Mansell, L., Deere, D., Ledet, T., \& Edwards, M. (2006). Measuring the potential for child maltreatment: The reliability and validity of the Adult Adolescent Parenting Inventory-2. Child Abuse and Neglect, 30(1), 39-53.

Coohey, C. (1996). Child maltreatment: Testing the social isolation hypothesis. Child Maltreatment, 20(3), 241-254.

Coulton, C. J., Crampton, D. S., Irwin, M., Spilsbury, J. C., \& Korbin, J. E. (2007). How neighborhoods influence child maltreatment: A review of the literature and alternative pathways. Child Abuse and Neglect, 31(11-12), 1117-1142. 
Counts, J. M., Buffington, E. S., Chang-Rios, K., Rasussen, H. N., \& Preacher, K. J. (2010). The development and validation of the protective factors survey: A selfreport measure of protective factors against child maltreatment. Child Abuse and Neglect, 34(10), 762-772.

Daro, D., \& Dodge, K. (2009). Creating community responsibility for child protection: Possibilities and challenges. The Future of Children, 19(2), 67-93.

Deater-Deckard, K., Dodge, K.A., Bates, J.E., \& Pettit, G.S. (1998). Multiple risk factors in the development of externalizing behavior problems: Group and individual differences. Development and Psychopathology, 10(3), 469-493.

Delgado, C. E., Vagi, S. J, \& Scott, K. G. (2007). Identification of early risk factors for developmental delay. Exceptionality, 15(2), 119-136.

Diaz, A., Simantov, E., \& Rickert, V. I. (2002). Effect of abuse on health: Results of a national survey. Archives of Pediatric and Adolescent Medicine, 156(8), 811-817.

Dube, S. R., Anda, R. F., Felitti, V. J., Chapman, D. P., Williamson, D. F., \& Giles, W. H. (2001). Childhood abuse, household dysfunction, and the risk of attempted suicide throughout the life span: Findings from the Adverse Childhood Experiences Study. Journal of the American Medical Association, 286(4), 30893096.

Dubowitz, H. (2006). Defining child neglect. In M. M. Feerick, J. F. Knutson, P. K. Trickett, \& S. M. Flanzer (Eds.), Child abuse and neglect: Definitions, classifications, and a framework for research (pp. 107-127). Baltimore, MD: Paul H. Brookes Publishing.

Duggan, A., McFarlane, E., Fuddy, L., Burrell, L., Higman, S. M., Windham, A., \& Sia, C. (2004). Randomized trial of a statewide home visiting program: impact in preventing child abuse and neglect. Child Abuse \& Neglect, 28(6), 597-622.

Duggan, A., Windham, A., McFarlane, E., Fuddy, L., Rohde, C., Buchbinder, S., \& Sia, C. (2000). Hawaii's Healthy Start program of visiting for at-risk families: Evaluation of family identification, family engagement, and service delivery. Pediatrics, 105, (Supplement 2), 250-259.

Dumas, J. E., \& Wekerle, C. (1995). Maternal reports of child behavior problems and personal distress as predictors of dysfunctional parenting. Development and Psychopathology, 7 (3), 465-479.

DuMont, K., Kirkland, K., Mitchell-Herzfeld, S., Ehrhard-Dietzel, S., Rodriquez, M., Lee, E.,... \& Greene, R. (2011). A randomized trial of healthy families New York 
(HFNY): Does home visiting prevent child maltreatment? Final report to National Institute of Justice (Grant \# 2006-MU-MU-0002). Retrieved from http://www.ncjrs.gov/pdffiles1/nij/grants/232945.pdf

DuMont, K., Mitchell-Herzfeld, S., Greene, R., Lee, E., Lowenfels, A., Rodriguez, M., \& Dorabawila, V. (2008). Healthy Families New York (HFNY) randomized trial: Effects on early child abuse and neglect. Child Abuse \& Neglect, 32(3), 295-315.

Dunifon, R., \& Kowaleski-Jones, L. (2002). Who's in the house? Race differences in cohabitation, single parenthood, and child development. Child Development, 73(4), 1249-1264.

Eckenrode, J., Rowe, E., Laird, M., \& Brathwaite, J. (1995). Mobility as a mediator of the effects of child maltreatment on academic performance. Child Development, 66(4), 1130-1142.

Easterbrooks, M. A., Jacobs, F. H., Bartlett, J. D., Goldberg, J., Contreras, M. M., Kotake, C., \& Chaudhuri, J. H. (2013). Initial findings from a randomized, controlled trial of Healthy Families Massachusetts: Early program impacts on young mothers' parenting. Retrieved from http://www.pewstates.org/uploadedFiles/PCS_Assets/2013/Healthy_Families_Ma ssachusetts_executive_summary.pdf

Felitti, V. J., Anda, R. F., Nordenberg, D., Williamson, D. F., Spitz, A. M., Edwards, V. \& Marks, J. S. (1998). Relationship of childhood abuse and household dysfunction to many of the leading causes of death in adults: The Adverse Childhood Experiences (ACE) study. American Journal of Preventative Medicine, 14(4), 354-364.

Garbarino, J., \& Kostelny, K. (1992). Child maltreatment as a community problem. Child Abuse and Neglect, 16(4), 455-464.

Garmezy, N., Masten, A. S., \& Tellegen, A. (1984). The study of stress and competence in children: A building block for developmental psychopathology. Child Development, 55(1), 97-111.

Giannoni, P. P., \& Kass, P. H. (2012). Outcomes of high-risk and developmentally delayed infants and children enrolled in a state early childhood intervention program. Infants \& Young Children, 25(3), 244-264.

Giles-Sims, J., Straus, M. A., \& Sugarman, D. B. (1995). Child, maternal, and family characteristics associated with spanking. Family Relations, 44(2), 170-176. 
Goldman, J., Salus, M., Wolcott, D., \& Kennedy, K. (2003). A coordinated response to child abuse and neglect: The foundation for practice. Child abuse and neglect user manual series. Washington, DC: U.S. Department of Health and Human Services, Office on Child Abuse and Neglect.

Green, B. (2009). Testing the effectiveness of healthy families America in an accredited statewide system: Outcomes and cost-benefits of Oregon's Healthy Start Program. Rigorous evaluations of existing child abuse prevention programs, HHS-2009-ACF-ACYF-CA-0055. October 2009-September 2014.Washington, DC: United States Department of Health and Human Services. Administration for Children, Youth, and Families (ACF); Children Bureau.

Green, B. L., Lambarth, C. H., Tarte, J. M., \& Snoddy, A. M. (2009). Oregon's Healthy Start Maltreatment Prevention Report 2007-2008. A report to the Oregon Commission on Children and Families. Portland, OR. Northwest Professional Consortium.

Gutman, L. M., Sameroff, A. J., \& Cole, R. (2003). Academic growth curve trajectories from 1st grade to 12th grade: Effects of multiple social risk factors and preschool child factors. Developmental Psychology, 39(4), 777-790.

Gutman, L. M., Sameroff, A. J., \& Eccles, J. S. (2002). The academic achievement of African-American students during early adolescence: An examination of multiple risk, promotive, and protective factors. American Journal of Community Psychology, 30(3), 367-400.

Haskett, M. E., Ahern, L. S., Ward, C. S., \& Allaire, J. C. (2006). Factor structure and validity of the Parenting Stress Index-Short Form. Journal of Clinical Child and Adolescent Psychology, 35(2) 302-312.

Healthy Families America. (2013). Healthy Families America. 2003-2013. Retrieved from http://www.healthyfamiliesamerica.org/about_us/index.shtml

Heller, S. S., Larrieu, J. A., D’Imperio, R., \& Boris, N. W. (1999). Research on resilience to child maltreatment: Empirical considerations. Child Abuse and Neglect, 23(4), 321-338.

Herrenkohl, T. I., Sousa, C., Tajima, E. A., Herrenkohl, R. C., \& Moylan, C. A. (2008). Intersection of child abuse and children's exposure to domestic violence. Trauma, Violence, and Abuse, 9(2), 84-99.

Hill, R. B. (2006). Synthesis of research on disproportionality in child welfare: An update. Seattle, WA: Casey-CSSP Alliance for Racial Equity in the Child Welfare 
System. Retrieved from http://www.cssp.org/reform/child-welfare/otherresources/synthesis-of-research-on-disproportionality-robert-hill.pdf

Hooper, S. R., Burchinal, M. R., Roberts, J. E., Zeisel, S. \& Neebe, E. (1998). Social and family risk factors for infant development for one year: An application of the Cumulative Risk Model. Journal of Applied Developmental Psychology 19(1), 8596.

Horton, C. (2003). Protective factors literature review: Early care and education programs and the prevention of child abuse and neglect. Washington, DC: Center for the Study of Social Policy.

Howard, K. S., \& Brooks-Gunn, J. (2009).The role of home-visiting programs in preventing child abuse and neglect. The Future of Children, 19(2), 119-146.

Hussey J. M., Chang J. J., \& Kotch, J. B. (2006). Child maltreatment in the United States: prevalence, risk factors, and adolescent health consequences. Pediatrics, 118(3), 933-942.

Institute for Educational Research \& Public Service. (2013). The development and validation

of the Protective Factors Survey: A self-report measure of protective factors against child maltreatment, phase IV report. FRIENDS National Resource Center for Community-Based Child Abuse, A Service of the Children's Bureau, 1-23. Retrieved from http://friendsnrc.org/protective-factors-survey

Jackson, S., Thompson, R. A., Christiansen, E. H., Colman, R. A., Wyatt, J., \& Buckendahl, C. (1999). Predicting abuse-prone parental attitudes and discipline practices in a nationally representative sample. Child Abuse \& Neglect, 23, 15-29.

Jessor, R., Turbin, M., \& Costa, F. (1998). Risk and protection in successful outcomes among disadvantaged adolescents. Applied Developmental Science, 2(4), 194208.

Jessor, R., Turbin, M., \& Costa, F. (2010). Predicting developmental change in healthy eating and regular exercise among adolescents in China and the United States: The role of psychosocial and behavioral protection and risk. Journal of Research on Adolescence, 20(3), 707-725.

Jessor, R., Van Den Bos, J., Costa, F., \& Turbin, M. (1995). Protective factors in adolescent problem behavior: Moderator effects and behavioral change. Developmental Psychology, 31(6), 923-933. 
Kempe, H. (1976). Child abuse and neglect: The family and community. Cambridge, MA: Ballinger Publishing.

King, E. H., Logsdon, D. A., \& Schroeder, S. R. (1992). Risk factors for developmental delay among infants and toddlers. Children's Health Care, 21(1), 39-52.

Korfmacher, J. (2000). The Kempe Family Stress Inventory: A review. Child Abuse and Neglect, 24(1), 129-140.

Kroenke, K., Spitzer, R. L., \& Williams, J. B. (2003). The Patient Health Questionnaire2: Validity of a two-item depression screener. Medical Care, 41(11), 1284-1292.

Larkin, H., Shields, J. J., \& Anda, R. F. (2012). The health and social consequences of Adverse Childhood Experiences (ACE) across the lifespan: An introduction to prevention and intervention in the community. Journal of Prevention and Intervention in the Community, 40(4), 263-270.

Lee, Y., \& Guterman, N. B. (2010). Young mother-father dyads and maternal harsh parenting behavior. Child Abuse \& Neglect, 34(11), 874-885.

Lemon, K., D’Andrade, A., \& Austin, M. J. (2005). Understanding and addressing racial/ethnic disproportionality in the front end of the Child Welfare System. San Francisco, CA: Bay Area Social Services Consortium; Center for Social Services Research, 1-63. Retrieved from http://cssr.berkeley.edu/

Leventhal, T., \& Brooks-Gunn, J. (2000). The neighborhoods they live in: The effects of neighborhood residence on child and adolescence outcomes. Psychological Bulletin, 126(2), 309-337.

Love, J. M., Kisker, E. E., Ross, C. M., Schochet, P. Z., Brooks-Gunn, J., Paulsell, D., ... Brady-Smith, C. (2002). Making a difference in the lives of infants and toddlers and their families: The impacts of Early Head Start. Vol. I: Final technical report (No. 3256). Princeton, NJ: Mathematica Policy Research.

Lundahl, B. W., Nimer, J., \& Parsons, B. (2006). Preventing child abuse: A meta-analysis of parent training programs. Research on Social Work Practice,16( 3), 251-262.

MacMillan, H. L., \& Wathen, C. N. (2005). Family violence research. Journal of the American Medical Association, 294(5), 618-620.

Manly, J., Cicchetti, D., \& Barnett, D. (1994). The impact of subtype, frequency, chronicity, and severity of child's maltreatment on social competence and behavior problems. Development and Psychopathology, 6, 121-143. 
Maxfield, M., \& Widom, C. (1996). The cycle of violence, revisited 6 years later. Archives of Pediatrics and Adolescent Medicine, 150(4), 390-395.

Mitchell-Herzfeld, S., Izzo C., Greene, R., Lee, E., \& Lowenfels, A. (2005). Evaluation of Healthy Families New York (HFNY): First year program impacts. Rensselaer, NY: New York State Office of Children \& Family Services. Retrieved from http://www.ocfs.state.ny.us/main/prevention/assets/HFNY_FirstYearProgramImp acts.pdf

Mujahid, M. S., Diez Roux, A. V., Morenoff, J. D., \& Raghunathan, T. (2007). Assessing the measurement properties of neighborhood scales: From psychometrics to ecometrics. American Journal of Epidemiology, 165(8), 858-867.

Nickel, R. E., \& Squires, J. (2000). Developmental screening and surveillance. In R. E. Nickel \& L. W. Desch (Eds.), The physician's guide to caring for children with disabilities and chronic conditions (pp. 15-30). Baltimore, MD: Brookes.

Nygren, P., Nelson, H. D., \& Klein, J. (2004). Screening children for family violence: A review of the evidence for the US Preventive Services Task Force. Annals of Family Medicine, 2, 161-169.

Nurse Family Partnership. (2013). Nurse Family Partnership snap-shot (July 2013). Denver, CO: Nurse Family Partnership Organization. Retrieved from http://www.nursefamilypartnership.org/assets/PDF/Factsheets/NFP_Snapshot

Oregon Commission on Children and Families. (2012). Healthy Start, Healthy Families Oregon (HS/HFO): Reference guide for program managers and supervisors (October 2012). State of Oregon; Salem Oregon. Retrieved from: http://www.umchs.org/umchsresources/administration/pandp/Healthy_Start/HS4 Healthy\%20Start $\% 20$ Guide\%20for\%20Supervisors\%20\&\%20Managers/Oregons _Healthy_Start_PM_Sup_Reference_Guide.pdf

Oregon Department of Human Services. (2012). 2011 child welfare data book. Salem, OR: Oregon Department of Health and Human Services, Office of Business Intelligence. Retrieved from http://www.oregon.gov/dhs/abuse/publications/children/2011-cw-data-book.pdf.

Olds, D. L., Eckenrode, J., Henderson, C. R., Kitzman, H., Powers, J., Cole, R., ... Luckey, D. (1997). Long-term effects of home visitation on maternal life course and child abuse and neglect. Journal of the American Medical Association, 278(8), 637-643. 
Olds, D. L., Henderson, C. R., Chamberlin, R., \& Tatlebaum, R. (1986). Preventing child abuse and neglect: A randomized trial of nurse home visitation. Pediatrics, 78(1), $65-78$.

Olds, D. L., Kitzman, H., Hanks, C., Cole, R., Anson, E., Sidora-Arcoleo, K., ... Bondy, J. (2007). Effects of nurse home visiting on maternal and child functioning: Age-9 follow-up of a randomized trial. Pediatrics, 120(4), e832-e845. Retrieved from http://pediatrics.aappublications.org/content/120/4/e832.full.html

Orkow, B. (1985). Implementation of a family stress checklist. Child Abuse and Neglect 9(3), 405-410.

Patient Protection and Affordable Care Act of 2009, Pub. L. No. 111-148 U.S.C.A. $\S 2702,124$ Stat. 119 (2010).

Peacock, S., Konrad, S., Watson, E., Nickel, D., \& Muhajarinez, N. (2013). Effectiveness of home visiting programs on child outcomes: a systematic review. Biomed Central Public Health, 13 (17), 1-14. Retrieved from http://www.biomedcentral.com/1471-2458/13/17

Pratt, C. C., McGuigan, W. M., \& Katzev, A. R. (2000). Measuring program outcomes using retrospective pretest methodology. American Journal of Evaluation, 21(3), 341-349.

Protective Factors Survey: (PFS). (2009). Retrieved from http://www.friendsnrc.org/protective-factors-survey/138-protective-factorssurvey.

Quality Improvement Center on Early Childhood. (2009). The need for the Quality Improvement Center on Early Childhood: Background research and evaluation framework. Washington, DC: Quality Improvement Center on Early Childhood.

Reitman, D., Currier, R. O., \& Stickle, T. R. (2002). A critical evaluation of the Parenting Stress Index-Short Form (PSI-SF) in a Head Start population. Journal of Clinical Child and Adolescent Psychology,31(3), 384-392.

Reynolds, A., Mathieson, L., \& Topitzes, J. W. (2009). Do early childhood interventions prevent child maltreatment? A review of research. Child Maltreatment, 14(2), 182-206.

Ross, T., \& Vandivere, S. (2009). Indicators for child maltreatment prevention programs: Report for the QIC-EC. Washington, DC: Quality Improvement Center on Early Childhood. 
Rutter, M. (1987). Psychosocial resilience and protective mechanisms. American Journal of Orthopsychiatry. 57(3), 316-331.

Rutter, M. (1990). Psychosocial resilience and protective mechanisms. In J. Rolf, A. S. Masten, D. Cicchetti, K. H. Nuechterlein, \& S. Weintraub (Eds.), Risk and protective factors in the development of psychopathology (pp. 181-214). New York, NY: Cambridge University Press.

Sameroff, A. (2000). Ecological perspectives on developmental risk. In J. D. Osofsky \& H. E. Fitzgerald (Eds.), World Association for Infant Mental Health handbook of infant mental health: Infant mental health in groups at high risk (Vol. 4, pp. 133). New York, NY: Wiley \& Sons.

Sameroff, A. J., \& Cole, R. (2003). Academic growth curve trajectories from 1st to 12th grade: Effects of multiple social risk factors and preschool child factors. Developmental Psychology, 694, 777-790.

Sameroff, A. J., Seifer, R., Baldwin, A., \& Baldwin, C. (1993). Stability of intelligence from preschool to adolescence: The influence of social and family risk factor. Child Development, 64(1), 80-97.

Sameroff, A. J., Seifer, R., Barocas, R., Zax, M., \& Greenspan, S. (1987). Intelligence quotient scores of 4-year-old children: Social-environmental risk factors. Pediatrics, 79(3), 343-350.

Sameroff, A. J., Seifer, R., \& Zax, M. (1982). Early development of children at risk for emotional disorder. Monographs of the Society for Research in Child Development, 47(7), 82-97.

Sampson, R. J. (1992). Family management and child development: Insights from social disorganization theory. In J. McCord (Ed.), Advances in criminological theory, (Vol. 3, pp. 63-93). New Brunswick, NJ: Transaction Books.

Sampson, R. J., Raudenbush, S. W., \& Earls, F. (1997). Neighborhoods and violent crime: A multilevel study of collective efficacy. Science, 277, 918-924.

Sar, B. K., Antle, B. F., Bledsoe, L. K., Barbee, A. P., \& Van Zyl, M. A. (2010). The importance of expanding home visitation services to include strengthening family relationships for the benefit of children. Children and Youth Services Review, 32(2), 198-205.

Schumacher J. A., Smith A. M, \& Heyman, R. E (2001). Risk factors for child neglect. Aggression and Violent Behavior, 6 (2-3), 231-254. 
Sedlak, A. J., \& Broadhurst, D. D. (1996). Third national incidence study of child abuse and neglect (NIS-3). Final report. Washington, DC: U.S. Department of Health and Human Services, Administration for Children and Families.

Sedlak, A. J., Mettenburg, J., Basena, M., Petta, I., McPherson, K., Greene, A., \& Li, S. (2010). Fourth national incidence study of child abuse and neglect (NIS-4): Report to Congress. Washington, DC: U.S. Department of Health and Human Services, Administration for Children and Families. Retrieved from http://www.acf.hhs.gov/sites/default/files/opre/nis4_report_congress_full_pdf_jan 2010.pdf

Selph, S., Nelson, H. D., Bougatsos, C., \& Blazina, I. (2013). Screening for child abuse and neglect: Systematic review to update the 2004 U.S. Preventive Services Task Force recommendation. Annals of Internal Medicine, 158(3), 179-190.

Shipman, K., \& Zeman, J. (2001). Socialization of children's emotion regulation in mother-child dyads: A developmental psychopathology perspective. Development and Psychopathology, 13(2), 317-336.

Sidebotham, P., Heron, J., \& The ALSPAC Study Team. (2006). Child maltreatment in the "Children of the Nineties:" A cohort study of risk factors. Child Abuse \& Neglect, 30(5), 497-522.

Simon, A. E., Pastor, P. N., Avila, R. M., \& Blumberg, S. J. (2013). Socioeconomic disadvantage and developmental delay among US children aged 18 months to 5 years. Journal of Epidemiology and Community Health, 67, 689-695.

Simpson, G.A., Colpe, L., \& Greenspan, S. (2003). Measuring functional developmental delay in infants and young children: Prevalence rates from the NHIS-D. Paediatric and Perinatal Epidemiology. 17(1), 68-80.

Slack, K. S., Holl, J. L., McDaniel, M., Yoo, J., \& Bolger, K. (2004). Understanding the risks of child neglect: An exploration of poverty and parenting characteristics. Child Maltreatment, 9, 395-408.

Smith, M. G., \& Fong, R. (2004). The children of neglect: When no one cares. New York, NY: Brunner-Routledge.

Shook-Slack, K., Berger, L. M., DuMont, K., Yang, M. Y., Kim, B., Ehrhard-Dietzel, S., $\&$ Holl, J. L. (2011). Risk and protective factors for child neglect during early childhood: A cross-study comparison. Children and Youth Services Review, 33, 1354-1363. 
Squires, J., Bricker, D., \& Twombly, E. (2002). Ages \& Stages Questionnaires ${ }^{\circledR}:$ SocialEmotional: A parent-completed, child-monitoring system for social-emotional behaviors. Baltimore, MD: Paul H. Brookes Publishing Co.

Stevens, J., \& Bakeman, R. (1985). A factor analytic study of the HOME Scale for infants. Developmental Psychology, 21(6), 1196-1203.

Stith, S. M., Liu, T., Davies, L. C., Boykin, E. L., Alder, M. C., Harris, J. M., ... Dees, J. E. (2009). Risk factors in child maltreatment: A meta-analytic review of the literature. Aggression and Violent Behavior, 14(1), 13-29.

Strathearn, L., Mamun, A. A., Najman, J. M., \& O'Callaghan, M. J. (2009). Does breastfeeding protect against substantiated child abuse and neglect? A 15 -year cohort study. Pediatrics, 123(2), 483-493.

Strathearn, L., Gray, P. H., O'Callaghan, M. J., \& Wood, D. O. (2001). Childhood neglect and cognitive development in extremely low birth weight infants: A prospective study. Pediatrics, 108(1), 142-151.

Straus, M. A., \& Stewart, J. H. (1999). Corporal punishment by American parents: National data on prevalence, chronicity, severity, and duration, in relation to child and family characteristics. Clinical Child \& Family Psychology Review, 2, 55-70.

Swahn, M. H., Whitaker, D. J., Pippen, C. B., Leeb, R. T., Teplin, L. A., Abram, K. M., $\&$ McClelland, G. M. (2006). Concordance between self-reported maltreatment and court records of abuse or neglect among high-risk youths. American Journal of Public Health, 96(10), 1849-1853.

Sweet, M. A., \& Appelbaum, M. I. (2004). Is home visiting an effective strategy? A meta-analytic review of home visiting programs for families with young children. Child Development, 75(5), 1435-1456.

Tabachnick, B. G., \& Fidell, L. S. (Eds.). (2007). Using multivariate statistics (5th ed.). Boston: MA, Pearson.

Taylor, C. A., Guterman, N. B., Lee, S. J., \& Rathouz, P. (2009). Intimate partner violence, maternal stress, nativity, and risk for maternal maltreatment of young children American Journal of Public Health, 99, 175-183.

Thornberry, T. P. (2001). The importance of timing: The varying impact of childhood and adolescent maltreatment on multiple outcomes. Development and Psychopathology, 13(4), 957-979. 
Timmer, S. G., Borrego, J., \& Urquiza, A. J. (2002). Antecedents of coercive interactions in physically abusive mother-child dyads. Journal of Interpersonal Violence, 17(8), 836-853.

Toth, S. L., \& Cicchetti, D. (1996). Patterns of relatedness, depressive symptomatology, and perceived competence in maltreated children. Journal of Consulting and Clinical Psychology, 64(1), 32-41.

U.S. Department of Health and Human Services (2012). Administration for Children and Families, Administration on Children, Youth, and Families, Children's Bureau (2012). Child maltreatment 2011. Retrieved from http://www.acf.hhs.gov/programs/cb/resource/child-maltreatment-2011

U.S. Department of Health and Human Services (2013a). Affordable Care Act Maternal, Infant, and Early Childhood Home Visiting Program (MIECHV) and Tribal $M I E C H V$. Washington, DC: U.S. Department of Health and Human Services. Retrieved from http://www.acf.hhs.gov/programs/ecd/programs/home-visiting

U.S. Department of Health and Human Services (2013b). Definitions of child abuse and neglect. Washington, DC: U.S. Department of Health and Human Services. Retrieved from https://www.childwelfare.gov/systemwide/laws_policies/statutes/define.pdf

U.S. Department of Health and Human Services (2013c). Protective factors: Child Welfare Information Gateway, protecting children--strengthening families. Washington, DC: U.S. Department of Health and Human Services. Retrieved from https://www.childwelfare.gov/can/factors/protective.cfm

Valentino, K., Nuttall, A. K., Comas, M., Borkowski, J. G., \& Akai, C. E. (2012). Intergenerational continuity of child abuse among adolescent mothers: Authoritarian parenting, community violence, and race. Child Maltreatment,17(2), 172-181.

Vigil, D. C., \& Hwa-Froelich, D. A. (2004). Interaction styles in minority caregivers: Implications for intervention. Communication Disorders Quarterly, 25(3), 119126.

Whiteside-Mansell, L., Ayoub, C., McKelvey, L., Faldowski, R. A., Hart, A., \& Shears, J. (2007). Parenting stress of low-income parents of toddlers and preschoolers: Psychometric properties of a short form of the Parenting Stress Index. Parenting Science and Practice, 7(1), 27-56. 
Whitman, T. L, Borkowski, J. G., Keogh, D. A., \& Weed, K. (2001). Interwoven lives: Adolescent mothers and their children. Mahwah, NJ: Lawrence Erlbaum Associates Publishers.

Windham, A. M, Rosenberg, L., Fuddy, L., McFarlane, E., Sia, C., \& Duggan, A. K. (2004). Risk of mother-reported child abuse in the first 3 years of life. Child Abuse and Neglect, 28(6), 645-667.

Wolfe, D. A. (2006). Preventing violence in relationships: Psychological science addressing complex social issues. Canadian Psychology, 47(1), 44-50.

Wolfe, D. A. (2011). Risk factors for child abuse perpetration. In J. W. White, M. P. Koss, \& A. E. Kazdin (Eds.), Violence against women and children: Mapping the terrain, (Vol. 1, pp. 31-53). Washington, DC: American Psychological Association.

Zhou, Y., Hallisey, E. J., \& Freymann, G. R. (2006). Identifying perinatal risk factors for infant maltreatment: An ecological approach. International Journal of Health Geographics, 5, 53-63.

Zielinski, D. S., Eckenrode, J., \& Olds, D. L. (2009). Nurse home visitation and the prevention of child maltreatment: Impact on the timing of official reports. Development and Psychopathology, 21(2), 441-453.

Zolotor, A. J., Theodore, A. D., Chang, J. J., Berkoff, M. C., \& Runyan, D. K. (2008). Speak softly - and forget the stick: Corporal punishment and child physical abuse. American Journal of Preventive Medicine, 35(4), 364-369.

Zuravin, S. J. (1991). Research definitions of child physical abuse and neglect: Current problems. In R. Starr, H., Jr. \& D.A.Wolfe, (Eds.). The effects of child abuse and neglect: Issues and research (pp.100-128). New York, NY: Guilford Press. 


\section{Appendix A. Comparison of Baseline Characteristics of Families Randomized to Program Group $(n=405)$ by Program Exposure - Home Visits $(n=248)$ and No Home Visits $(\mathbf{n}=157)$}

To determine if important differences existed among the participants randomized to the HS/HFO home visiting program group who received one or more visits $(n=248)$ and those families that did not receive visits $(n=157)$, baseline characteristics were compared.

Table A. Comparison of Baseline Characteristics of Families Randomized to Program Group $(n=405)$ by Program Exposure - Home Visits $(n=248)$ and No Home Visits $(n=157) *$

\begin{tabular}{lll}
\hline \multicolumn{1}{c}{ Characteristic } & $\begin{array}{c}\text { 1 or more } \\
\text { home visits } \\
\text { \% }\end{array}$ & No home visits \\
Mother's age, Mean (SD) & $22.8(4.9)$ & $22.5(4.9)$ \\
Teen parent $<18$ & 11 & 11 \\
White/Non-Hispanic & $60^{*}$ & 71 \\
Hispanic & $31^{*}$ & 16 \\
Non-English speaking at home $\quad 9$ & $13^{*}$ \\
Single $\quad 22$ & 16 \\
Financial trouble & 77 & 82 \\
Parents unemployed & 83 & 79 \\
Less than HS education & 35 & 30 \\
Troubled family relationships & 26 & 32 \\
Maternal depression & $25^{\S}$ & 17 \\
Late prenatal care & $27^{* * *}$ & 8 \\
\# Risk factors baseline (mean) & 26 & 29 \\
\hline
\end{tabular}

Note. ${ }^{*} p<.05 ; * * p<.01 ; * * * p<.001 ;{ }^{\S} p<.1$ trend. 


\section{Appendix B. Comparison of Baseline Characteristics for Families with Outcome Data and Families With Missing Outcome Data $(n=248)$}

Missing outcome data for program families with $\geq 1$ home visit ranged from less than $1 \%$ to $43 \%$. To better understand the groups and to identify potential patterns in the missing data, important demographic characteristics were compared for those with data and those with missing data for each outcome with greater than $20 \%$ of cases missing (Table B). Three outcomes had $>20 \%$ missing data. All figures represent percentages within the data categories unless otherwise specified.

Table B. Percentage with Characteristic: > 20\% Missing Outcome Data $(N=248)$

\begin{tabular}{|c|c|c|c|c|c|c|}
\hline \multirow{3}{*}{ Characteristic } & \multicolumn{2}{|c|}{$\begin{array}{c}\text { HOME Scale } 12 \mathrm{~m} \\
\text { (45 items; } 6 \text { subscales) }\end{array}$} & \multicolumn{2}{|c|}{$\begin{array}{l}\text { Health Well-Being } 12 \mathrm{~m} \\
\text { (6 item scale) }\end{array}$} & \multicolumn{2}{|c|}{$\begin{array}{l}\text { Child Maltreatment } \\
\text { HV report up to } 12 \mathrm{~m}\end{array}$} \\
\hline & $\mathrm{N}$ miss & $\begin{array}{l}(\% \text { missing }) \\
(43)\end{array}$ & $\mathrm{N}$ missi & $\begin{array}{l}\text { \% missing) } \\
25)\end{array}$ & $\mathrm{N}$ mis & $\begin{array}{l}g(\% \text { missing }) \\
0(24)\end{array}$ \\
\hline & $\begin{array}{c}\text { Data } \\
\%\end{array}$ & $\begin{array}{c}\text { No Data } \\
\%\end{array}$ & $\begin{array}{c}\text { Data } \\
\%\end{array}$ & $\begin{array}{c}\text { No Data } \\
\%\end{array}$ & $\begin{array}{l}\text { Data } \\
\%\end{array}$ & $\begin{array}{c}\text { No Data } \\
\%\end{array}$ \\
\hline Age (mean) & 24 & $21 * * *$ & 23 & $21^{* *}$ & 23 & $21 * *$ \\
\hline Teen mother $<18$ & 6 & $18 * *$ & 8 & $20 *$ & 8 & $20^{*}$ \\
\hline $\begin{array}{l}\text { Race } \\
\text { White/Non-Hispanic } \\
\text { Hispanic } \\
\text { Other race/ethnicity } \\
\text { Single }\end{array}$ & $\begin{array}{l}65 \\
28 \\
8 \\
70\end{array}$ & $\begin{array}{l}53 \\
37 \\
10 \\
85^{* *}\end{array}$ & $\begin{array}{l}62 \\
30 \\
9 \\
77\end{array}$ & $\begin{array}{l}54 \\
37 \\
9 \\
77\end{array}$ & $\begin{array}{l}62 \\
30 \\
9 \\
77\end{array}$ & $\begin{array}{l}55 \\
36 \\
9 \\
77\end{array}$ \\
\hline Financial trouble & 83 & 84 & 84 & 82 & 84 & 82 \\
\hline Unemployment & 31 & 40 & 36 & 33 & 36 & 33 \\
\hline Education $<$ HS & 24 & 27 & 25 & 26 & 25 & 27 \\
\hline Troubled relationships & 31 & $17^{*}$ & 28 & $16^{\S}$ & 28 & $15^{*}$ \\
\hline Maternal depression & 31 & $23^{\S}$ & 30 & $20^{\S}$ & 30 & $20^{\S}$ \\
\hline Late prenatal care & 25 & 25 & 25 & 25 & 25 & 25 \\
\hline Drug issue intake & 40 & 36 & 40 & 33 & 40 & 33 \\
\hline $\begin{array}{l}\text { \# Risk factors baseline } \\
\text { (mean) }\end{array}$ & 3.0 & 3.2 & 3.2 & 3 & 3.1 & 3 \\
\hline
\end{tabular}




\section{Appendix C. Comparisons on Selected Participant Characteristics, Predictors, and Outcome Variables by Race/ Ethnicity ${ }^{\mathrm{a}}$}

\begin{tabular}{|c|c|c|}
\hline Characteristics or Variable & $\begin{array}{c}\text { White }- \text { Non } \\
\text { Hispanic }\end{array}$ & Persons of Color \\
\hline Continuous $^{\mathrm{b}}$ & Mean (SD) & Mean (SD) \\
\hline Age & $23.07(4.8)^{\S}$ & $21.9(4.8)$ \\
\hline New Baby Questionnaire (NBQ) Screener & $3.04(1.08)$ & $3.31(1.36)$ \\
\hline Risk Factor Index (RFI) & $4.83(1.70)$ & $4.55(1.91)$ \\
\hline Protective Factor Index (PFI) & $5.45(1.54)^{*}$ & $4.91(1.59)$ \\
\hline Total number home visits in 6 months & $16.82(6.89)$ & $15.47(6.97)$ \\
\hline Social Support (DUKE) & $4.24(.66)$ & $4.14(.66)$ \\
\hline Neighborhood Cohesion & $3.8(.77)$ & $3.8(.71)$ \\
\hline Family Functioning Subscale & $3.06(.78)$ & $3.00(.88)$ \\
\hline Child Health and Well-Being (6 items) & $.67(.23)$ & $.70(.21)$ \\
\hline AAPI Corporal Punishment Subscale & $1.79(.79)$ & $1.9(.77)$ \\
\hline HOME Responsivity/Acceptance Subscales & $.91(.11)$ & $.91(.06)$ \\
\hline Parenting Stress Index-Short Form & $1.85(.65)$ & $1.95(.65)$ \\
\hline HOME - 4 Supportive Learning Subscales & $.911(.11)$ & $.937(.09)$ \\
\hline Parent Child Activities & $3.9(.56)$ & $3.67(.74)^{* *}$ \\
\hline Dichotomous $^{c}$ & $\%$ Yes & $\%$ Yes \\
\hline Single & 74.3 & 81.3. \\
\hline Late prenatal care & 25.4 & 28.1 \\
\hline Financial trouble & 85.3 & 78.9 \\
\hline Unemployment & 32.4 & 39.6 \\
\hline High school or less education & 19 & $33^{*}$ \\
\hline Troubled family relationships & 26.3 & 28.9 \\
\hline Maternal depression & 32.1 & 23 \\
\hline Drugs issues & 52.9 & $21^{* *}$ \\
\hline Caregiver family history of maltreatment & 23 & 18.7 \\
\hline Frequent mobility & 54 & $38^{*}$ \\
\hline Child welfare involvement $^{d}$ & 13 & $4.5^{\S}$ \\
\hline Developmental delay screen & 14.7 & 12.1 \\
\hline
\end{tabular}

Note. Study outcomes in bold. ${ }^{\text {a}}$ Race is a categorical variable: White/Non-Hispanic (0) and persons of color (1) (Hispanic/Latina, African American, Asian/Pacific Islander, American Indian/Alaska Native, or Multi-racial).

${ }^{b}$ Continuous variables show mean and standard deviation (Independent-samples t-test by race/ethnicity). ${ }^{\mathrm{c}}$ Dichotomous variables show percentages for groups (Chi-square test for independence). ${ }^{\mathrm{d}}$ Further breakdown shows the following percentages for those with child welfare involvement for the following: White/Non-Hispanic (13\%), Hispanic/Latina $(2 \%)$, and all other races $(13 \%)$.

$* p<.05 ; * * p<.01 ; * * * p<.001 ;{ }^{\S} p<.1$ trend 


\section{Appendix D. Normality Tests for Protective Factor Index (PFI) and Risk Factor \\ Index (RFI)}

Figure D1. Protective Factor Index - Scores and Frequency with Overlay of Normal Curve Distribution

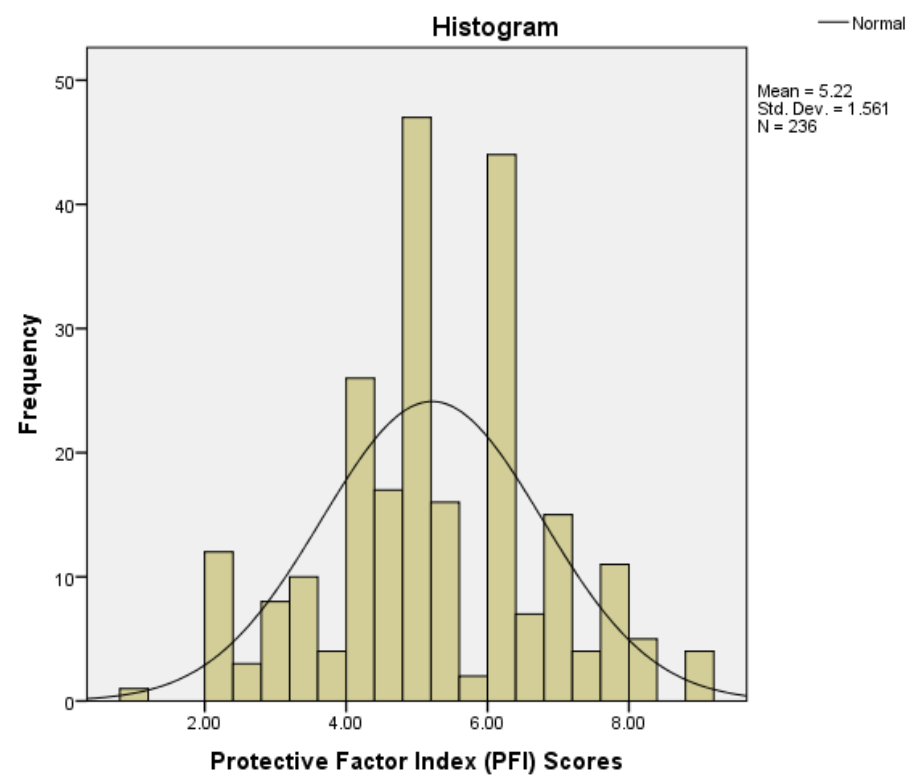

Figure D2. Protective Factor Index Distribution - Normal Q-Q Plot

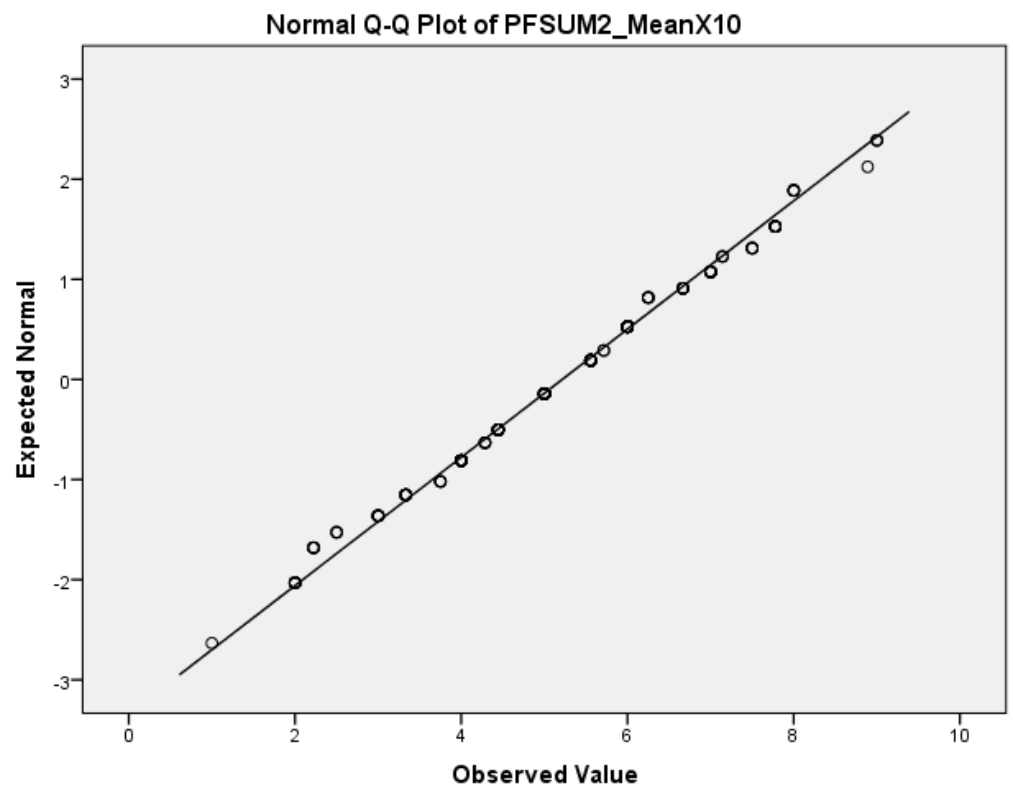


Figure D3. Risk Factor Index - Scores and Frequency with Overlay of Normal Curve Distribution

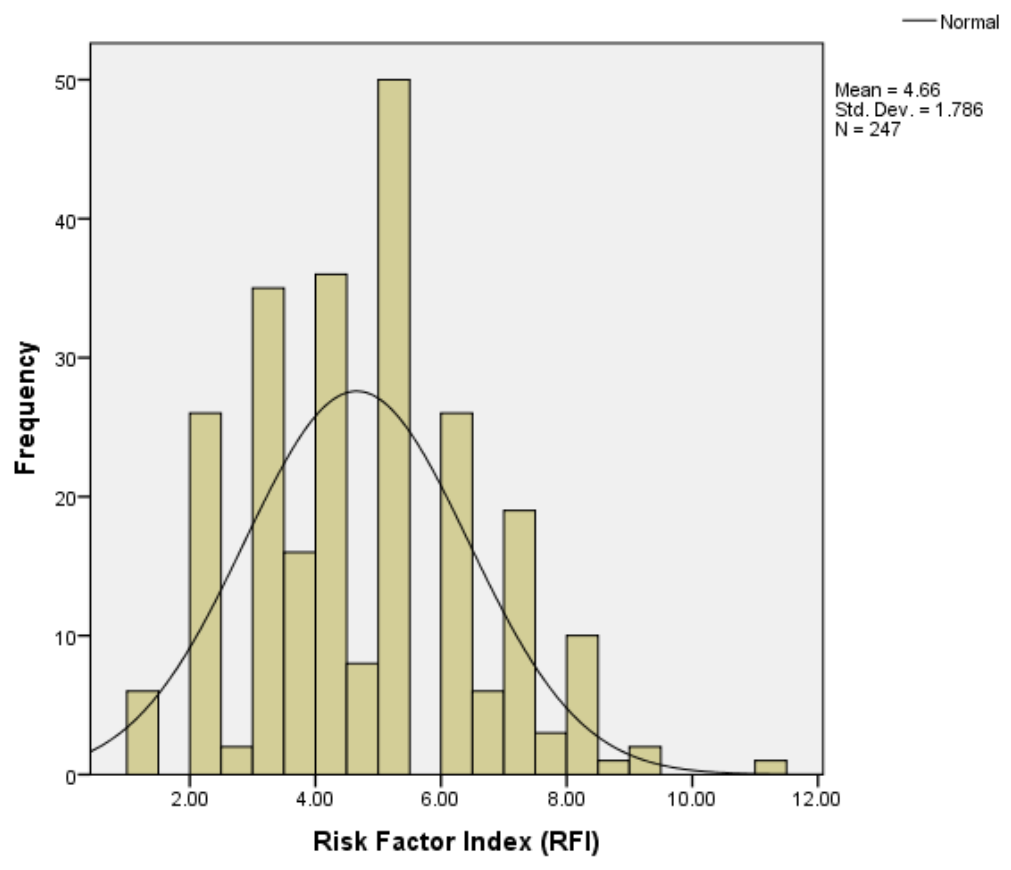

Figure D4. Risk Factor Index Distribution - Normal Q-Q Plot

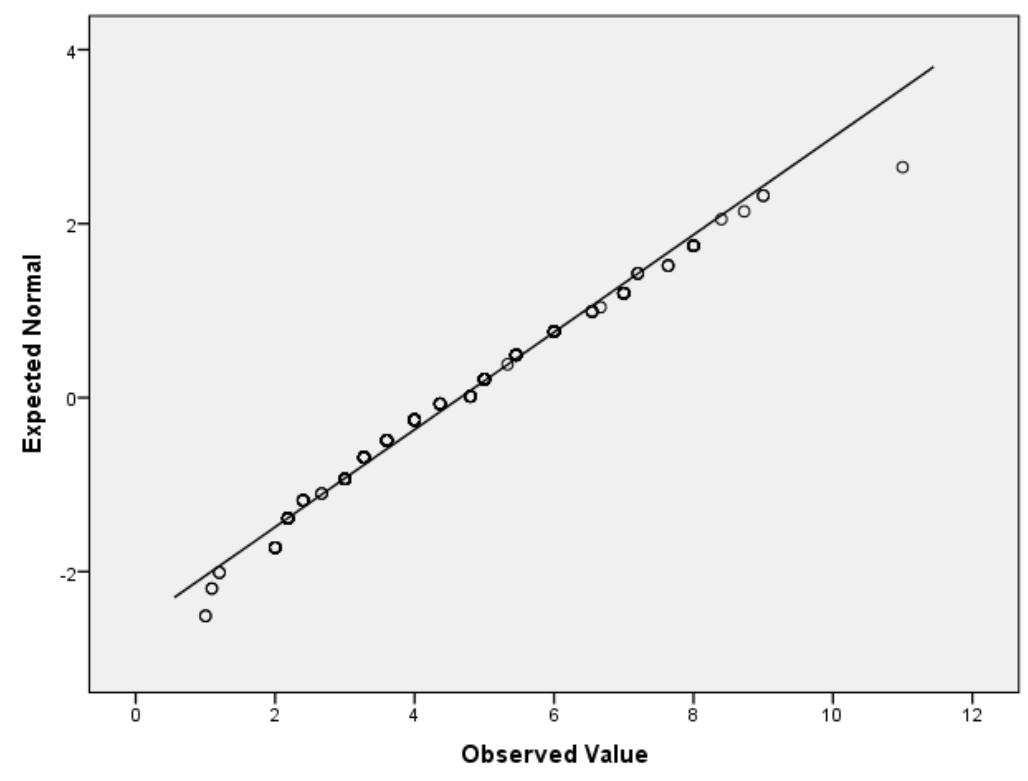




\section{Appendix E. Bivariate Analyses for Factor Indices and Individual Factors}

\section{Table E1}

Risk Factor Index (RFI) and Individual Risk Factor Items Used to Develop the Index

\begin{tabular}{|c|c|c|c|c|c|c|c|c|c|c|c|c|c|}
\hline & 1 & 2 & 3 & 4 & 5 & 6 & 7 & 8 & 9 & 10 & 11 & 12 & 13 \\
\hline 1. RFI & - & $-.348^{* *}$ & $.230^{* *}$ & $.320^{* *}$ & $.243^{* *}$ & $.408^{* *}$ & $.241^{* *}$ & $.256^{* *}$ & $.205^{* *}$ & $.479^{* *}$ & $.450^{* *}$ & $.429^{* *}$ & $.383^{* *}$ \\
\hline 2. Age & & -- & -.009 & $-.257^{* *}$ & -.001 & $-.260^{* *}$ & $-.241^{* *}$ & -.010 & $.228^{* *}$ & -.055 & .076 & -.119 & .012 \\
\hline 3. $\mathrm{PC}$ & & & -- & -.038 & .085 & -.023 & -.073 & .015 & -.100 & .026 & -.049 & -.028 & .040 \\
\hline 4. SS & & & & -- & .013 & $.120^{\S}$ & .100 & $-.118^{\S}$ & $-.182^{* *}$ & .068 & $-.173^{*}$ & .098 & -.012 \\
\hline 5. FS & & & & & -- & -.060 & $-.212^{* *}$ & $.106^{\S}$ & -.022 & $.179^{* *}$ & .045 & .074 & .088 \\
\hline 6. UN & & & & & & -- & $.136^{*}$ & -.008 & -.031 & -.005 & -.007 & .080 & -.017 \\
\hline 7. LE & & & & & & & -- & $-.148^{*}$ & $-.110^{\S}$ & -.095 & -.029 & -.074 & .026 \\
\hline 8. TR & & & & & & & & -- & .104 & .029 & $.150^{\S}$ & .048 & -.055 \\
\hline 9. DEP & & & & & & & & & -- & $.124^{\S}$ & .110 & $.121^{\S}$ & .063 \\
\hline 10. DR & & & & & & & & & & -- & $.391^{* *}$ & $.144^{*}$ & $.176^{*}$ \\
\hline 11. $\mathrm{MH}$ & & & & & & & & & & & -- & .137 & .136 \\
\hline 12. MO & & & & & & & & & & & & -- & $.213^{* *}$ \\
\hline 13. NV & & & & & & & & & & & & & -- \\
\hline
\end{tabular}

Note. $\mathrm{RFI}=$ Risk Factor Index, $\mathrm{PC}=$ Prenatal care, $\mathrm{SS}=$ Single status, $\mathrm{FS}=$ Financial stress,

$\mathrm{UN}=$ Unemployment, $\mathrm{LE}=$ Low education, $\mathrm{TR}=$ Troubled relationships, $\mathrm{DEP}=\mathrm{Depression}, \mathrm{DR}=\mathrm{Drugs}$, $\mathrm{MH}=$ Maltreatment history in family, $\mathrm{MO}=$ Mobility, $\mathrm{NV}=$ Neighborhood violence. ${ }^{*} p<.05, * * p<.01$;

${ }^{\S}$ Trend level $p<.10$ 
Table E2

Correlation Matrix for Protective Factor Index (PFI) and Individual Protective Factor Items Used to Develop the Index

\begin{tabular}{|c|c|c|c|c|c|c|c|c|c|c|c|}
\hline & 1 & 2 & 3 & 4 & 5 & 6 & 7 & 8 & 9 & 10 & 11 \\
\hline 1. PFI & - & $.322^{* * *}$ & $.302^{* * *}$ & $.331^{* * *}$ & $.306^{* * *}$ & $.357^{* * *}$ & $.416^{* * *}$ & $.195^{* *}$ & .090 & $.287^{* * *}$ & $.359^{* * *}$ \\
\hline 2. SS & & -- & $.141^{*}$ & .088 & -.079 & $.264^{* *}$ & .033 & -.047 & -.012 & $-.130^{\S}$ & .091 \\
\hline 3. SU & & & -- & .095 & .051 & $.154^{*}$ & .038 & .068 & -.103 & $-.133^{*}$ & .000 \\
\hline 4. $\mathrm{PC}$ & & & & -- & $.176^{*}$ & .087 & .063 & -.083 & .040 & .002 & .012 \\
\hline 5. MIL & & & & & -- & .078 & .025 & -.040 & $-.112^{\S}$ & .034 & .058 \\
\hline 6. FF & & & & & & -- & .054 & -.017 & -.028 & -.011 & $.180^{* *}$ \\
\hline 7. $\mathrm{CHO}$ & & & & & & & -- & $.218^{* *}$ & $-.140^{*}$ & .051 & .076 \\
\hline 8. CM & & & & & & & & -- & -.064 & -.052 & -.091 \\
\hline 9. HV & & & & & & & & & -- & $.114^{\S}$ & $-.106^{\S}$ \\
\hline 10. OP & & & & & & & & & & -- & -.014 \\
\hline 11. NC & & & & & & & & & & & -- \\
\hline
\end{tabular}

Note. $\mathrm{PFI}=$ Protective Factor Index, $\mathrm{SS}=$ Social Support Scale (DUKE), SU=number of supports, $\mathrm{PC}=$ previous parent confidence, $\mathrm{MIL}=$ Infant milestones, $\mathrm{FF}=$ Family functioning, $\mathrm{CHO}=$ concrete housing support, $\mathrm{CM}=$ concrete money support, $\mathrm{HV}=$ home visits, $\mathrm{OP}=$ other programs, $\mathrm{NC}=$ Neighborhood cohesion. ${ }^{*} p<.05 .{ }^{* *} p<.01 .{ }^{* * *} p<.001 .{ }^{\S}$ Trend level $p<.10$. 


\section{APPENDIX F. Correlations Matrices for Individual Risk Factors, Protective Factors, Race, and Outcomes}

\begin{tabular}{|c|c|c|c|c|c|c|c|c|c|c|c|c|c|c|c|c|c|c|c|c|c|}
\hline Variable & 1 & 2 & 3 & 4 & 5 & 6 & 7 & 8 & 9 & 10 & 11 & 12 & 13 & 14 & 15 & 16 & 17 & 18 & 19 & 20 & 21 \\
\hline 1. Age & - & -.009 & $-.257^{* *}$ & -.001 & $-.260^{* *}$ & $-.241^{* *}$ & -.010 & $.228^{* *}$ & -.055 & .076 & $-.119^{\S}$ & .012 & $-.117^{\S}$ & $-.158^{*}$ & $.139^{*}$ & $.221^{* *}$ & .025 & $.188^{*}$ & -.007 & .122 & -.001 \\
\hline 2. $\mathrm{PC}^{\mathrm{a}}$ & & -- & -.038 & .085 & -.023 & -.073 & .015 & -.100 & .026 & -.049 & -.028 & .040 & .030 & .044 & .062 & -.035 & .067 & -.084 & -.027 & -.123 & -.106 \\
\hline 3. $\mathrm{SS}^{\mathrm{a}}$ & & & -- & .013 & $.120^{\S}$ & .100 & -.118 & $-.182^{* *}$ & .068 & $-.173^{*}$ & .098 & -.012 & .082 & $.129^{\S}$ & -.082 & $-.123^{\S}$ & -.019 & -.080 & -.099 & -.076 & -.078 \\
\hline 4. $\mathrm{FS}^{\mathrm{a}}$ & & & & -- & -.060 & $-.212^{* *}$ & .106 & -.022 & $.179^{* *}$ & .045 & .074 & .088 & -.083 & .038 & .006 & -.038 & -.027 & .083 & -.083 & .100 & .084 \\
\hline 5. $\mathrm{UN}^{\mathrm{a}}$ & & & & & -- & $.136^{*}$ & -.008 & -.031 & -.005 & -.007 & .080 & -.017 & .074 & .116 & .084 & $-.125^{\S}$ & -.078 & $-.242^{* *}$ & -.011 & $-.300^{* *}$ & .034 \\
\hline 6. $\mathrm{LE}^{\mathrm{a}}$ & & & & & & -- & $-.148^{*}$ & $-.110^{\S}$ & -.095 & -.029 & -.074 & .026 & $.157^{*}$ & .074 & -.026 & -.054 & .006 & $-.279^{* *}$ & .094 & $-.178^{*}$ & $-.165^{* *}$ \\
\hline 7. $\mathrm{TR}^{\mathrm{a}}$ & & & & & & & -- & .104 & .029 & $.150^{\S}$ & .048 & -.055 & .028 & .049 & .070 & .069 & -.086 & -.038 & .011 & .118 & .066 \\
\hline 8. $\mathrm{DEP}^{\mathrm{a}}$ & & & & & & & & -- & $.124^{\S}$ & .110 & $.121^{\S}$ & .063 & -.098 & -.002 & -.011 & -.087 & -.002 & -.104 & $.209^{* *}$ & -.080 & .102 \\
\hline 9. $\mathrm{DR}^{\mathrm{a}}$ & & & & & & & & & -- & $.391^{* *}$ & $.144^{*}$ & $.176^{*}$ & $-.324^{* *}$ & $.252^{* *}$ & .045 & -.027 & $-.156^{*}$ & -.006 & $.143^{*}$ & -.104 & .052 \\
\hline 10. $\mathrm{MH}^{\mathrm{a}}$ & & & & & & & & & & -- & .137 & .136 & $-.171^{*}$ & $.361^{* *}$ & .058 & -.076 & $-.157^{\S}$ & -.093 & $.165^{\S}$ & -.172 & -.020 \\
\hline 11. $\mathrm{MO}^{\mathrm{a}}$ & & & & & & & & & & & -- & $.213^{* *}$ & -.051 & $.203^{* *}$ & .009 & $-.224^{* *}$ & .067 & .061 & $.162^{*}$ & -.083 & .018 \\
\hline 12. NV & & & & & & & & & & & & -- & -.100 & .077 & .023 & $-.192^{* *}$ & .028 & .006 & .082 & -.026 & -.018 \\
\hline 13. $\mathrm{RC}^{\mathrm{a}}$ & & & & & & & & & & & & & -- & $-.141^{\S}$ & -.037 & .069 & .100 & .011 & .068 & .119 & $-.188^{* *}$ \\
\hline 14. $\mathrm{CW}^{\mathrm{a}}$ & & & & & & & & & & & & & & -- & -.076 & -.108 & -.004 & $-.285^{* *}$ & .022 & $-.233^{* *}$ & .107 \\
\hline 15. $\mathrm{DD}^{\mathrm{a}}$ & & & & & & & & & & & & & & & -- & .026 & .003 & .009 & $.167^{* *}$ & -.133 & -.049 \\
\hline 16. $\mathrm{CH}$ & & & & & & & & & & & & & & & & -- & -.037 & $.250^{* *}$ & -.031 & $.323^{* * *}$ & -.034 \\
\hline 17. $\mathrm{CP}$ & & & & & & & & & & & & & & & & & -- & -.127 & $.222^{* *}$ & -.130 & $-.132^{*}$ \\
\hline 18. HRA & & & & & & & & & & & & & & & & & & -- & -.020 & $.686^{* * *}$ & $.162^{\S}$ \\
\hline 19. PSI & & & & & & & & & & & & & & & & & & & -- & -.096 & $-.134^{*}$ \\
\hline 20. $\mathrm{H} 4$ & & & & & & & & & & & & & & & & & & & & -- & .070 \\
\hline 21. PCA & & & & & & & & & & & & & & & & & & & & & -- \\
\hline
\end{tabular}


Table F1 continued; 2 of 2 pages

\section{Outcomes are numbers 14-21 in variables column.}

Note. ${ }^{\mathrm{a}}$ Dichotomous variable. $\mathrm{PC}=$ Prenatal Care, $\mathrm{SS}=$ Single Status, $\mathrm{FS}=$ Financial Stress, $\mathrm{UN}=$ Unemployment, $\mathrm{LE}=\mathrm{Low}$ education, $\mathrm{TR}=$ Troubled relationships, $\mathrm{DEP}=$ Depression, $\mathrm{DR}=$ Drugs, $\mathrm{MH}=$ Maltreatment history in family, $\mathrm{MO}=$ Mobility, $\mathrm{NV}=$ Neighborhood violence. $\mathrm{RC}=\mathrm{Race}$, Race is a categorical variable: $0=\mathrm{White} / \mathrm{Non}-$ Hispanic, 1= Hispanic/Latina, African American, Asian/Pacific Islander, American Indian/Alaska Native, or Multi-racial. CW= Child welfare involvement (0/no, 1/yes); $\mathrm{DD}=$ Developmental delay (0/no; 1/yes); $\mathrm{CH}=$ Health-Well Being Scale; $\mathrm{CP}=$ Adult-Adolescent Parenting Inventory-Corporal Punishment AAPI subscale; HL=HOME Learning subscale, HRA=HOME Responsivity and Acceptance subscales; PSISF=Parenting Stress Inventory Short Form; PCA=Parent Child Activities Scale. * $p<.05$, $* * p<.01$,

${ }^{\S}$ Trend level $p<.10$.

$\overline{\mathrm{n}}$ 
Table F2. Correlation Matrix for All Individual Protective Factor Variables, Race and Outcomes (1 of 2 pages)

\begin{tabular}{|c|c|c|c|c|c|c|c|c|c|c|c|c|c|c|c|c|c|c|c|}
\hline Variable & 1 & 2 & 3 & 4 & 5 & 6 & 7 & 8 & 9 & 10 & 11 & 12 & 13 & 14 & 15 & 16 & 17 & 18 & 19 \\
\hline 1. SS & -- & $.141^{*}$ & .088 & -.079 & $.264^{* *}$ & .033 & -.047 & -.012 & -.130 & .091 & -.071 & -.013 & -.086 & -.095 & -.032 & -.020 & $-.295^{* *}$ & -.086 & -.023 \\
\hline 2. SU & & -- & .095 & .051 & $.154^{*}$ & .038 & .068 & -.103 & $-.133^{*}$ & .000 & -.025 & -.090 & -.045 & .009 & $.128^{*}$ & .043 & .022 & -.092 & .030 \\
\hline 3. $\mathrm{PC}$ & & & -- & $.176^{*}$ & .087 & .063 & -.083 & .040 & .002 & .012 & $-.135^{\S}$ & .001 & -.049 & -.085 & -.073 & $.177^{\S}$ & -.101 & $.154^{\S}$ & $.139^{\S}$ \\
\hline 4. $\mathrm{MIL}^{\mathrm{a}}$ & & & & -- & .078 & .025 & -.040 & $-.112^{\S}$ & .034 & .058 & .006 & -.059 & $.184^{* *}$ & $.132^{\S}$ & -.033 & $.282^{* *}$ & -.039 & $.231^{* *}$ & -.088 \\
\hline 5. FF & & & & & -- & .054 & -.017 & -.028 & -.011 & $.180^{* *}$ & -.032 & -.096 & -.006 & .073 & -.088 & $.172^{*}$ & $-.270^{* *}$ & .038 & $.165^{* *}$ \\
\hline 6. $\mathrm{CHO}^{\mathrm{a}}$ & & & & & & -- & $.218^{* *}$ & $-.140^{*}$ & .051 & .076 & -.043 & $-.143^{\S}$ & .042 & .019 & .094 & $.149^{\S}$ & -.002 & $.203^{*}$ & .042 \\
\hline 7. $\mathrm{CM}^{\mathrm{a}}$ & & & & & & & -- & -.064 & -.052 & -.091 & $-.213^{* *}$ & -.071 & .070 & -.117 & .005 & .010 & .087 & -.034 & .009 \\
\hline 8. HV & & & & & & & & -- & $.114^{\S}$ & $-.106^{\S}$ & -.095 & -.026 & .059 & $.168^{*}$ & -.071 & -.014 & -.093 & -.004 & .087 \\
\hline 9. $\mathrm{OP}^{\mathrm{a}}$ & & & & & & & & & -- & -.014 & -.012 & -.004 & .059 & .104 & $-.163^{*}$ & .140 & .000 & $.200^{*}$ & .049 \\
\hline 10. $\mathrm{NC}$ & & & & & & & & & & -- & -.021 & -.103 & .065 & $.167^{*}$ & -.078 & .096 & $-.108^{\S}$ & .036 & .082 \\
\hline 11. $\mathrm{RC}^{\mathrm{a}}$ & & & & & & & & & & & -- & $-.141^{\S}$ & -.037 & .069 & .100 & .011 & .068 & .119 & $-.188^{* *}$ \\
\hline 12. $\mathrm{CW}^{\mathrm{a}}$ & & & & & & & & & & & & -- & -.076 & -.108 & -.004 & $-.285^{* *}$ & .022 & $-.233^{* *}$ & .107 \\
\hline 13. $\mathrm{DD}^{\mathrm{a}}$ & & & & & & & & & & & & & -- & .026 & .003 & .009 & $.167^{* *}$ & -.133 & -.049 \\
\hline 14. $\mathrm{CH}$ & & & & & & & & & & & & & & -- & -.037 & $.250^{* *}$ & -.031 & $.323^{* * *}$ & -.034 \\
\hline 15. CP & & & & & & & & & & & & & & & -- & -.127 & $.222^{* *}$ & -.130 & $-.132^{*}$ \\
\hline 16. HRA & & & & & & & & & & & & & & & & -- & -.020 & $.686^{* * *}$ & $.162^{\S}$ \\
\hline 17. PSISF & & & & & & & & & & & & & & & & & -- & -.096 & $-.134^{*}$ \\
\hline 18. $\mathrm{H} 4$ & & & & & & & & & & & & & & & & & & -- & .070 \\
\hline 19. PCA & & & & & & & & & & & & & & & & & & & -- \\
\hline
\end{tabular}

Outcomes are numbers 12-19 in variable column. 
Table F2 continued; 2 of 2 pages

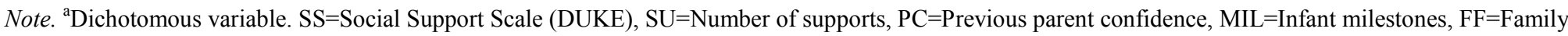
Functioning, $\mathrm{CHO}=$ Concrete housing support, $\mathrm{CM}=$ Concrete money support, $\mathrm{HV}=$ Home visits, $\mathrm{OP}=$ Other programs, $\mathrm{NC}=$ Neighborhood cohesion, $\mathrm{RC}=\mathrm{Race}$, $\mathrm{Race}$ is a categorical variable: $0=$ White/Non-Hispanic, $1=$ Hispanic/Latina, African American, Asian/Pacific Islander, American Indian/Alaska Native, or Multi-racial. $\mathrm{CW}=\mathrm{Child}$ welfare involvement (0/no, 1/yes); DD=Developmental delay (0/no; 1/yes); $\mathrm{CH}=$ Health-Well Being Scale; $\mathrm{CP}=$ Adult-Adolescent Parenting Inventory-Corporal Punishment AAPI subscale; HL=HOME Learning subscale, HRA=HOME Responsivity and Acceptance subscales; PSISF=Parenting Stress Inventory Short Form; PCA=Parent Child Activities. ${ }^{*} p<.05 .{ }^{* *} p<.01 .{ }^{\S}$ Trend level $p<.10$ 